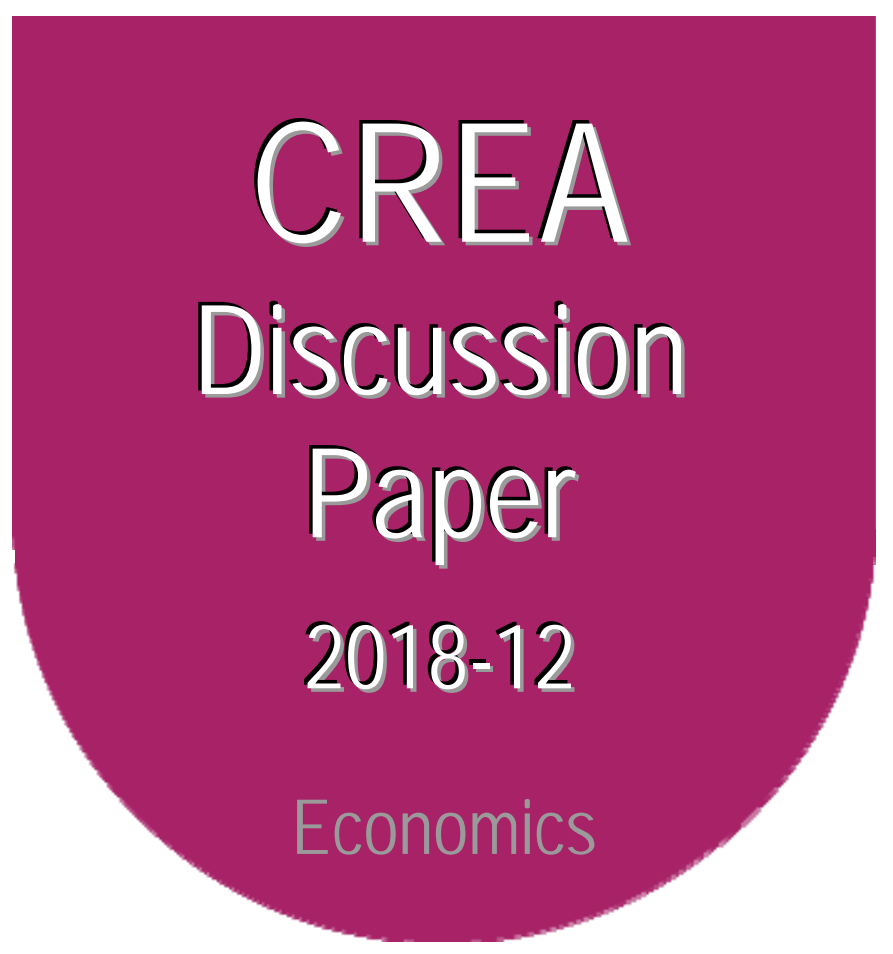

Center for Research in Economics and Management University of Luxembourg

\title{
Do Demographics Prevent Consumption Aggregates From Reflecting Micro-Level Preferences?
}

available online : http://wwwfr.uni.lu/recherche/fdef/crea/publications2/discussion_papers

Christos Koulovatianos, CREA, University of Luxembourg, Goethe Institut Frankfurt, Germany

Carsten Schroeder, Free University of Berlin and DIW, Berlin, Germany Ulrich Schmidt, University of Kiel, Germany, University of Johannesburg, South Africa,

April, 2018

For editorial correspondence, please contact: crea@uni.lu

University of Luxembourg

Faculty of Law, Economics and Finance

162A, avenue de la Faïencerie

L-1511 Luxembourg

The opinions and results mentioned in this paper do not reflect the position of the Institution 


\title{
Do Demographics Prevent Consumption Aggregates From Reflecting Micro-Level Preferences?*
}

\author{
Christos Koulovatianos ${ }^{\mathrm{a}, \mathrm{b}, \boldsymbol{*}, \text { Carsten Schröder }}{ }^{\mathrm{c}, \mathrm{d}}$ and Ulrich Schmidte,f,g
}

April 11, 2018

a Department of Economics, University of Luxembourg

b Center for Financial Studies, Goethe University Frankfurt

${ }^{c}$ Department of Economics, Free University of Berlin

d SOEP at DIW Berlin

${ }^{\mathrm{e}}$ Department of Economics, University of Kiel

${ }^{\mathrm{f}}$ Kiel Institute for the World Economy

g University of Johannesburg, Johannesburg, South Africa

* Corresponding author. Department of Economics, University of Luxembourg, 162A avenue de la Faïencerie, Campus Limpertsberg, BRA 3.05, L-1511, Luxembourg. Email: christos.koulovatianos@uni.lu, Tel.: +352-46-66-44-6356, Fax: +352-46-66-44-6341. Email Schröder: cschroeder@diw.de Email Schmidt: uschmidt@bwl.uni-kiel.de

* Previous drafts circulated under the title "Confronting the Representative Consumer with Household-Size Heterogeneity". Special thanks go to Dirk Krueger for his thorough discussion of the theoretical ideas of the paper at the 6th "AGE" RTN conference in Frankfurt, to two anonymous referees, and to Carlos Alos-Ferrer, Manfred Nermuth, Gerhard Orosel, and Gerhard Sorger, 
who provided detailed comments on the mathematical exposition of the theory. We thank Daron Acemoglu, Fernando Alvarez, David Andolfatto, Tony Atkinson, Ruediger Bachmann, Alexander Bick, Mark Bils, Chris Carroll, Francesco Caselli, Yongsung Chang, Satyajit Chatterjee, Jerome Detemple, Peter Diamond, David Donaldson, Simon Gaechter, Christian Gollier, Michael Haliassos, Robert Hall, Thomas Hintermeier, Miles Kimball, David K. Levine, Masao Ogaki, Krishna Pendakur, Ray Rees, Manuel Santos, Harald Uhlig, Frederic Vermeulen, and Volker Wieland, for useful comments and discussions. We also thank participants in the EFACR group at the NBER Summer Institute, at the "Macroeconomics and Survey Data" conference in Munich, the Kiel conference "Income Distribution and the Family" for their comments and suggestions, as well as seminar participants at the European Central Bank, Goethe University Frankfurt, Free University of Berlin, in Exeter, Munich, Nottingham, Reading, Verona, Vienna, and at the University of York, for useful remarks and discussions. Lei Gao, Eric Bürger, and Sukumaran Nair provided outstanding research assistance. We acknowledge financial support from the TMR network "Living Standards, Inequality and Taxation," contract No ERBFMRXCT980248. Koulovatianos thanks the Leventis foundation, the Austrian Science Fund under project P17886, and the RTN project on "The Economics of Ageing in Europe" for financial support, and Goethe University Frankfurt for their hospitality and financial support. Schmidt acknowledges financial support from the Deutsche Forschungsgemeinschaft, contract No. Schm1396/1-1. All authors thank the Nottingham School of Economics and the CFS, Frankfurt, for their hospitality and financial support. 


\title{
Do Demographics Prevent Consumption Aggregates From Reflecting Micro-Level Preferences?
}

\begin{abstract}
Most simulated micro-founded macro models use solely consumer-demand aggregates in order to estimate preference parameters of a representative consumer, for use in policy evaluation. Focusing on dynamic models with time-separable preferences, we show that aggregation holds if, and only if, momentary utility functions fall in the Identical-Shape Harmonic Absolute-Risk Aversion (ISHARA) utility class, identifying which parameters of ISHARA utility functions are allowed to vary over time. Given this theoretical result, it should be easy to empirically reject the aggregation properties that the macroeconomic representative-consumer identification approach requires: it suffices to show that permanent incomes guaranteeing the same living standard across households of different size violate an affine relationship. In order to test the validity of this affine equation, we develop a vignette survey that produces appropriate data without demand-estimation restrictions imposed by models. Surprisingly, in six countries, this equation is not rejected, lending support to using consumer-demand aggregates.
\end{abstract}

Keywords: Linear Aggregation, Dynamic Representative Consumer, Generalized Absolute Equivalence Scale Exactness (GAESE), Equivalent Incomes, Vignette Survey

JEL classification: C42, E21, D12, E01, D11, D91, D31, I32 


\section{Introduction}

Most simulated micro-founded macro models are combined with aggregate-consumption time series to estimate economy-wide preference parameters, which are then used in forecasting and policy evaluation. These models make an implicit aggregation assumption: that the incentives behind consumption choices are transmitted directly from the micro level to the macro level and are reflected in aggregate consumption fluctuations. The strong form of exact linear aggregation which implies the existence of a representative consumer (RC) is also used as a working hypothesis in existing macroeconomic studies with heterogeneous agents to analyze observed consumer choices in a more tractable way.

One study clarifying the tractability of aggregation in the analysis of heterogeneous-agent models is Caselli and Ventura (2000), which builds on previous findings of Chatterjee (1994). This tractability is also the starting point for the compelling review paper by Heathcote, Storesletten and Violante (2009) regarding the role of household heterogeneity in quantitative macroeconomics. ${ }^{1}$ There are concepts of micro-econometric aggregation in which preference heterogeneity among utility maximizers is combined with specific distributional properties of consumer characteristics that enter the budget constraint (wealth, income, skill distributions, etc.; for a review, see Blundell and Stoker, 2005). In this study, we focus on a stricter concept, namely exact aggregation that does not depend on features of wealth/income distributions at all. Imposing exact aggregation properties to a heterogeneous-agent model is equivalent to using particular functional forms for the utility function(s) of households, that guarantee the existence of an RC: a fictitious agent who is always endowed with the aggregate resources of a heterogeneous-agent economy and whose choices always coincide with economy-wide aggregated choices under any price regime and under any underlying distribution of resources

\footnotetext{
1 In particular, see their section "Heterogeneity with complete markets".
} 
at the individual or household level. ${ }^{2}$

Since most consumption data are collected at the household level, and since incentives behind household-consumption choices differ for households with more members, it is reasonable to think that aggregation could fail due solely to household-size heterogeneity. In this paper, (i) we theoretically identify the comprehensive class of heterogeneous utility functions that are time-separable and time-varying, and that allow for linear aggregation in dynamic environments where households have savings options and dynasties change family size over time; (ii) we devise a test that can empirically identify whether utility functions driving actual choices belong to the identified aggregation class; (iii) we design a vignette survey that generates data enabling us to perform the aggregation test without using models and without demand-estimation restrictions; and (iv) we test the validity of the survey method itself.

\subsection{Aggregation in a dynamic environment}

We study dynasties with changing family size that can also accumulate wealth. ${ }^{3}$ In order to capture family-size changes, we allow a household's momentary objective function to change over time. Our theory and our empirical tests apply to both collective-bargaining household analyses of the Mazzocco (2007) type as well as to unitary-household analyses. The household-level utility functions we analyze can be seen as welfare functions among

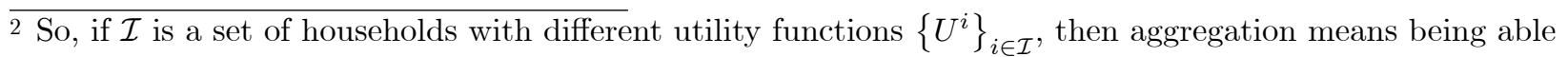
to use $\left\{U^{i}\right\}_{i \in \mathcal{I}}$ as ingredients for constructing a utility function of RC, i.e. $\left.U^{R C}\right|_{\left\{U^{i}\right\}_{i \in \mathcal{I}}}$, which is maximized subject to the aggregated economy-wide resource constraints and always replicates aggregated choices by the community having $\left\{U^{i}\right\}_{i \in \mathcal{I}}$, when solutions are interior. Section 2 of this paper is devoted to understanding the necessary and sufficient functional properties of $\left\{U^{i}\right\}_{i \in \mathcal{I}}$ that enable the construction of $\left.U^{R C}\right|_{\left\{U^{i}\right\}_{i \in \mathcal{I}}}$. 3 One paper documenting the dramatic family-size changes in the US since the 19th century is Salcedo, Schoellman and Tertilt (2012, cf. Figure 1, p. 138). We do not accommodate endogenous family formation, but our results should be useful for that extension. There is a substantial body of macroeconomics literature that introduces family-formation decisions in dynamic frameworks. See, for example, Aiyagari et al. (2000), Greenwood and Seshadri (2002), Greenwood et al. (2005), Fernández et al. (2005), Knowles (2013), Fernández-Villaverde et al. (2014), among others. 
household members, irrespective of whether there is within-household bargaining or not. ${ }^{4}$

Our theoretical contribution is that we provide necessary and sufficient conditions for exact linear aggregation, for any time-varying momentary utility functions. To our knowledge, the only linear-aggregation study that allows for time-variant momentary utility functions is Caselli and Ventura (2000). Yet, Caselli and Ventura (2000) identify one class of utility functions that is sufficient for aggregation, while here we also provide necessary aggregation conditions that characterize all types of utility functions that lead to exact linear aggregation. The comprehensive class of household objective functions that are consistent with exact linear aggregation is a generalized class of the Identical-Shape Harmonic-AbsoluteRisk-Aversion (ISHARA) utility function, and of the exponential form in which particular parameters (subsistence levels or bliss points) are allowed to vary over time and across family types.

A set of utility functions, $\left\{u^{i}\right\}_{i \in \mathcal{I}}$, in a community belongs to the same ISHARA class if absolute risk aversion of a utility function $u^{i}(c)$, with $c$ being consumption, is a harmonic function $\left[\alpha c+\beta^{i}(t)\right]^{-1}$, i.e., the coefficient $\alpha$ multiplying consumption is the same for all $i \in \mathcal{I}$, and constant over time, while $\beta^{i}(t)$ differs across households and over time.

A key difference in our analysis is that the momentary-utility functions in Mazzocco (2007) are time-invariant, as Mazzocco (2007) does not allow for demographic changes over time. Given that Mazzocco (2007) also conducts his analysis in discrete time, there are similarities with the proofs of Pollak (1971), who finds necessary and sufficient aggregation conditions for static environments with multiple goods when individual utilities are

4 Samuelson (1956, pp. 8-12) explains that the existence problem of non-intersecting "social indifference curves", to which exact Gorman aggregation is a solution (see Samuelson 1956, p. 5), is the same, no matter if one analyzes aggregation of consumer demands across households or aggregation of consumer demands among members within a household. The requirement of within-household Pareto efficiency in collective household models (see, for example, Vermeulen, 2002, pp. 540-3) is central to showing that aggregation results can be applied to collective household models. 
additively-separable across different goods. Our analysis, in contrast, accommodates that whenever a family anticipates a change in its size, it will incorporate the impact of this demographic change into the intertemporal Euler equation that governs its savings. ${ }^{5}$

\subsection{Empirical implications}

Our aggregation result leads to a testable equation. This equation involves permanent equivalent incomes (EIs): permanent household incomes that equate the level of material comfort of individuals living in households of different size. If utilities belong to the timevarying ISHARA and exponential family class that we identify as necessary and sufficient for aggregation, then each permanent EI is an affine transformation of any other household type's permanent EI. These affine relationships across EIs mean that, once expenditures for subsistence needs are subtracted from permanent income, then the remainder of permanent incomes must entail the same benefits from within-household sharing of goods for the rich and for the poor, satisfying the "Generalized Equivalence Scale Exactness (GAESE)" property suggested by Donaldson and Pendakur (2006).

\subsection{Testing aggregation using static-model Engel curves may be invalid}

In a static framework, aggregation requires that Engel curves are linear and parallel (see Gorman, 1953, 1955). Most studies reject this linearity (see Blundell and Stoker, 2005, for an extensive empirical literature review). Yet, falsifying the static-analysis aggregation condition of linear and parallel Engel curves does not mean that corresponding dynamic-analysis

5 Examples of studies that examine only sufficient conditions for aggregation in dynamic environments of consumer choice are Chatterjee (1994), Atkeson and Ogaki (1996), Caselli and Ventura (2000), and Maliar and Maliar (2001, 2003). A strand of literature numerically examines whether "approximate aggregation" holds (see also Heathcote, Storesletten and Violante (2009) for further discussion). For example, Krusell and Smith (1998) and Carroll (2000) examine cases of heterogeneity in rates of time preference in incompletemarkets environments with Carroll (2000) focusing on conditions under which "approximate aggregation" fails. 
aggregation conditions would be falsified as well. Dynamic-analysis aggregation conditions mean that consumption decision rules are linear and parallel in wealth and permanent income. The dynamic aggregation conditions nest the static aggregation conditions because the static conditions do not control for wealth, life-cycle effects or anticipations about future changes in tastes due to demographic heterogeneity. Thus, an aggregation test with missing variables may not be valid due to misspecification.

An example of a paper that discusses how misspecification of nested models can lead to erroneous conclusions is Godfrey (1984). The problem of missing variables may also be present in the context of semiparametric or nonparametric tests due to missing variables. Cherchye et al. (2013) suggest an alternative aggregation test to testing for linear and parallel Engel curves, again in a static-model context, without considering anticipations of future income or demographic changes. Missing-variable problems may therefore apply to this test as well.

\subsection{Addressing the need for additional data in dynamic-analysis aggregation}

Testing the dynamic aggregation condition requires information on permanent EIs. Such household-type-specific EIs are not available in existing databases, as one needs models and identification restrictions in order to derive EIs. For this reason, we collect information relating permanent income to household demographic composition using a vignette survey introduced by Koulovatianos et al. (2005, 2009). Our database consists of a nationally representative survey from Germany, and several pilot surveys conducted in France, Cyprus, China, India, and Botswana. In these surveys, different household compositions are described in short vignettes.

In the vignette survey, respondents are asked to assess permanent EIs for different house- 
hold compositions relative to a one-member household with given levels of permanent incomes, known as reference incomes (RI). Specifically, we ask respondents: "What is the net monthly household income that would allow a household with two adults and one child to attain the same level of material comfort as a net monthly income of $\$ 2,000$ for a onemember household" In this example, the amount of $\$ 2,000$ is the RI, and the response is the EI specific to that household type. RIs are drawn from the top to bottom of a country's personal income distributions. This EI data allows us to test for aggregation.

\subsection{Test results}

The dynamic aggregation condition requires that respondents' permanent EI assessments are a linear function of RI. In the representative survey, one out of five RIs is randomly assigned to each respondent. Hence, for any given household composition, all permanent EI assessments come from different respondents: respondent groups evaluating different RI levels are mutually independent. Because of this independence it should be easy to break dynamic aggregation. Yet, the EI assessments of all five independent respondent groups fall into a straight line. This nonrejection of aggregation holds for all seven of the householdcomposition types we investigate.

We also report evidence of nonrejection of the affine equation relating EIs using pilot data from six dissimilar countries (Germany, France, Cyprus, China, India, and Botswana). Although the respondent groups evaluating each RI were not independent in these small pilot samples, in all 49 cases we examine, aggregation is not rejected, supporting the results from the large German survey. 


\subsection{Usefulness of aggregation for policy analysis}

Our results are encouraging for macroeconomists who use aggregative models. Furthermore, they have a message for welfare and policymaking analysis, too. Most policies are likely to change both resource allocations and price patterns. Exact linear aggregation does not require any assumptions regarding the distribution of resources, nor does it impose any price-pattern restrictions. As Gorman $(1953,1955)$ prove, linear aggregation coincides with the requirement of non-intersecting social indifference curves. ${ }^{6}$ Thus, every time one changes policies in markets with properties that are far from exact linear aggregation, welfare and policy evaluation problems emerge due to potentially intersecting social indifference curves.

\section{Theoretical Results on Multidimensional Heterogeneity and the Existence of a Representative Consumer}

In this section, we fully characterize the class of utility functions of heterogeneous households that leads to the existence of a representative consumer: a fictitious consumer whose preferences represent an entire community-preference profile (the set of utility functions of all household types) and whose choices always coincide with actual aggregated choices under any price regime. The question we pose is: How much heterogeneity in household objective functions can the representative consumer survive?

There is compelling theoretical work on the topic of aggregation and we can mention only a few key advances here. For a set of heterogeneous households that live for one period and decide once and for all about the consumption of different consumer goods, Gorman (1953) shows that the indifference curves of a representative consumer are non-intersecting

6 Specifically, Kirman (1992, p. 123-125) provides graphic representations depicting the (high) possibility of welfare misrepresentation, and Gorman (1955) offers explicit and intuitive explanations of the problems arising in the absence of aggregation. One of the most comprehensive treatments of this welfare misrepresentation is in Jerison (1994). 
if, and only if, Engel curves for all traded commodities are always linear and parallel across all households for any given price regime. In a later study Gorman (1961) shows that, for Engel curves to be linear and parallel, utility functions must meet a particular functional property. Based on this property, Pollak (1971) offers a complete characterization of the set of utility functions of households that allow the existence of a representative consumer, under the assumption that all utility functions are additively separable with respect to each different good. Concerning households that act for more than one period, in particular those that are infinitely-lived dynasties, previous work focuses on households that consume a single composite consumer basket and accumulate financial wealth over time: Chatterjee (1994) and Caselli and Ventura (2000) identify household utility functions that are sufficient for the existence of a representative consumer. Here we extend their work by showing the set of utility functions that is also necessary for the existence of a representative consumer.

Focusing on dynasties with changing demographic composition, Theorem 1 proves necessary and sufficient conditions for aggregation in the context of a community with households having time-variant momentary utility functions. Theorem 1 identifies which parameters of the resulting ISHARA utility functions are allowed to vary over time and which parameters are not allowed to vary over time, which is a novel result and the main theoretical contribution of this paper.

The proof of Theorem 1 is tedious and it relies on arguments we developed for the proof of Theorem A.1, which appears in Online Appendix A. Theorem A.1 refers to momentary utility functions that do not change over time, and it states that exact linear aggregation holds if, and only if, utility functions fall in the Identical-Shape Harmonic Absolute-Risk Aversion (ISHARA) utility class. Mazzocco (2007) provides a similar result to Theorem A.1 in a discrete-time framework, relying on previous proofs provided by Pollak (1971). Here we 
study aggregation in continuous time, which requires a different approach for establishing and proving Theorem A.1. Our continuous-time approach is most useful for introducing heterogeneous rates of time preference in Theorem 1, which is one reason we place Theorem A.1 in Online Appendix A. Another reason for linking Theorem A.1 to this paper is that it results from weaker conditions and it is directly related to our empirical tests.

\subsection{Economic environment}

Time is continuous and the time horizon is infinite, $t \in[0, \infty)$. Households are all infinitely lived and belong to a constant set $\mathcal{I}$ of different types, with generic element $i$. The set of household types can be countable, finite, or a continuum. It may also be that all households are of the same type and, regardless, there is a "large" number of households, meaning that an individual household has a negligible impact on the aggregate economy, i.e., all households are price-takers. Belonging to type $i$ does not mean a fixed demographic type over time in the application of this paper. Instead, belonging to type $i$ at time $t=0$ means that there is a fixed exogenously pre-determined future path of changing demographic profiles of the infinitely-lived dynasty. Assuming that set $\mathcal{I}$ is constant, means that we do not have entry and exit of other dynasties after time 0 .

Assume a measure $\mu: \mathcal{I} \rightarrow[0,1]$, with density, $d \mu$, having the property,

$$
\inf \{d \mu(i) \mid i \in \mathcal{I}\}>0
$$

i.e., if $\mathcal{I}$ is finite, $d \mu(i)>0$ for all $i \in \mathcal{I}$, whereas if $\mathcal{I}$ is a compact interval, $d \mu(i)$ is continuous on $\mathcal{I}$ and bounded away from 0 . Households of different types can differ with respect to their initial endowment of capital claims (assets) and also with respect to their labor productivity, which is given by the exogenous function of time, $\theta^{i}: \mathbb{R}_{+} \rightarrow \mathbb{R}_{+}$. Asset holdings for household $i \in \mathcal{I}$ at time 0 are denoted as $a_{0}^{i}$. 
We assume that a community preference profile given by a set of utility functions, $\left(U^{i}\right)_{i \in \mathcal{I}}$, is fixed, while within a preference group $i \in \mathcal{I}$, there can be many individuals with heterogeneous initial endowments, $a_{0}^{j}$, and labor-productivity functions, $\theta^{j}$. Instead of distinguishing individuals across groups through a multi-dimensional measure (e.g., $\tilde{\mu}(i, j)$, where $i$ denotes the utility group and $j$ denotes a single household unit with $\left.\left(a_{0}^{j}, \theta^{j}\right)\right)$, we resort to the reduced notation recommended above.

There is a single composite consumable good, $c$. We examine the case in which individual rates of time preference have a consumption-choice-independent part that is common across households, and a consumption-choice-dependent part implied by their momentary utility function. $^{7}$ In particular, consumer preferences of each $i \in \mathcal{I}$ are given by the general additively-separable utility function, which implies heterogeneous rates of time preference,

$$
U^{i}\left(\left(c^{i}(t)\right)_{t \geq 0}\right)=\int_{0}^{\infty} e^{-\int_{0}^{t} \rho(\tau) d \tau} u^{i}\left(c^{i}(t), t\right) d t
$$

with $\rho: \mathbb{R}_{+} \rightarrow \mathbb{R}_{++}$.

Note that rates of time preference are a-priori heterogeneous and habit formation can be accommodated by our model. In equation (2), the functional form $\int_{0}^{\infty} e^{-\int_{0}^{t} \rho(\tau) d \tau} u^{i}\left(c^{i}(t), t\right) d t$ could have also been expressed as $\int_{0}^{\infty} v^{i}\left(c^{i}(t), t\right) d t$. We do not express momentary utility as $v^{i}\left(c^{i}(t), t\right)$, because at any $t \geq 0$ we want the rate of time preference to be equal to,

$$
-\frac{v_{12}^{i}\left(c^{i}(t), t\right)}{v_{1}^{i}\left(c^{i}(t), t\right)}=\rho(t)-\frac{u_{12}^{i}\left(c^{i}(t), t\right)}{u_{1}^{i}\left(c^{i}(t), t\right)} .
$$

The above equation shows that the rate of time preference is additively separable into a choice-independent $(\rho(t))$ and a choice-dependent component $\left(-u_{12}^{i} / u_{1}^{i}\right)$. This formulation offers convenience in constructing asymptotically convergent paths of the present value of consumption in our proofs.

\footnotetext{
7 Koulovatianos (2005, Theorem 2) provides an analysis of a class of utility functions that allows for heterogeneous choice-independent rates of time preference. The necessary class of utility functions allowing for linear aggregation is very restricted: it consists of utility functions with constant absolute risk aversion.
} 
We make the following technical assumptions:

$$
\begin{aligned}
& \text { Assumption } 1 \text { For all } i \in \mathcal{I} \text {, and all } t \geq 0, u^{i}: \mathbb{R}_{+}^{2} \rightarrow \mathbb{R} \text {, is twice-continuously } \\
& \text { differentiable with respect to } c \text {, once continuously differentiable with respect to } t \text {, } \\
& \text { and such that } u_{1}^{i}(c, t)>0 \text { and } u_{11}^{i}(c, t)<0 \text { on some interval, } \mathbb{C}^{i}(t) \subseteq \mathbb{R}_{+} \text {, with } \\
& u_{1}^{i}(c, t)<\infty,-\infty<u_{11}^{i}(c, t),-\infty<u_{12}^{i}(c, t)<\infty \text { for all } c \in \mathbb{C}^{i}(t) \subseteq \mathbb{R}_{+} \text {, with } \\
& \underline{c}^{i}(t) \equiv \inf \left(\mathbb{C}^{i}(t)\right)<\sup \left(\mathbb{C}^{i}(t)\right) \equiv \bar{c}^{i}(t) .
\end{aligned}
$$

Assumption 1 ensures that, for all $i \in \mathcal{I}$, and all $t \geq 0$, there is a choice domain, $\mathbb{C}^{i}(t) \subseteq \mathbb{R}_{+}$, which is an interval, and also that standard desirable properties of momentary utility functions are present. Assumption 2 allows households to choose consumption paths such that, asymptotically, the consumption level is non-decreasing.

\section{Assumption $2 \quad \int_{0}^{\infty} e^{-\int_{0}^{t} \rho(\tau) d \tau} d t<\infty$.}

The momentary time endowment is normalized to one, without loss of generality: all adults in the household work full time, and if a household is larger, with more than one working adult, personal labor incomes within the household can be summed up and the household's total labor income can be used instead.

For any given price vector $(r(t), w(t))_{t \geq 0}>>0$, with $r(t)$ being the interest rate and $w(t)$ the labor wage per unit of time at each instant, the budget constraint faced by household $i \in \mathcal{I}$ is,

$$
\dot{a}^{i}(t)=r(t) a^{i}(t)+\theta^{i}(t) w(t)-c^{i}(t)
$$

for all $t \geq 0,(\dot{x}(t) \equiv d x(t) / d t$ for any variable $x)$ and the transversality condition is,

$$
\lim _{t \rightarrow \infty} e^{-\int_{0}^{t} r(\tau) d \tau} a^{i}(t)=0
$$


We define the domains of wealth- and productivity heterogeneity at any given price vector for which the existence of a representative consumer is conceptually relevant. That is the domain that guarantees interiority of solutions to each individual optimization problem. The following assumption states this formally.

\begin{abstract}
Assumption 3 Given a community preference profile captured by the collection of functions $\left(u^{i}\right)_{i \in \mathcal{I}}$ and $\rho$, the domain of, (i) initial distribution of assets $\left(a_{0}^{i}\right)_{i \in \mathcal{I}}$, (ii) the collection of labor-productivity functions $\left(\theta^{i}\right)_{i \in \mathcal{I}}$, and (iii) prices $(r(t), w(t))_{t \geq 0}$, is restricted so that the optimization problems of all households $i \in \mathcal{I}$ are well-defined, and the solution to each individual problem is interior for all $t \geq 0$.
\end{abstract}

Given Assumption 3, maximizing (2) subject to constraints (4) and (5) for any given $a_{0}^{i}$ is an optimal-control problem with necessary optimality conditions given by,

$$
\dot{c}^{i}(t)=-\frac{u_{1}^{i}\left(c^{i}(t), t\right)}{u_{11}^{i}\left(c^{i}(t), t\right)}[r(t)-\rho(t)]
$$

that, together with (4) and (5), lead to decision rules of the form,

$$
c^{i}(t)=C^{i}\left(a^{i}(t), t \mid\left(r(\tau), w(\tau), \theta^{i}(\tau)\right)_{\tau \geq t}\right) .
$$

Equation (7) implies that consumption rules at each moment are memoryless, depending only on current personal assets as well as current and future prices. Assumptions 1 and 3 have a particular connection that is revealed by equation (6). The term $-\frac{u_{1}^{i}\left(c^{i}(t), t\right)}{u_{11}^{i}\left(c^{i}(t), t\right)}$ must always be well-defined in order to have interiority. Thus, to meet Assumption 3 (interior solutions), it is necessary that $c^{i}(t) \in \mathbb{C}^{i}(t)$, for all $t \geq 0$, and all $i \in \mathcal{I}$. 
Definition 1 Given a community preference profile captured by the collection of functions $\left(u^{i}\right)_{i \in \mathcal{I}}$, and $\rho$, complying with Assumptions 1 and 2 , a representative consumer (denoted by "RC") is a (fictitious) consumer who has time-separable preferences, $\int_{0}^{\infty} v^{R C}(c(t), t) d t$, with $v_{1}^{R C}(c, t), v_{11}^{R C}(c, t)$ and $v_{12}^{R C}(c, t)$ existing, and with $0<v_{1}^{R C}(c, t)<\infty$ and $-\infty<v_{11}^{R C}(c, t), v_{12}^{R C}(c, t)$ well-defined for all consumption levels, $c \in \mathbb{C}^{R C} \equiv\left\{c \in \mathbb{R}_{+} \mid c=\int_{\mathcal{I}} c^{i} d \mu(i), c^{i} \in \mathbb{C}^{i}, i \in \mathcal{I}\right\}$, for all $t \geq 0$, and who possesses the economy-wide aggregate wealth and productivity at all times, and whose demand functions coincide with the aggregate demand function of the economy at all times, namely,

$$
\begin{array}{r}
c^{R C}(t)=C^{R C}\left(\int_{\mathcal{I}} a^{i}(t) d \mu(i), t \mid\left(r(\tau), w(\tau), \int_{\mathcal{I}} \theta^{i}(\tau) d \mu(i)\right)_{\tau \geq t}\right)= \\
=\int_{\mathcal{I}} C^{i}\left(a^{i}(t), t \mid\left(r(\tau), w(\tau), \theta^{i}(\tau)\right)_{\tau \geq t}\right) d \mu(i),
\end{array}
$$

for all $t \geq 0$, for the complete domain of prices $(r(t), w(t))_{t \geq 0}$, initial distributions of assets, $\left(a_{0}^{i}\right)_{i \in \mathcal{I}}$, and functions $\left(\theta^{i}: \mathbb{R}_{+} \rightarrow \mathbb{R}\right)_{i \in \mathcal{I}}$ that comply with Assumption 3.

This is a rather strong representative-consumer concept: it focuses on solving a single household's optimization problem using standard optimal-control techniques, in order to derive aggregate demands at any point in time. ${ }^{8}$ Our final two assumptions place a weak

\footnotetext{
8 Our aggregation concept differs from the aggregation concept used by Gollier and Zeckhauser (2005), where Pareto weights are used to construct the objective of a "representative agent". Our goal is to examine conditions on the community preference profile that are necessary and sufficient for the existence of social preferences (representative-consumer preferences) consistent with the independence axiom of Koopmans (1960): if two different intertemporal paths have a common outcome at a certain point in time, preferences over these two paths should always, and solely, be determined by comparing them with remaining outcomes that differ at that particular date. In other words, the focus of our analysis is to characterize community preference profiles where social preferences are time-separable and where, at each separate point in time, non-intersecting social indifference curves exist.
} 
constraint on the scope of preference heterogeneity. We assume that nobody's bliss point (if any) should be lower than or equal to anyone else's subsistence level of consumption (if any), hence $\cap_{i \in \mathcal{I}} \mathbb{C}^{i}(t)$ is an interval. Since the consumable good is considered to be a composite good (a consumer basket), Assumptions 4 and 5 convey this point, and are not unreasonably restrictive (notice that if a function $f: \mathbb{R} \rightarrow \mathbb{R}$ is strictly decreasing, and if $[a, b]$ is an interval, then by $f([a, b])$ we denote the interval $[f(b), f(a)])$.

Assumption 4 For all $i \in \mathcal{I}, \underset{t \geq 0}{\cap} u_{1}^{i}\left(\mathbb{C}^{i}(t), t\right)$ is non-empty and not a singleton.

Assumption 5 For any $i \in \mathcal{I}$, let,

$$
\mathfrak{C}^{i} \equiv\left\{\begin{array}{l|l}
c \in \underset{t \geq 0}{\cap} \mathbb{C}^{i}(t) \mid \underset{t \geq 0}{\cap} u_{1}^{i}\left(\mathbb{C}^{i}(t), t\right) \text { is non-empty and not a singleton }
\end{array}\right\} .
$$

Then, $\underset{i \in \mathcal{I}}{\cap \mathfrak{C}^{i}}$ is non-empty and not a singleton.

Based on these assumptions, Theorem 1 states our aggregation result.

Theorem 1 Under Assumptions 1 through 5, a representative consumer exists if and only if

$$
u^{i}(c, t)=\left\{\begin{array}{cc}
\frac{\left[\alpha c+\beta^{i}(t)\right]^{1-\frac{1}{\alpha}}-1}{\alpha\left(1-\frac{1}{\alpha}\right)} & \text { with } \alpha>0 \text { and } \beta^{i}(t) \in \mathbb{R} \text { or } \alpha<0 \text { and } \beta^{i}(t)>0 \\
\text { or } & \text { with } \beta_{i}>0 \\
-e^{-\frac{1}{\beta_{i} G(t)}} c & ,
\end{array}\right.
$$

for all $i \in \mathcal{I}$, with functions $\beta^{i}(t)$ such that Assumptions 4 and 5 are met.

The representative consumer has utility

$$
U^{R C}\left((c(t))_{t \geq 0}\right)=\int_{0}^{\infty} e^{-\int_{0}^{t} \rho(\tau) d \tau} u^{R C}(c(t), t) d t
$$


with,

$$
u^{R C}(c, t)=\left\{\begin{array}{cc}
\frac{\left[\alpha c+\beta^{R C}(t)\right]^{1-\frac{1}{\alpha}}-1}{\alpha\left(1-\frac{1}{\alpha}\right)} & \text { for } \alpha \neq 0, \beta^{R C}(t)=\int_{\mathcal{I}} \beta^{i}(t) d \mu(i) \\
-e^{-\frac{1}{\beta_{R C} G(t)}} c & \text { else, } \quad \beta_{R C}=\int_{\mathcal{I}} \beta_{i} d \mu(i)
\end{array}\right.
$$

Proof Theorem 1 See Appendix "Proofs".

The message conveyed by Theorem 1 (and the additional insight to Theorem A.1 in Online Appendix A) is that parameter $\alpha$ is not only common across all household types, but also a cannot vary over time. This result is in perfect agreement with Jackson and Yariv (2015), who stress the impossibility of having a representative consumer if parameter $\alpha$ is heterogeneous across agents. The only utility parameters that can vary over time are subsistence levels (or bliss points) $\beta^{i}(t)$. As long as $\beta^{i}(t)$ varies with time for some $i \in \mathcal{I}$, preferences given by (9) imply that rates of time preference are heterogeneous. As long as $\beta^{i}(t) \neq 0$ for some $i \in \mathcal{I}$ and some $t \geq 0$, elasticities of intertemporal substitution are heterogeneous as well. Yet exact linear aggregation applies. While Theorem 1 is precise about the functional forms that allow for aggregation, it does not offer a precise characterization of the trajectories of parameters $\left(\left(\beta^{i}(t)\right)_{t \geq 0}\right)_{i \in \mathcal{I}}$. The trajectories of these parameters are free, subject to our interiority assumptions regarding each household's optimization problem. Also notice that if utility functions are of the exponential form, then $\beta^{i}(t) / \beta^{i}(0)=\beta^{j}(t) / \beta^{j}(0)$ for all $i, j \in \mathcal{I}$, a restriction that does not hold for all other utility functions of Theorem 1.

The consumption decision rules of all household types, $i \in \mathcal{I}$, are of the form,

$$
c^{i}(t)=b(t) a^{i}(t)+\zeta^{i}(t)
$$

i.e., they are always linear in wealth, $a^{i}(t)$, and parallel across all households. Carroll and Kimball (1996) show that if labor income uncertainty is introduced, the consumption 
function becomes concave. Nevertheless, the class of preferences we identify promotes a linear shape for the consumption function, at least when wealth is sufficiently far from borrowing constraints.

As rates of time preference are given by equation (3), they can be heterogeneous. If $\beta^{i}(t) \neq 0$, then elasticities of intertemporal substitution, $\alpha \cdot\left[1-\beta_{i}(t) / c\right]$, can also be heterogeneous. These two aspects of heterogeneity are in line with a large body of heterogeneousagent literature in macroeconomics and household finance. These features characterize the extended ISHARA utility class identified by Theorem 1.

\subsubsection{How static and dynamic aggregation analyses differ}

The distinction between static and dynamic aggregation analysis has implications for the empirical testing of aggregation. Static-model demand aggregation coincides with linear and parallel Engel curves. The consumption decision in a static model would be of the form $c^{i}=b_{0}^{i}+b_{1} y^{i}$, and parallel Engel curves would require that $b_{1}$ is common across households, while $b_{0}^{i}$ would be allowed to vary across households. ${ }^{9}$ In the dynamic model we do not have just Engel curves but decision rules involving wealth and future income anticipation. Our decision rules are of the form (see explicit formulas (28) and (29) in the Appendix),

$$
c^{i}(t)=b_{0}^{i}\left(t \mid\left(\beta^{i}(\tau)\right)_{\tau \geq t}\right)+b_{1}(t) y^{i}(t)+b_{2}(t) a^{i}(t)+b_{3}^{i}\left(t \mid\left(y^{i}(\tau)\right)_{\tau>t}\right) .
$$

The decision rule given by (12) is linear in $y^{i}(t) \equiv \theta^{i}(t) w(t)$, and with a common-acrosshouseholds coefficient $b_{1}(t)$ at time $t$ (note that $b_{1}(t)$ can also vary over time). But it includes household wealth, a variable that is usually missing from household microdatabases and it also contains two time-varying coefficients, $b_{0}^{i}\left(t \mid\left(\beta^{i}(\tau)\right)_{\tau \geq t}\right)$ and $b_{3}^{i}\left(t \mid\left(y^{i}(\tau)\right)_{\tau>t}\right)$.

${ }_{9}$ In a static framework $c$ refers to a consumer-item category, while in our dynamic model we have the comprehensive consumer basket ( $c$ can be seen as a different good at different future times). Variable $y$ is the income flow. 
The latter depends on future income expectations and differs across individuals; the former depends on anticipated changes in household preferences, e.g., due to anticipated changes in household size. Apparently, a static-analysis Engel curve given by $c^{i}=b_{0}^{i}+b_{1} y^{i}$, is nested in equation (12). Failing to control sufficiently for wealth, life-cycle effects, futureincome expectations, and anticipated future taste changes due to demographic heterogeneity may lead to an erroneous rejection of actual linearity between consumption categories and current income. Indeed, in a dynamic empirical analysis, Calvet and Comon (2003) report evidence that failing to account for taste heterogeneity can lead to imprecise conclusions about relationships between budget shares and income.

\subsection{Application to household-size heterogeneity and the necessity of the linear relationship across EIs}

If individuals have utility from the class presented in Theorems 1 and A.1 (Online Appendix), then these two theorems imply that, whenever such individuals form multi-member households, the objective function of household members can be merged into a single utility function of the representative household member. That utility function will be of the same

functional form but with a different parameter $\beta^{i}(t)$, and rescaled to capture the change in household size.

Following a standard assumption in the literature, assume (i) that $\rho(t)=\rho$ for all $t$; and (ii) that households of the same size also have the same utility function. If a representative consumer exists, then utility functions should fall in the class given by Theorem 1. Focusing on the case where $r(t)=\bar{r}=\rho$ for all $t$, and with $w(t)=\bar{w}$, and $\theta^{i}(t)=\bar{\theta}^{i}$ for all $t$, a steady-state condition for all households, (6) and (4) imply that

$$
\bar{c}^{i}=\bar{r} a^{i}+\bar{w} \bar{\theta}^{i}=\bar{y}^{i}
$$


where $\bar{y}^{i}$ is the permanent income of household $i$ in the steady state. ${ }^{10}$ Moreover, we assume that each household type stays the same forever, with $\beta^{i}(t)=\beta_{i}$, for all $t \geq 0$, when preferences of Theorem A.1 apply. With $\beta^{i}(t)=\beta_{i}$, for all $t \geq 0$, the model referring to Theorem 1 collapses to the model of Theorem A.1. The interpretation of the model of Theorem 1 is the case where a dynasty is shifting from one household type to another over time, keeping smoothness of such transitions so as to comply with Assumption 1. On such a permanent-income trajectory, the lifetime utility of a household is $\int_{0}^{\infty} e^{-\rho t} u^{i}\left(\bar{y}^{i}\right) d t=$ $u^{i}\left(\bar{y}^{i}\right) / \rho$. We define a set of permanent equivalent incomes, denoted by $\bar{y}_{E}$, of households belonging to any two different family types $i, j \in \mathcal{I}$, as incomes that equate lifetime utilities, $u^{i}\left(\bar{y}^{i}\right) / \rho=u^{j}\left(\bar{y}^{j}\right) / \rho$, i.e. any pair $\left(\bar{y}_{E}^{i}, \bar{y}_{E}^{j}\right), i, j \in \mathcal{I}$, that solves

$$
u^{i}\left(\bar{y}_{E}^{i}\right)=u^{j}\left(\bar{y}_{E}^{j}\right)
$$

Proposition 1 below provides a result that holds under the above steady-state conditions.

Proposition 1 Let all households of the same size have the same utility function. If $r(t)=\bar{r}=\rho$ for all $t \geq 0$, and all household types receive their permanent incomes $\bar{y}^{i}$ for all $i \in \mathcal{I}$. Then if each household type stays the same forever, with $\beta^{i}(t)=\beta_{i}$, for all $t \geq 0$, the existence of a representative consumer implies that for all $i, j \in \mathcal{I}$,

$$
\bar{y}_{E}^{j}=\chi_{i, j}+\psi_{i, j} \bar{y}_{E}^{i},
$$

for some $\chi_{i, j} \in \mathbb{R}$, and $\psi_{i, j}>0$.

\section{Proof See Appendix "Proofs".}

\footnotetext{
10 In the empirical analysis below it can be seen that in asking respondents about vignette average permanent monthly incomes, we designed our survey questionnaire to approximate the above steady-state conditions where households consume their average permanent incomes.
} 
In words, equation (15) means that if all household types are in a zero-growth steady state where they receive their permanent income, then household-size economies entailed in discretionary incomes (income minus subsistence needs) are the same across the rich and the poor.

As mentioned above, in this case, where households are in a zero-growth steady state $(r(t)=\bar{r}=\rho)$, and are receiving their permanent income, they optimally choose to spend their discretionary income at every instant of time. For some $\xi$, equation (15) can be rewritten as

$$
y^{j}-\xi \cdot \chi_{i, j}=\psi_{i, j}\left(y^{i}-\frac{\xi-1}{\psi_{i, j}} \chi_{i, j}\right),
$$

where $\xi$ is to be identified empirically and it will specify subsistence needs for the two types. In our empirical analysis in the next section we find that if $i$ in the last equation above is a one-member household, then $\chi_{i, j}>0$ in all cases. That $\chi_{i, j}>0$ in all cases where $j$ is a multi-member household implies subsistence needs that increase as household members are added to the household and it motivates the assumption that $\xi>1$ (each household has non-trivial subsistence needs). In the above equation, $\psi_{i, j}$ measures the economies of household size achieved by discretionary incomes across household types $i$ and $j$, and the equation implies that these are the same for the rich and the poor.

Corollary 1 is an immediate consequence of Proposition 1, which we state without proof.

Corollary 1 Empirically falsifying equation (15), falsifies the existence of a representative consumer in the strict linear-aggregation sense proposed by Gorman (1953).

Throughout the rest of this paper, we claim that equation (15) is testable; we demonstrate how it can be tested; and we subject it to scrutiny. 


\section{Empirical Analysis}

Equation (15) in Proposition 1 says that the existence of a representative consumer requires that household-size economies entailed in permanent equivalent incomes, after subtracting subsistence needs, are the same across the rich and the poor. Empirically testing (15) requires data on EIs. Identifying EIs from observed choices, i.e. demand data, has long occupied researchers. ${ }^{11}$ Most researchers use demand systems to impose a theoretical framework for identifying EIs. Their works share a common feature: identification assumptions must be imposed. Examples of such identification assumptions are "independence of base," or "generalized (absolute) equivalence scale exactness". Imposing an identification assumption means to postulate a particular relationship for EI functions. For example, Lewbel (1989) and Blackorby and Donaldson (1993) assume a special case of (15), where $\chi_{i, j}=0$, in order to identify EIs, while Donaldson and Pendakur (2006) impose (15) in their estimation. Yet these assumptions are a-priori untestable. In order to sidestep the challenges involved in testing for ISHARA using actual consumption data, we designed a vignette survey in which we ask respondents to provide their own assessments of EIs for a set of household types.

\subsection{Overview of survey design}

Our vignette survey of a representative sample of the German population consists of two main parts (our questionnaire appears in Online Appendix E). Part A pre-assigns a net monthly income for a one-member household, a reference income (RI), and asks respondents to state EIs for seven other household types. Each respondent is randomly assigned one of five different RIs. RIs are drawn from the top to bottom of a country's personal income

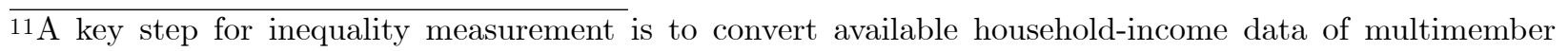
households into incomes that are equivalent to the income of a one-member household. In this way the distribution of living standards across individuals can be measured from an observed distribution of household incomes. 
distributions (see Online Appendix B for details). The question asked is of the following type: "What net monthly household income would allow a household with two adults and one child to attain the same level of material comfort as a net monthly income of $\$ 2,000$ for a one-member household? What income would one need if, instead, there were two children in the household?"12

Part A relies on the idea that respondents are experienced at recognizing the connection between a household's demographic composition and the level of material comfort that income can buy for its members. In this sense, respondents are 'real-life experts' in assessing EIs. Pooling diverse insights of a large number of respondents may correct potential biases of a single expert. Yet respondents must have sufficient information to assess EIs for households with a demographic composition and a level of material comfort that differ from their own actual experiences. Otherwise, estimates of EI may suffer from limited information bias (LIB). In order to test for LIB, we use a large sample that is representative with respect to the income dimension and that oversamples household types that are scarce in the overall population (e.g., single parents with two or more children).

Moreover, respondents should demonstrate sufficient understanding in answering the question about assessing EIs. To test for this crucial aspect of survey effectiveness, our survey instrument is equipped with a tool that tests whether people 'mean what they say'. ${ }^{13}$ In particular, Part B asks an assessment question that is equivalent to the one in Part A, using different means of representation to cross-check for consistency: Likert-scale evaluations of material comfort (for an example of Likert-scale evaluations, see Kahneman et al., 2004).

\footnotetext{
12Here we use material comfort or living standard, as measured by the goods, services, and luxuries available to an individual or group, which should be distinguished from the concept of overall life satisfaction used in Kahneman and Krueger (2006) and Kahneman et al. (2006). In addition, we frame our questionnaires using monthly incomes instead of annual incomes, because in all countries examined, income is communicated or measured in terms of monthly salaries.

13See, for example, Bertrand and Mullainathan (2001) for a discussion of the validity of respondent data in surveys.
} 
The question asked is: "Consider that the net monthly household income of a household with two adults and one child is $\$ 5,500$. State a number from 1 to 100 that best characterizes the level of material comfort of this household, given that ' 10 ' is 'very bad,' '50' is 'sufficient,' and '90' is 'very good."' Respondents receive such a question for the one-member household and the seven household types of Part A. Household incomes provided in Part B were obtained through a previous pilot study in Germany using the same RIs as in Part A. ${ }^{14}$ If a respondent states a Likert-scale value for a household type with pre-assigned income $Y$ that is higher than what she/he stated for the one-member household with the RI in Part B, then, in Part A, this respondent should have stated an EI for that household type that is lower than $Y$.

\subsection{Using our vignette-survey data for the aggregation test}

The aggregation condition given by equation (15) involves permanent incomes. The intention of the survey is to ask respondents to imagine a stationary environment in which the net income of a household is constant, $r(t)=\rho(t)$ for all $t$, and a household's size is the same forever. To the extent that such conditioning to a stationary hypothetical environment is achieved, RI should be a proxy of the permanent income of a one-member household $(\mathrm{OMH}), \bar{y}_{\mathrm{OMH}}$. Our working hypothesis is that, in Part A of the survey, respondents provide constant levels of monthly household income streams that bring households with alternative demographic composition to the same level of material comfort as the OMH with a given RI. In other words, Part A asks respondents to give a proxy of a permanent EI, $\bar{y}_{E}$. Empirically relating our EI estimates to RIs is then equivalent to empirically relating permanent incomes, $\bar{y}_{O M H}$ and $\bar{y}_{E}^{i}$ for any household-type $i$.

In order to validate our test, there is an additional working hypothesis and underlying

14The previous pilot study produced the German data used in Koulovatianos et al. (2005). 
assumption: respondents think of a fairly constant and similar across respondents long-term interest rate, in order to convert streams of income into permanent equivalent incomes referring to the hypothetical situations they evaluate. Yet, in the survey we do not mention interest rates, or pre-existing stocks of wealth of the hypothetical households, $a^{i}$, or savings plans, or even potential future demographic changes. The vignettes do not mention such details because every survey optimally requires some economy of survey instructions. Vignette surveys provide a simplified description of the world in order to keep the cognitive burden of the respondents in limits. In this sense, there is always a trade-off between the researcher's aim to provide a complete and precise description of the environment, and the need to provide a task that is comprehensible to the survey participants. Certainly, some respondents may deviate from the utilized economy of survey instructions, and different respondents may imagine different situations regarding pre-accumulated wealth or future savings or demographic plans of the hypothetical households they evaluate. Nevertheless, our test of equation (15) focuses on examining differences across rich and poor hypothetical households. As long as there are no systematic differences in how the survey's questions are interpreted for hypothetical low versus high incomes, such deviations should not create problems for our tests.

Whether surveys provide accurate information is open to debate and economists seem to be more critical than researchers from other disciplines. Potential issues that may affect the way people respond are framing, anchoring, interviewer effects, and the hypothetic nature of the survey (see, for example, Bertrand and Mullainathan, 2001). Through careful design one hopes to minimize biases resulting from the survey limitations mentioned above. Most importantly, in order to avoid framing effects, each respondent in our main survey was provided only one reference income, which, in addition, was randomly assigned. Further, to 
avoid interviewer effects and biases from social desirability that arises if respondents want to provide politically correct answers to an in-person interviewer, the survey was carried out in anonymous form.

Furthermore, in sections that follow below, we examine whether respondents provide consistent answers on the material comfort of different household types. This involves two tests. One test is on whether the same respondent gives consistent answers when the same evaluation task is represented/framed differently. The second test is on whether respondents with background characteristics that are similar to those provided in the vignette, respond differently from respondents whose characteristics differ.

Inherent in the nature of hypothetical vignette surveys like ours, however, is the lack of a mechanism that ensures that respondents have an interest to provide credible information. Such mechanisms are used in laboratory experiments, for example, in assessments of risk preferences by means of lotteries; or in willingness-to-pay surveys by means of revelation mechanisms. We do not see a reason why respondents in the vignette survey should have an incentive to give biased answers, and we do not see how the data could be gathered in such an incentive-compatible framework. ${ }^{15}$

\subsection{Survey samples}

In our empirical analysis, we use a large sample of 2,042 respondents from Germany collected in 2006. This large sample comes from across Germany and is representatively sampled along the dimension of household incomes. In order to secure sufficient power of LIB tests, we over-sampled single parents with two or more children. The intended over-representation of respondents having children contributed considerably to the high percentage of female

15We thank two anonymous referees for asking us to elaborate on the potential limitations of vignette surveys and on how our survey design addresses the desired empirical test. 
respondents. ${ }^{16}$

Previously to conducting this large German survey we ran six pilot studies in countries as different as Botswana, China, Cyprus, France, Germany, and India. There is a key difference in survey design between the large German survey and the six pilot surveys. In the large German survey, in Part A, each respondent was asked to provide EIs for seven household types, all referring to the a single randomly selected RI (out of five available RIs). In the six pilot studies, each respondent was asked to do the same, but for all five RIs. That is, in the pilot studies, each respondent provided $35 \mathrm{EI}$ assessments in total. ${ }^{17}$ This is a reason why the sample sizes of our pilot surveys (ranging from 130 to 223 respondents) are sufficient for testing. ${ }^{18}$

\subsection{The raw data support aggregation}

The scatter plots of uncontrolled (raw) responses in Part A of the representative-sample survey appear in Figure 1. Each panel refers to a household type distinguished by its demographic composition. On the horizontal axis of each panel is the one-member household RI (five fixed levels that are exogenously determined in the questionnaire - amounts are in 2006 euros). Against these fixed RIs, we plot the survey responses about EIs. In each panel there are 2,042 scatter points, each corresponding to a response from each of our 2,042 respondents. Since each panel contains one EI assessment by each respondent, all EI assessments for particular household types are independent. Independence secures that aggregation tests are not invalidated by framing or anchoring effects. ${ }^{19}$

Each panel in Figure 1 suggests an affine relationship between EI and RI, as suggested by

16Details about data collection and personal characteristics of respondents appear in Online Appendix B. 17The only exception is Botswana, where three instead of five RIs were provided (see Online Appendix B for details).

18 In addition, the pilot surveys do not include part $\mathrm{B}$ of the questionnaire.

19 On the possibility of anchoring effects, see Koulovatianos et al. (2007, Section 6). 
equation (15): for all seven household types, a sixth-degree polynomial least-squares curve (solid line) is hardly distinguishable from a linear fit (dashed line). Only for the fourth RI (EUR 2,750) does the polynomial fit indicate a slight deviation downwards. In brief, Figure 1 suggests that five independent groups of respondents seem to place their assessments of EIs on a straight line for seven different household types, on average.

The affine relationship among EIs is also present in all pilot studies appearing in Figures 2 and 3 (raw responses again). ${ }^{20}$ In all panels of Figures 2 and 3 the sixth-degree polynomial fit is visually close to a line. Nevertheless, it should be noted that in our pilot studies, each respondent provided assessments for all five RIs for each household type. Thus, in each panel of Figures 2 and 3 one respondent (per country) has provided five scatter points (EI assessments), one for each RI.

Regarding our pilot surveys, an objection may be raised concerning the validity of our tests about affine relationship (15). If each respondent follows an affine rule of thumb in providing EI assessments, the average picture in each country may be a result of framing: respondents may be lazy in thinking and perhaps follow an affine rule of thumb that dominates the total picture. For this reason, in the large-scale German survey each respondent assesses EIs for a single (randomly assigned) RI. Further, the large-scale survey collects data that allow for assessing whether respondents mean what they say. We devote the remainder of this section to providing formal tests of (15), and of the effectiveness of our survey method.

20The structure of Figures 2 and 3 is the same as that in Figure 1, with the sole difference that we have merged scatter plots from three countries in each figure and that we present only sixth-degree polynomial fits (and not linear fits as is the case with the dashed lines appearing in Figure 1). For inter-country comparisons all amounts appearing in Figures 2 and 3 are in purchasing power parity (PPP) adjusted euros for Germany in the year 2006 . 


\subsection{Regression analysis}

\subsubsection{Regression model and results}

Our regression model for the large survey from Germany is,

$$
\begin{aligned}
E S_{i}^{h}= & f^{h}\left(R I_{i}\right)+b_{0}^{h} R I_{-} \text {Dummies }_{i}+b_{1}^{h} N L S E_{i}^{h}+b_{2}^{h} L I B_{h, i}+b_{3}^{h} L I B_{m c, i} \\
& +b_{4}^{h}\left(L I B_{h, i} \cdot L I B_{m c, i}\right)+b_{5}^{h} \text { Personal_Characteristics }{ }_{i}+\varepsilon_{i}^{h},
\end{aligned}
$$

where

$$
f^{h}(R I)=a^{h}+\frac{b^{h}}{R I}
$$

The dependent variable is defined as $E S_{i}^{h}=E I_{i}^{h} / R I_{i}$, where $E I_{i}^{h}$ is the EI stated by respondent $i$ about household type $h$, given that respondent $i$ was asked to state EIs using a one-member household with RI equal to $R I_{i}$ as a benchmark. ${ }^{21}$ The term $\varepsilon_{i}^{h}$ is the error term. Using the specification of equation (16) we jointly run the following tests:

(i) An aggregation/linearity test, using the combination of $f^{h}\left(R I_{i}\right)$ and a set of reference-income dummies, $R I_{-}$Dummies $_{i}$.

(ii) A test of "whether people mean what they say", exploring the consistency between responses from the survey's Parts $\mathrm{A}$ and $\mathrm{B}$, using the variable $N L S E_{i}^{h}$ which describes Likert-scale evaluations.

(iii) A test of limited-information bias (LIB), using a set of LIB dummies $L I B_{h, i}$ and $L I B_{m c, i}$

(iv) The dependence of responses of respondent personal characteristics, captured by a set of variables named Personal_Characteristics ${ }_{i}$.

Definitions and roles of all conditioning variables in equation (16) appear below.

21 An EI divided by RI is an equivalence scale (ES), a normalization following the convention in the literature on equivalence scales which is innocuous for the test procedure. 
Aggregation test The function $f^{h}\left(R I_{i}\right)$ given by (17) in equation (16) complies with

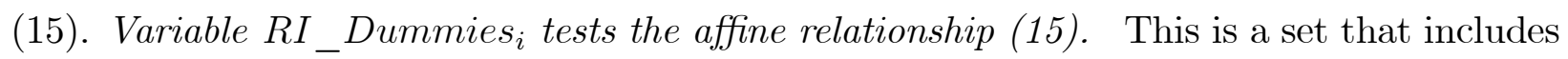
three dummy variables related to $R I_{i}$, the $\mathrm{RI}$ assigned to respondent $i$ in Part $\mathrm{A}$. If, for example, the RI equal to EUR 2,000 is included in this set, then the RI_Dummy(=EUR 2,000) takes the value of 1 for all respondents who where assigned RI equal to 2,000 EUR, and 0 otherwise.

The conditioning set RI_Dummies is $_{i}$ the instrument for conducting the specification test for any candidate function $f^{h}(R I)$ : if there is any variation left unexplained by the affine relationship (15) that is now transformed into (17) in regression (16), then it should be captured by $R I_{-}$Dummies $_{i}$; so a test of exclusion of RI_Dummies $s_{i}$ reveals whether $f^{h}(R I)$ satisfactorily captures the dependence of ESs on RI. Since the function $f^{h}\left(R I_{i}\right)$ is perfectly correlated with four income dummies and a constant, we only use three $R I$ dummies in the set RI_Dummies ${ }_{i}$, in order to avoid perfect collinearity.

In Table 1, most of these RI dummy variables are insignificant. Only the RI dummy variable at RI $=$ EUR 2,750 is significant (based on $t$-tests), but it suggests only a small deviation from the affine relationship (15). The exclusion tests concerning all three RI dummy variables have moderately low F-test statistics. None of these tests rejects exclusion with a confidence level of $99 \%$ or more. In sum, given how tough this test of exclusion is, equation (17) gives a reasonable specification for $f^{h}(R I)$, which has meaningful intuition. Coefficient $b^{h}$ in (17) can be interpreted as fixed costs of consumption, in addition to the fixed costs of the one-member household. The constant $a^{h}$ in equation (17) is a measure of household size economies after controlling for the presence of household-type-specific fixed costs of consumption. As household income increases, fixed costs become a smaller share of the household's budget. In other words, ES is a decreasing function of RI. 
Testing whether "people mean what they say" In this section, we address the effectiveness of the vignettes in Part A, namely if the respondents have understood the survey question and provided credible information. To test the effectiveness of the vignettes, Part B posed an assessment problem equivalent to the one in Part A that, however, uses different means of representation, and thus allows to cross-check for consistency of participants' responses: Likert-scale evaluations of material comfort. Suppose Part B provided a reference income of 1000 EURO for the one-member household and 2000 EURO for a couple with one child, and the respondent had answered 20 Likert points for the former and 15 Likert points for the latter household. In other words, (s)he believes that the couple with one child requires more than the stated income to attain the same living standard as the one-member household. Consistency of a survey participant's responses between Parts A and B requires that she should have stated an equivalent income for the couple with one child that is higher than 2000 EUR. Hence there should be a negative relationship between equivalent incomes and Likert-scale evaluations.

The inclusion of variable $N L S E_{i}^{h}$ in our regressions undertakes this task of testing this negative relationship between equivalent incomes and Likert-scal evaluations. The acronym NLSE stands for "Normalized Likert Scale Evaluation" and the NLSE value of respondent $i$ for a household type $h$ is given by $N L S E_{i}^{h}=\ln \left(L_{i}^{h} / L_{i}^{*}\right)$, where $L_{i}^{h}$ denotes respondent $i$ 's stated Likert-scale value for household type $h$, and $L_{i}^{*}$ denotes the Likert-scale value given by the same respondent, $i$, for the one-member household in Part B of the questionnaire. If the sign of $b_{1}^{h}$ corresponding to NLSE in regression (16) is negative, then such evidence confirms a necessary condition behind the hypothesis: that respondents understand the main evaluation task in Part A. Moreover, the estimator of $b_{1}^{h}$ may control for some respondents' deviant opinions about, for example, the cost of partners or children, so a test of exclusion of 
the NLSE in the regression provides information about the possible presence of such deviant evaluations. $^{22}$

As in Part A, in Part B each respondent was provided with a randomly assigned RI plus seven EIs corresponding to that particular RI (see Online Appendix E for details). The RIs in Part A are assigned independently from those assigned in Part B. This feature avoids the possibility that the NLSE is spuriously correlated with the dependent variable in the regression analysis. ${ }^{23}$ The NLSE uses the stated Likert-scale value assessing the living standard of the one-member household as a benchmark, and measures the deviation of each other Likert-scale value stated by the same respondent from this benchmark. In Online Appendix C, we provide evidence that the NLSE is effective in suppressing noise from heterogeneity in respondent perceptions of verbal characterizations. ${ }^{24}$

In Table 1 we can see that all NLSE coefficients have a negative sign and all tests of exclusion are rejected $(\mathrm{P}<0.001)$. These findings support the effectiveness of the survey method. Moreover, the size of all NLSE coefficients is small, indicating that respondents' deviant opinions about household-size economies do not affect the estimators of coefficients of equation (17) to a large extent.

22See Pollak and Wales (1979) for concerns about consumer choices and fertility preferences. For example, biases stemming from any possible dislike for children by respondents may be corrected by including NLSE, which offers a way to deal with the critique by Pollak and Wales (1979) about "conditional" vs. "unconditional" equivalence scales.

${ }^{23}$ Spurious correlation may result from having the same respondent focus on the same level of material comfort in the evaluations in Parts A and B: some respondents may consciously attempt to provide consistent responses between Parts A and B, instead of focusing on the evaluation question in each part.

${ }^{24}$ Heterogeneity in respondents' perceptions of words is formally defined and tested in Online Appendix C. Kahneman and Krueger (2006, pp. 19-21) discuss this issue and propose a technique for coping with this problem in an analysis that uses Likert scales on verbal descriptions of well being (although, as we explained above, the concept of well being used in our survey is material comfort instead of "happiness"). Similar concerns are also discussed in Bertrand and Mullainathan (2001). In Online Appendix C, we present evidence on how our NLSE variable deals with this problem of stated Likert scale evaluations by respondents. 
Testing whether respondents have limited-information bias To test for LIB, answers from respondents who state an EI for the household type and/or living standard that is the same as their own are distinguished from answers where this is not the case. In our regression analysis, LIB is tested through control variables $L I B_{h, i}, L I B_{m c, i},\left(L I B_{h, i} \cdot L I B_{m c, i}\right)$. Let respondent $i$ belong to household type $h$ and let $Y_{i}$ be the disposable household income of respondent $i$. From responses to Part A, we calculate five average EIs for household type $h$, each corresponding to an RI. We identify the average EI for household type $h$ that is closest to $Y_{i}$. This identified average EI corresponds to an RI that should give the same level of material comfort for the one-member household. If this particular RI coincides with the RI that was randomly assigned to $i$ in Part A, then $i$ provided an EI for hypothetical households with material comforts close to his/her own. We use this identification procedure to create the dummy variables,

$L I B_{m c, i}=1$ if respondent $i$ 's material comfort is closest to the material comfort of the one-member household, based on the RI that respondent $i$ evaluated in Part A; 0 otherwise; and

$L I B_{h, i}=1$ if respondent $i$ belongs to household type $h$, and the dependent variable in the regression refers to household type $h ; 0$ otherwise.

Variables $L I B_{h, i}, L I B_{m c, i}$, and the product $L I B_{h, i} \cdot L I B_{m c, i}$, serve as conditioning variables in the regression analysis of the stated EIs from Part A, and test for $\mathrm{LIB}^{25} \mathrm{~A}$ coefficient t-student test and a test of exclusion of each of these three variables test LIB. If none of $b_{2}^{h}$, $b_{3}^{h}$, and $b_{4}^{h}$, is significantly different from zero, then LIB does not prevent respondents from 25Table B4 in Online Appendix B shows the household-type distribution of respondents who are included in the $L I B_{m c, i}$ dummy variable. This is a total of 415 respondents, the sum of the entries in the first column of Table B4. Each entry in the first column of Table B4 shows the number of respondents in the $\left(L I B_{h, i} \cdot L I B_{m c, i}\right)$ dummy variable for each household type. Apart from single-adult households with two or three children, LIB tests based on the $\left(L I B_{h, i} \cdot L I B_{m c, i}\right)$ dummy variable have sufficient statistical power. 
effectively performing the evaluation task of Part A. Table 1 shows that only two out of 21 dummy variables related to testing LIB are significant, but with small coefficients. Only one exclusion test is rejected $(\mathrm{P}<0.01)$ - for the household type with two adults and one child. These findings offer supporting evidence that respondents' own household type and/or level of material comfort do not bias their assessments of EIs in Part A.

\section{Testing whether personal characteristics of respondents affect their answers} Personal_Characteristics ${ }_{i}$ is a set of conditioning variables referring to personal characteristics of the respondents. A coefficient t-student test and a test of exclusion of each of these variables indicate whether any characteristics of the respondents affect their assessments of EI. With two exceptions, Table 2 shows that respondents' personal characteristics do not appear statistically significant in the regressions. Respondents living in the "new" (former East German) Laender report slightly higher equivalence scales (ESs). This is consistent with the findings of Alesina and Fuchs-Schündeln (2007) regarding differences in opinions between East and West Germans. More educated respondents also state slightly higher ESs for hypothetical household types with children. More educated parents probably encourage their children to pursue higher education. All significant coefficients are small.

Explanatory power of the regressions The regressions fit the data quite well; they explain $30-54 \%$ of the total variation of stated ESs. Small standard errors for coefficients $a^{h}$ and $b^{h}$ in equation (17) indicate a broad consensus across respondents concerning the evaluation task of Part A.

Testing the affine relationship (15) using the six pilot surveys As we discuss above, Figures 2 and 3 support the affine relationship given by (15) as well. Table 3 presents speci- 
fication tests based on seemingly unrelated regressions (SUR) and the inclusion of dummies around the linear functional form having the same structure as in the regression model (16). The reason we use SUR regressions for the pilot surveys is a key difference: unlike the representative-sample survey in Germany, in the pilot surveys, for each family type, the same respondent provides five EI evaluations. So, in the pilot surveys the error terms across the seven family types might be cross-correlated. This can generate a loss in the efficiency of estimators and can weaken the confidence in our specification tests. As seen in Table 3, with the highest value of the F-test statistic being 1.75, in all 42 cases examined, the affine relationship given by (15) is not rejected.

\section{Potential limitations of survey data}

The main survey of this paper followed the state of the art in terms of vignette-survey design. ${ }^{26}$ The sample is representative and randomly drawn, the understandability of the vignettes was pre-tested in pilot surveys, the tasks provided are manageable in a reasonable amount of time to limit cognitive burdens, anonymity was guaranteed to prevent respondents from feeling obliged to provide "politically correct" answers, and for avoiding framing (anchoring), each respondent was provided with only one randomly drawn reference income to evaluate. In addition, the previous section presented tests for cognitive efficiency, limited information bias, and potential biases by respondent personal characteristics. None of these tests provide evidence in favor of such biases.

Nevertheless, nobody can read respondents' minds, and nobody can guarantee that participants respond perfectly in line with what the vignettes seek to elicit: to provide equivalent incomes appropriate for testing equation (15). In particular, it is not easy to guarantee that

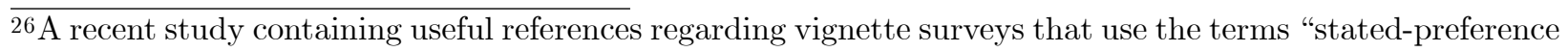
analysis" and "hypothetical choice analysis" is Delavande and Manski (2015). 
respondents do not imagine savings plans of the hypothetical households, or that respondents ignore that children may move in or out, or that marriages get dissolved. They may also have different perceptions of dimensions that have not been explicitly defined in the vignettes (e.g., the number of hours worked). Yet, even if such vignette-paradigm deviations

are present, it is difficult to think of a specific source of bias that invalidates the tests of equation (15). This would require that the deviations are systematically related to the material living standards described in the vignettes. In sum, while we cannot formally prove that our survey provides valid information on equivalent incomes, all our tests are in favor of the effectiveness of the survey, and we do not see an alternative available dataset suited for rigorous testing of aggregation.

\section{Applications}

We see three potential applications of our findings. First, is the use of a representativeconsumer utility function for aggregative (representative-agent models). Second, is the use of the class of preferences with heterogeneous household sizes in partial-equilibrium analyses of cross-sectional data. Third, is the use of the identified class of heterogeneous preferences in heterogeneous-agent general-equilibrium models.

Regarding the first application, this of aggregative macroeconomic models, we check whether our survey estimates imply unreasonable quantitative restrictions on the momentary utility function of the representative consumer. Using our estimates from Table 1 and data from the 2003 German Income and Expenditure Survey, the momentary utility function of the German representative consumer in 2003 is given by,

$$
u^{R C}(c, t=2003)=\frac{\left(c+\frac{14.91}{\alpha} \cdot \beta_{O M H}-E U R 3,281\right)^{1-\frac{1}{\alpha}}-1}{1-\frac{1}{\alpha}},
$$

where $\alpha$ is a free calibrating parameter, $-\beta_{O M H} / \alpha$ is the subsistence consumption of a 
one-member household, and the amount is in 2003 euros. $^{27}$ So, the vector of parameters $\theta=\left(\alpha, \beta_{O M H}\right)$, gives two degrees of freedom for calibrating models.

The logarithmic utility case, which is the special case of (18) with $\alpha=1$, is not supported by our estimates of Tables 1 and $3 .^{28}$ In the proof of Proposition 1 we show that, for the logarithmic case, equation (15) holds under the restriction $\psi_{i j}=1$ for all different household types $(i \neq j$, see equation (32) in the Appendix). The constants of the regressions appearing in Tables 1 and 3 correspond to $\psi_{i, O M H}$. These estimates of $\psi_{i, O M H}$ are typically different from 1 , and also change across different household types (i.e. $\psi_{i, O M H} \neq \psi_{j, O M H}$ for $i \neq j$ ).

The case of exponential utility is not rejected by our data (see equation (38) in the Appendix). Assuming that all German households have exponential utility, according to our estimates of Table 1, in Online Appendix D, we prove that the momentary utility function of the German representative consumer in 2003 is given by,

$$
u^{R C}(c, t=2003)=-e^{-\frac{1}{14.91 \cdot \beta} \beta_{M H}} c
$$

where $\beta_{O M H}$ is the only free calibrating parameter in equation (19).

Returning to the functional form of equation (18) with $\alpha \neq 1$, the observation that all intercepts in Figure 1 are strictly positive supports the existence of subsistence consumption. In business-cycle applications, it is known that having a representative consumer with constant subsistence consumption over time is not consistent with having balanced growth, which is convenient for detrending business-cycle models. ${ }^{29}$ There exist modifications to equation (18) that can serve as remedies for this inability to detrend models. One is to pick a vector of parameters $\theta=\left(\alpha, \beta_{O M H}\right)$ so that $\beta_{O M H}=E U R 3,281 / 14.91 \cdot a$, and to keep 27See Online Appendix D for the derivation of (18). In an aggregative model that uses the utility function given by (18), the appropriate measure of aggregate income to use is one-member-household equivalent income. In Online Appendix D we present how we construct the distribution of one-member-household equivalent incomes using data from the 2003 German Income and Expenditure Survey.

28 We thank an anonymous referee for noticing this inconsistency of the logarithmic case.

29See, for example, King, Plosser and Rebelo (1988, 2002). 
doing this for every year, in order to eliminate the subsistence level from the representative consumer's utility function, a standard assumption in the literature. Another is to allow for a subsistence consumption level, but to let this subsistence level grow at the same rate as total factor productivity. An alternative remedy is to introduce an external habit, multiplying the value of $\beta_{O M H}$, making the function $u^{R C}(c, t)$ explicitly dynamic, in a way consistent with a balanced-growth path.

The second potential application is this of fitting cross-sectional data through partialequilibrium models. Using a vector of parameters $\theta=\left(\alpha, \beta_{O M H}\right)$ with $\alpha, \beta_{O M H}>0$, two papers that use the implications of subsistence consumption in order to explain cross-sections of micro data (household-portfolio choices) are Achury et al. (2012) and Hubar et al. (2014). Alternatively, our survey data can be combined with econometrically estimated demand systems in the fashion of Lewbel (1989) or Donaldson and Pendakur (2006). Survey based EIs are a complementary goodness-of-fit criterion to existing data.

Given the potential of our analysis to address both macro and micro data, our EI estimates can aid the third potential application: the calibration of heterogeneous-agent models in the fashion of Aiyagari (1994), Krusell and Smith (1998), or Achdou, Han, Lasry, Lions, and Moll (2015). As we show, exact linear aggregation can be consistent with heterogeneous rates of time preference and elasticities of intertemporal substitution. So, we are confident that there is flexibility for both matching cross-sectional micro data features and for studying heterogenous-agent macroeconomic implications. Certainly, studying market incompleteness, borrowing constraints, and other nonconvexities, oblige us to assume approximate aggregation. Nevertheless, with preferences from the class shown in Theorem 1, approximate aggregation properties are difficult to get rid of. ${ }^{30}$

${ }^{30}$ We thank Dirk Krueger for explaining this point to us in his formal discussion of an earlier version of this paper. 


\section{Conclusion}

Aggregation is of central importance to micro-founded macro models that rely on estimation based on macro aggregates alone. Here we provided aggregation results that pertain to a dynamic representative consumer with savings options and dynasties with changing family size over time. Specifically, we provided necessary and sufficient conditions for aggregation encompassing heterogeneity in (i) initial wealth; (ii) current and anticipated future income; and (iii) current and anticipated future household demographic composition.

These aggregation results suggest that the aggregation-testing agenda is still open to further research. In particular, empirical analyses framed by static models that reject the Gorman requirement of linear and parallel Engel curves may suffer from misspecification due to missing variables. If households are forward-looking, expectations of future events, such as changes in household income or composition, may impact their present consumer choices. If these expectations are not adequately modeled, empirical tests may not be valid.

We introduced household-size heterogeneity in a dynamic environment with savings possibilities and potentially changing household size over time. As we showed, in order to falsify aggregation, it suffices to empirically reject a single affine equation relating permanent incomes that retain living standards across households with different size. This affine equation means that once expenditures for subsistence needs are subtracted from permanent income, the remainder of permanent incomes must entail the same household-size economies for the rich and for the poor. We tested the validity of this equation without a-priori assumptions or conditioning on a model. We have not performed tests of linear consumption decision rules. Our tests focused on the additional aggregation requirements introduced by household-size heterogeneity.

We produced survey data from a large sample of respondents in Germany, both testing the 
critical equation for falsifying the representative consumer concept and also demonstrating the effectiveness of our survey instrument. In the context of our aggregation tests, five independent groups of respondents evaluated household-size economies of rich vs. poor households, with each single respondent evaluating a different level of living standard. The average assessments of these five independent groups of respondents fall into a straight line, as required for exact linear aggregation. In seven demanding tests, aggregation is not falsified, at least not with high confidence in marginal cases. In 42 more tests, using pilot data from six countries in which every respondent evaluates all levels of living standards, aggregation is never falsified, providing supporting evidence. Although our results do not prove the existence of a representative consumer, our findings offer external empirical validation that household-size heterogeneity may not hinder consumer-demand aggregation properties.

Crucial for the aggregation tests is that our estimates of household-size economies are valid. While we find supportive evidence that this is the case, we cannot give a formal empirical proof, an issue that holds for (vignette) survey data in general. Nevertheless, we do not see an alternative available dataset that is better suited for the aggregation testing undertaken in the present study.

Our results do not mean that heterogeneity does not matter. Heterogeneity matters, and it should be modeled. Yet, our results suggest that the job of analyzing the role of heterogeneity in models is likely to be simpler than initially thought since our empirical tests advocate the presence of approximate aggregation. Specifically, using utility functions similar to those suggested by Krusell and Smith (1998) in models, adding perhaps timevarying subsistence or habit expressions to consumption in Gorman-type momentary utility seems to be the correct direction to follow. Most importantly, models exhibiting approximate aggregation a-la Krusell and Smith (1998) possess welfare-analysis properties that allow 
for a reliable comparison among alternative policies, providing a useful platform for policy prescription (see Gorman, 1955, and Jerison, 1994).

An extension would be to examine aggregation conditions using non-time-separable utility. For example, it may be that utility implying habit persistence, in some functional forms similar to those proposed by Constantinides (1990), might be both sufficient and necessary for aggregation, and it is interesting to examine whether equation (15) is also an implication of aggregation. Being more specific about habit formation formulations than allowing for time-varying utility functions is beyond the scope of the present analysis. Improved survey instruments in future work may reveal more about the structure of utility that underlies observed consumer choices. It may also prove fruitful to combine survey data with observed choices. Survey data can add another goodness-of-fit criterion for estimating preference parameters, especially for multimember households, irrespective of whether there is within-household bargaining or not. 


\section{REFERENCES}

Achury, C., S. Hubar, and C. Koulovatianos (2012): "Saving Rates and Portfolio Choice with Subsistence Consumption," Review of Economic Dynamics, 15, 108-126.

Achdou, Y., J. Han, J.-M. Lasry, P.-L. Lions, and B. Moll (2015), "Heterogeneous Agent Models in Continuous Time."Mimeo, Princeton University.

Aiyagari, S. Rao (1994), "Uninsured Idiosyncratic Risk and Aggregate Saving," Quarterly Journal of Economics, 109, 659-684.

Aiyagari, S.R., Greenwood, J. and Guner, N. (2000), "On the state of the union," Journal of Political Economy, 108, 213-244.

Alesina, A. and Fuchs-Schündeln, N. (2007), "Good bye Lenin (or not?) - The effect of communism on people's preferences," American Economic Review, 97, 1507-1528.

Apps, P. and R. Rees (2009): "Public Economics and the Household," Cambridge University Press, Cambridge.

Atkeson, A. and M. Ogaki (1996): "Wealth-Varying Intertemporal Elasticities of Substitution: evidence from Panel and Aggregate Data, Journal of Monetary Economics, $38,507-534$.

Bertrand, M. and Mullainathan, S. (2001), "Do people mean what they say? Implications for subjective survey data," American Economic Review, 91, 67-72.

Blackorby, C. and Donaldson, D. (1993), "Adult-equivalence scales and the economic implementation of interpersonal comparisons of well-being," Social Choice and Welfare, 10, 335-361.

Blundell, R. and T. M. Stoker (2005), "Heterogeneity and Aggregation," Journal of Economic Literature, 43, 347-391.

Calvet, L. and E. Comon (2003), "Behavioral heterogeneity and the income effect," Review of Economics of Statistics, 85, 653-669.

Carroll, C. D. (2000): "Requiem for the Representative Consumer? Aggregate Implications of Microeconomic Consumption Behavior," American Economic Review, Papers and Proceedings 90(2), 110-115.

Carroll, C. D. and Kimball, M. S. (1996), "On the Concavity of the Consumption Function," Econometrica, 64, 981-992.

Caselli, F. and Ventura, J. (2000), "A representative consumer theory of distribution," American Economic Review, 90, 909-926. 
Chatterrjee, S. (1994), "Transitional dynamics and the distribution of wealth in a neoclassical growth model," Journal of Public Economics, 54, 97-119.

Cherchye, L.J.H., Crawford, I., Rock, B. de and Vermeulen, F.M.P. (2013), "Gorman revisited: Nonparametric conditions for exact linear aggregation," KU Leuven, Center for Economic Studies, Discussion Paper Series DPS13.05.

Constantinides, G. M. (1990), "Habit Formation: A Resolution of the Equity Premium Puzzle," Journal of Political Economy, 98, 519-543.

Delavande, A., C.F. Manski (2015), "Using elicited choice probabilities in hypothetical elections to study decisions to vote", Electoral Studies, 38, 28-37.

Donaldson, D. and Pendakur, K. (2004) "Equivalent income functions and incomedependent equivalence scales," Journal of Public Economics, 88, 175-208.

Donaldson, D. and Pendakur, K. (2006) "The identification of fixed costs from consumer behavior," Journal of Business and Economic Statistics, 24, 255-265.

German Social Science Infrastructure Services.

http://www.gesis.org/en/social_monitoring/GML/data/inc\&exp/index.htm.

Godfrey, L. G. (1984): "On the Uses of Misspecification Checks and Tests of NonNested Hypotheses in EmpiricalEconometrics," Economic Journal, 94 (Supplement), 69-81.

Fernández, R, N. Guner and J. A. Knowles (2005): "Love and Money: A Theoretical and Empirical Analysis of Household Sorting and Inequality", Quarterly Journal of Economics, 120, 273-344.

Fernández-Villaverde, J., J. Greenwood, N. Guner (2014): "From Shame to Game in One Hundred Years: The Rise in Premarital Sex and its Destigmitization", Journal of the European Economic Association, 12, 25-61.

German Social Security Code. http://www.sozialgesetzbuchbundessozialhilfegesetz.de/_buch/sgb_ii.htm.

Goett, A.A., Hudson, K., Train, K.E. (2000): "Customers' Choice among Retail Energy Suppliers: The Willingness-to-pay for Service Attributes", The Energy 21, 1-28.

Gollier, C. and R. Zeckhauser (2005): "Aggregation of Heterogeneous Time Preferences," Journal of Political Economy, 113, 878-896.

Gorman, W.M. (1953), "Community preference fields," Econometrica, 21, 63-80.

Gorman, W.M. (1955), "The Intransitivity of Certain Criteria Used in Welfare Economics," Oxford Economic Papers, 7, 25-35. 
Gorman, W.M. (1961), "On a class of preference fields," Metroeconomica, 13, 53-56.

Greenwood, J. and Seshadri, A. (2002), "The U.S. demographic transition," American Economic Review, 92, 153-159.

Greenwood, J., Seshadri, A. and Yorukoglu, M. (2005), "Engines of liberation," Review of Economic Studies, 72, 109-133.

Heathcote, J., Storesletten, K. and Violante, G. L. (2009), "Quantitative Macroeconomics with Heterogeneous Households," Annual Review of Economics, 1, 319-354.

Hubar, S., C. Koulovatianos, and J. Li (2014), "Fitting Parsimonious HouseholdPortfolio Models to Data", mimeo, University of Luxembourg.

Huggett, M. (1993). "The risk-free rate in heterogeneous-agent incomplete-insurance economies," Journal of Economic Dynamics and Control, 17, 953-969.

Jackson, M. O. and L. Yariv (2015), "The Non-Existence of Representative Agents", SSRN Working paper series, No. 2684776.

Jerison, M. (1994), "Optimal Income Distribution Rules and Representative Consumers," Review of Economic Studies, 61, 739-771.

Kahneman, D. and Krueger, A.B. (2006), "Developments in the measurement of subjective well-being," Journal of Economic Perspectives, 20, 3-24.

Kahneman, D., Krueger, A.B., Schkade, D., Schwarz, N. and Stone, A.A. (2004), "A survey method for characterizing daily life experience: the Day Reconstruction Method," Science, 306, 1776-1780.

Kahneman, D., Krueger, A.B., Schkade, D., Schwarz, N. and Stone, A.A. (2006), "Would you be happier if you were richer? A focusing illusion," Science, 312, 19081910.

King, R. G., Plosser, C. I., Rebelo, S. (1988), "Production, Growth and Business Cycles: I. The basic neoclassical model", Journal of Monetary Economics, 21, 195-232.

King, R. G., Plosser, C. I., Rebelo, S. (2002), "Production, Growth and Business Cycles: Technical Appendix", Computational Economics, 87-116.

Kirman, A. P. (1992), "Whom or What Does the Representative Individual Represent?" Journal of Economic Perspectives, 6, 117-136.

Knowles, J. A. (2013): "Why are Married Men Working So Much? An Aggregate Analysis of Intra-Household Bargaining and Labour Supply", Review of Economic Studies, 80, 1055-1085. 
Koopmans, T. C. (1960), "Stationary ordinal utility and impatience," Econometrica, 28, 287-309.

Koulovatianos, C. (2005), "Preferences and the Dynamic Representative Consumer," Vienna Economics Papers 0505, University of Vienna, Department of Economics.

Koulovatianos, C., Schröder, C. and Schmidt, U. (2005), "On the income dependence of equivalence scales," Journal of Public Economics, 89, 967-996.

Koulovatianos, C., Schröder, C. and Schmidt, U. (2007), "Family-type subsistence incomes," SSRN Working Paper Series 989167.

Koulovatianos, C., Schröder, C. and Schmidt, U. (2009), "Nonmarket Household Time and the Cost of Children," Journal of Business and Economic Statistics, 27, 42-51.

Krusell, P. and A. A. Smith Jr. (1998), "Income and Wealth Heterogeneity in the Macroeconomy," Journal of Political Economy, 106, 867-896.

Lewbel, A. (1989), "Household equivalence scales and welfare comparisons," Journal of Public Economics, 39, 377-391.

Lewbel, A. (1991), "The Rank of Demand Systems: Theory and Nonparametric Estimation," Econometrica, 59, 711-730.

Maliar, L. and S. Maliar (2001): "Heterogeneity in capital and skills in a neoclassical stochastic growth model," Journal of Economic Dynamics and Control, 25, 1367-1397.

Maliar, L. and S. Maliar (2003): "The Representative Consumer in the Neoclassical Growth Model with Idiosyncratic Shocks," Review of Economic Dynamics, 6, 362-380.

Mazzocco, M. (2007): "Household Intertemporal Behaviour: A Collective Characterization and a Test of Commitment", Review of Economic Studies, 74, 857-895.

Organisation for Economic Co-operation and Development. http://www.oecd.org/LongAbstract/0,2546,en_2825_497118_35411112_1_1_1_1,00.html.

Pollak, R. (1971), "Additive utility functions and linear Engel curves," Review of Economic Studies, 38, 401-413.

Pollak, R.A. \& Wales, T.J. (1979), "Welfare comparisons and equivalence scales," American Economic Review, 69, 216-221.

Samuelson, P. A. (1956), "Social Indifference Curves," Quarterly Journal of Economics, 70, 1-22.

Salcedo, A., Schoellman, T. and M. Tertilt (2012), "Families as Roommates: Changes in U.S. Household Size from 1850 to 2000," Quantitative Economics, 3, 133-175. 
Vermeulen, F. (2002), Collective Household Models: Principles and Main Results, Journal of Economic Surveys, 16, 533-564. 


\section{Appendix - Proofs}

\section{Proof of Theorem 1}

Part 1: Necessity

Fix any function $\rho: \mathbb{R}_{+} \rightarrow \mathbb{R}_{++}$, and any collection $\left(u^{i}\right)_{i \in \mathcal{I}}$, with properties complying with Assumptions 1 through 5. Assume that a representative consumer exists with some momentary utility function $v^{R C}: \mathbb{C}^{R C} \times \mathbb{R}_{+} \rightarrow \mathbb{R}$, of the form $v^{R C}(c(t), t)$, at each point in time.

Considering any $i \in \mathcal{I}$, its optimality conditions imply that,

$$
-\frac{u_{11}^{i}\left(c^{i}(t), t\right)}{u_{1}^{i}\left(c^{i}(t), t\right)} \dot{c}^{i}(t)-\frac{u_{12}^{i}\left(c^{i}(t), t\right)}{u_{1}^{i}\left(c^{i}(t), t\right)}=r(t)-\rho(t), \quad t \geq 0 .
$$

Now pick $r(t)=\rho(t)$ for all $t \geq 0$, substitute it to (20) and take the indefinite integral with respect to time to get,

$$
u_{1}^{i}\left(c^{i}(t), t\right)=\kappa, \quad t \geq 0
$$

where $\kappa$ is some constant. Due to the fact that $u_{11}^{i}\left(c^{i}(t), t\right)<0$, and due to Assumptions 4 and 5 , there is always a $\kappa>0$ such that $c^{i}(t) \in \mathbb{C}^{i}(t)$ for all $t \geq 0$, satisfying (21). For $r(t)=\rho(t),(20)$ implies that,

$$
\dot{c}^{i}(t)=-\frac{u_{12}^{i}\left(c^{i}(t), t\right)}{u_{11}^{i}\left(c^{i}(t), t\right)} .
$$

The level of $\kappa$ in (21) will be uniquely identified by setting $u_{1}^{i}\left(c^{i}(0), 0\right)=\kappa$ and applying equation (6) in Online Appendix A at time 0, combined with the dynamics of $c^{i}(t)$ implied by (22). Due to Assumption 4, such an interior path exists on $\mathfrak{C}^{\mathfrak{i}}$, as $\mathfrak{C}^{\mathfrak{i}}$ is defined in Assumption 5. This means that with the right choices of initial wealth and labor productivity, we can construct interior paths that span $\mathfrak{C}^{i}$. Moreover, always for the case where $r(t)=\rho(t)$ for all $t \geq 0$, due to Assumption 5, for any $i \in \mathcal{I}$, we can generate any choice of $c \in \underset{i \in \mathcal{I}}{\cap \mathfrak{C}^{i}}$ at 
any point in time, picking the appropriate initial wealth and labor productivity, since the dynamics of consumption are solely driven by (22).

With this facility at hand, we can look at the problem of the representative consumer, whose optimal Euler equation gives,

$$
-\frac{v_{11}^{R C}\left(\int_{\mathcal{I}} c^{i}(t) d \mu(i), t\right)}{v_{1}^{R C}\left(\int_{\mathcal{I}} c^{i}(t) d \mu(i), t\right)} \int_{\mathcal{I}} \dot{c}^{i}(t) d \mu(i)-\frac{v_{12}^{R C}\left(\int_{\mathcal{I}} c^{i}(t) d \mu(i), t\right)}{v_{1}^{R C}\left(\int_{\mathcal{I}} c^{i}(t) d \mu(i), t\right)}=r(t), \quad t \geq 0
$$

and combining it with (20), it is,

$$
\begin{gathered}
\frac{v_{1}^{R C}\left(\int_{\mathcal{I}} c^{i}(t) d \mu(i), t\right)}{v_{11}^{R C}\left(\int_{\mathcal{I}} c^{i}(t) d \mu(i), t\right)} r(t)+\frac{v_{12}^{R C}\left(\int_{\mathcal{I}} c^{i}(t) d \mu(i), t\right)}{v_{1}^{R C}\left(\int_{\mathcal{I}} c^{i}(t) d \mu(i), t\right)}= \\
=[r(t)-\rho(t)] \int_{\mathcal{I}} \frac{u_{1}^{i}\left(c^{i}(t), t\right)}{u_{11}^{i}\left(c^{i}(t), t\right)} d \mu(i)+\int_{\mathcal{I}} \frac{u_{12}^{i}\left(c^{i}(t), t\right)}{u_{11}^{i}\left(c^{i}(t), t\right)} d \mu(i) .
\end{gathered}
$$

Setting $r(t)=\rho(t)$ for all $t \geq 0,(24)$ becomes,

$$
\frac{v_{1}^{R C}\left(\int_{\mathcal{I}} c^{i}(t) d \mu(i), t\right)}{v_{11}^{R C}\left(\int_{\mathcal{I}} c^{i}(t) d \mu(i), t\right)} \rho(t)+\frac{v_{12}^{R C}\left(\int_{\mathcal{I}} c^{i}(t) d \mu(i), t\right)}{v_{1}^{R C}\left(\int_{\mathcal{I}} c^{i}(t) d \mu(i), t\right)}=\int_{i \in \mathcal{I}} \frac{u_{12}^{i}\left(c^{i}(t), t\right)}{u_{11}^{i}\left(c^{i}(t), t\right)} d \mu(i) .
$$

But since, as explained above, for the case where $r(t)=\rho(t)$ for all $t \geq 0$, one can generate any distribution of consumption choices, (25) holds for the whole domain implied by Assumption 3. So, substituting (25) into (24), it is,

$$
\frac{v_{1}^{R C}\left(\int_{\mathcal{I}} c^{i}(t) d \mu(i), t\right)}{v_{11}^{R C}\left(\int_{\mathcal{I}} c^{i}(t) d \mu(i), t\right)}=\int_{i \in \mathcal{I}} \frac{u_{1}^{i}\left(c^{i}(t), t\right)}{u_{11}^{i}\left(c^{i}(t), t\right)} d \mu(i)
$$

for the whole domain implied by Assumption 3, including the case where $r(t)=\rho(t)$ for all $t \geq 0$. But then, for any $t \geq 0$, the same argument that was developed in step 2 of the necessity part of the proof of Theorem A.1 in Online Appendix A, to get,

$$
\begin{gathered}
\frac{u_{1}^{i}(c, t)}{u_{11}^{i}(c, t)}=\alpha(t) c+\beta^{i}(t), \text { and }, \\
\frac{v_{1}^{R C}(c, t)}{v_{11}^{R C}(c, t)}=\alpha(t) c+\int_{\mathcal{I}} \beta^{i}(t) d \mu(i),
\end{gathered}
$$

for some $\alpha(t) \in \mathbb{R}$ and some $\beta^{i}(t) \in \mathbb{R}$, for all $i \in \mathcal{I}, t \geq 0$ 
Using (27), with the same procedure as in step 3 of the necessity part of Theorem A.1 in Online Appendix A, candidate utility functions arise. Deriving individual demands, one can verify that this is possible only if

$$
\alpha(t)=\alpha \neq 0, \text { and } \beta^{i}(t) \text { meeting Assumptions 4, 5, } t \geq 0
$$

and

$$
\alpha=0, \quad \beta^{i}(t)=\beta_{i} G(t)
$$

that match the utility functions of the theorem. In particular, for the case where $\alpha \neq 0$, demands are,

$$
c^{i}(t)=\frac{a^{i}(t)+\int_{t}^{\infty} e^{-\int_{t}^{\tau} r(s) d s} \theta^{i}(\tau) w(\tau) d \tau+\frac{1}{\alpha} \int_{t}^{\infty} e^{\int_{t}^{\tau}[(\alpha-1) r(s)-\alpha \rho(s)] d s} \beta^{i}(\tau) d \tau}{\int_{t}^{\infty} e^{\int_{t}^{\tau}[(\alpha-1) r(s)-\alpha \rho(s)] d s} d \tau}-\frac{\beta^{i}(t)}{\alpha},
$$

which are linear with respect to $\beta^{i}$ 's. On the contrary, the demands for the utility function,

$$
u^{i}(c, t)=-e^{-\frac{1}{\beta^{i}(t)} c},
$$

are,

$$
c^{i}(t)=\frac{a^{i}(t)+\int_{t}^{\infty} e^{-\int_{t}^{\tau} r(s) d s} \theta^{i}(\tau) w(\tau) d \tau-\int_{t}^{\infty} e^{-\int_{t}^{\tau} r(s) d s} \beta^{i}(\tau) \int_{t}^{\tau}[r(s)-\rho(s)] d s d \tau}{\int_{t}^{\infty} e^{-\int_{t}^{\tau} r(s) d s} \frac{\beta^{i}(\tau)}{\beta^{i}(t)} d \tau}
$$

which can be linearly aggregated only if $\frac{\beta^{i}(t)}{\beta^{i}(0)}=\frac{\beta^{j}(t)}{\beta^{j}(0)}$ for all $i, j \in \mathcal{I}$, i.e. only when $\beta^{i}(t)=$ $\beta_{i} G(t), \beta_{i}>0$ for all $i \in \mathcal{I}$, completing the necessity part.

\section{Part 2: Sufficiency}

Follows by (28) and (29), observing that, under the statement of the theorem, they are linear with respect to $a^{i}$ s, $\theta^{i}$, s and $\beta^{i}$ s. Q.E.D. 


\section{Proof of Proposition 1}

Suppose a representative consumer exists. In the proof of Theorem 1, we show that an aggregation requirement is given by equation (27). In particular, under all assumptions made in the statement of Proposition 1, according to which utility functions of each household type do not change over time, equation (27) implies,

$$
\frac{u_{11}^{i}(c, t)}{u_{1}^{i}(c, t)}=\frac{1}{\alpha c+\beta_{i}} .
$$

The derivation of utility functions involves integrating both sides of equation (30) with respect to $c$ twice. Every time that (30) is integrated, an integration constant is involved. There are three cases to examine.

In the case where $\alpha=0$, after integrating both sides of equation (30) with respect to $c$ twice, we obtain,

$$
u^{i}(c, t)=-e^{\kappa_{i}-\frac{1}{\beta_{i}} c}+\kappa .
$$

Under all assumptions made in the statement of Proposition 1, equation (14) holds for all $i, j \in \mathcal{I}$, but for the empirical identification of any pair $\left(\bar{y}_{E}^{i}, \bar{y}_{E}^{j}\right), i, j \in \mathcal{I}$ (for avoiding indeterminacy), constants added to the functional form (31) cannot be different across any two $i, j \in \mathcal{I}$. On the contrary, parameter $\kappa_{i}$, in (31) can differ across $i, j \in \mathcal{I}$, since $\kappa_{i}$ determines the level of $i$ 's marginal utility of consumption in relation to the marginal utility of all other household types. So, combining equations (14) and (31), i.e., setting $u^{i}\left(\bar{y}_{E}^{i}, t\right)=$ $u^{j}\left(\bar{y}_{E}^{j}, t\right)$, implies,

$$
\bar{y}_{E}^{j}=\beta_{j}\left(\kappa_{j}-\kappa_{i}\right)+\frac{\beta_{j}}{\beta_{i}} \bar{y}_{E}^{i},
$$

which is consistent with (15).

In the case where $\alpha \neq 0$, and $\alpha \neq 1$, after integrating both sides of equation (30) with respect to $c$ twice, we obtain, 


$$
u^{i}(c)=e^{\kappa_{i}} \frac{\left(\alpha c+\beta_{i}\right)^{1-\frac{1}{\alpha}}}{\alpha\left(1-\frac{1}{\alpha}\right)}+\kappa .
$$

Under the constraint that constants added to the functional form (33) cannot be different across any two $i, j \in \mathcal{I}$, for enabling the empirical identification of any pair $\left(\bar{y}_{E}^{i}, \bar{y}_{E}^{j}\right), i, j \in \mathcal{I}$, while parameter $\kappa_{i}$ can differ across $i, j \in \mathcal{I}, i \neq j$. Equations (14) and (33) imply,

$$
\bar{y}_{E}^{j}=\frac{e^{\frac{\alpha}{\alpha-1}\left(\kappa_{i}-\kappa_{j}\right)} \beta_{i}-\beta_{j}}{\alpha}+e^{\frac{\alpha}{\alpha-1}\left(\kappa_{i}-\kappa_{j}\right)} \bar{y}_{E}^{i},
$$

which is also consistent with (15).

For the case where $\alpha=1$, the existence of a representative consumer and empirical identification of any pair $\left(\bar{y}_{E}^{i}, \bar{y}_{E}^{j}\right), i, j \in \mathcal{I}$, imply that $\kappa_{i}=\kappa_{j}=0$ for all $i, j \in \mathcal{I}$. To see this, suppose, that, to the contrary, for some $i, j \in \mathcal{I}, i \neq j$, it is $\kappa_{i} \neq \kappa_{j}$ and also $\kappa_{i} \neq 0$, without loss of generality. Then $\ln \left[u_{1}^{i}(c)\right]=-\frac{1}{\alpha} \ln \left(\alpha c+\beta_{i}\right)+\kappa_{i}$, implies, after setting $\alpha=1$, that

$$
u_{1}^{i}(c)=\frac{e^{\kappa_{i}}}{c+\beta_{i}} .
$$

Integrating (35) with respect to $c$ yields,

$$
u^{i}(c)=e^{\kappa_{i}} \ln \left(c+\beta_{i}\right)+b
$$

where $b$ is some constant that is common across all household types. Alternatively, (35) can be re-written as

$$
u_{1}^{i}(c)=\frac{1}{e^{-\kappa_{i}} c+e^{-\kappa_{i}} \beta_{i}},
$$

and integrating this last equation with respect to $c$ gives,

$$
u^{i}(c)=e^{\kappa_{i}}\left[\ln \left(c+\beta_{i}\right)-\kappa_{i}\right]+b .
$$

Comparing (36) with (37) implies that the constant $b$ must be adjusted for $i \in \mathcal{I}$, which contradicts the requirement that any pair $\left(\bar{y}_{E}^{i}, \bar{y}_{E}^{j}\right), i, j \in \mathcal{I}$, can be uniquely identified by 
data by not allowing household-type-specific constants to be added to utility functions. So, the only way that (36) and (37) coincide is setting $\kappa_{i}=0$. Since choice of $\kappa_{i}$ is arbitrary, set $\kappa_{i}=\kappa_{j}=0$ for all $i, j \in \mathcal{I}$. So, (14) implies

$$
\bar{y}_{E}^{j}=\beta_{i}-\beta_{j}+\bar{y}_{E}^{i},
$$

which is the special case of (34) with $\kappa_{i}=\kappa_{j}=0$ for all $i, j \in \mathcal{I}$ and with $\alpha=1$. In fact, setting $\alpha=1$ in (34) directly implies that it can only be $\kappa_{i}=\kappa_{j}=0$ for all $i, j \in \mathcal{I}$. Since (38) is also consistent with (15), the proposition is proved. Q.E.D. 
Table 1. Summary of ordinary least squares regressions. Endogenous variable: equivalence scales stated by respondents. Number of observations: 2,042. Standard Errors in parentheses. P-values of Ftests in brackets. *** $\mathrm{P}<0.001,{ }^{*} \mathrm{P}<0.01,{ }^{*} \mathrm{P}<0.05$.

\begin{tabular}{|c|c|c|c|c|c|c|c|}
\hline & \multicolumn{7}{|c|}{ Household type } \\
\hline & $\begin{array}{l}1 \text { adult, } \\
1 \text { child }\end{array}$ & $\begin{array}{c}1 \text { adult, } \\
2 \text { children }\end{array}$ & $\begin{array}{l}1 \text { adult, } \\
3 \text { children }\end{array}$ & $\begin{array}{l}2 \text { adults, } \\
0 \text { children }\end{array}$ & $\begin{array}{l}2 \text { adults, } \\
1 \text { child }\end{array}$ & $\begin{array}{l}2 \text { adults, } \\
2 \text { children }\end{array}$ & $\begin{array}{l}2 \text { adults, } \\
3 \text { children }\end{array}$ \\
\hline Constant & $\begin{array}{l}1.06^{* * *} \\
(0.03)\end{array}$ & $\begin{array}{l}1.12^{* * *} \\
(0.05)\end{array}$ & $\begin{array}{l}1.20^{* * *} \\
(0.08)\end{array}$ & $\begin{array}{l}1.42^{\star \star *} \\
(0.06)\end{array}$ & $\begin{array}{l}1.44^{\star \star *} \\
(0.07)\end{array}$ & $\begin{array}{l}1.53^{\star \star *} \\
(0.09)\end{array}$ & $\begin{array}{l}1.61^{* * *} \\
(0.11)\end{array}$ \\
\hline $\begin{array}{l}\text { Reciprocal of } \\
\text { reference income }\end{array}$ & $\begin{array}{l}269.74^{\star \star \star} \\
(9.77)\end{array}$ & $\begin{array}{c}498.34^{\star \star \star} \\
(16.28)\end{array}$ & $\begin{array}{c}728.85^{\star \star \star} \\
(23.45)\end{array}$ & $\begin{array}{c}329.38^{\star \star *} \\
(15.91)\end{array}$ & $\begin{array}{c}592.99 * \star \star \\
(20.81)\end{array}$ & $\begin{array}{c}839.25^{\star \star \star} \\
(27.41)\end{array}$ & $\begin{array}{c}1,079.86^{\star * \star} \\
(34.34)\end{array}$ \\
\hline $\begin{array}{l}\text { Dummy reference } \\
\text { income } 1,250 \text { Euros }\end{array}$ & $\begin{array}{r}0.00 \\
(0.01)\end{array}$ & $\begin{array}{r}-0.00 \\
(0.02)\end{array}$ & $\begin{array}{r}-0.02 \\
(0.03)\end{array}$ & $\begin{array}{r}0.03 \\
(0.02)\end{array}$ & $\begin{array}{r}0.00 \\
(0.03)\end{array}$ & $\begin{array}{r}-0.02 \\
(0.03)\end{array}$ & $\begin{array}{r}-0.04 \\
(0.04)\end{array}$ \\
\hline $\begin{array}{l}\text { Dummy reference } \\
\text { income } 2,000 \text { Euros }\end{array}$ & $\begin{array}{r}0.02 \\
(0.01)\end{array}$ & $\begin{array}{r}0.02 \\
(0.02)\end{array}$ & $\begin{array}{r}0.02 \\
(0.02)\end{array}$ & $\begin{array}{r}0.00 \\
(0.02)\end{array}$ & $\begin{array}{r}-0.00 \\
(0.02)\end{array}$ & $\begin{array}{r}-0.00 \\
(0.03)\end{array}$ & $\begin{array}{r}-0.02 \\
(0.03)\end{array}$ \\
\hline $\begin{array}{l}\text { Dummy reference } \\
\text { income } 2,750 \text { Euros }\end{array}$ & $\begin{array}{l}-0.02^{*} \\
(0.01)\end{array}$ & $\begin{array}{l}-0.04^{\star *} \\
(0.02)\end{array}$ & $\begin{array}{l}-0.07^{\star \star} \\
(0.02)\end{array}$ & $\begin{array}{l}-0.05^{*} \\
(0.02)\end{array}$ & $\begin{array}{l}-0.08^{\star \star} \\
(0.02)\end{array}$ & $\begin{array}{l}-0.11^{\star \star \star} \\
(0.03)\end{array}$ & $\begin{array}{l}-0.13^{\star \star *} \\
(0.04)\end{array}$ \\
\hline $\begin{array}{l}\text { Normalized Likert } \\
\text { scale evaluation }\end{array}$ & $\begin{array}{c}-0.04^{\star \star \star} \\
(0.01)\end{array}$ & $\begin{array}{c}-0.07^{\star \star \star} \\
(0.01)\end{array}$ & $\begin{array}{c}-0.10^{\star \star \star} \\
(0.02)\end{array}$ & $\begin{array}{c}-0.05^{\star \star \star} \\
(0.01)\end{array}$ & $\begin{array}{c}-0.07^{\star \star \star} \\
(0.02)\end{array}$ & $\begin{array}{c}-0.09 * \star \star \\
(0.02)\end{array}$ & $\begin{array}{c}-0.13^{\star \star \star} \\
(0.02)\end{array}$ \\
\hline $\begin{array}{l}\text { Dummy for same } \\
\text { household type of } \\
\text { respondent }\end{array}$ & $\begin{array}{c}0.04 \\
(0.02)\end{array}$ & $\begin{array}{l}-0.01 \\
(0.05)\end{array}$ & $\begin{array}{l}-0.14^{*} \\
(0.06)\end{array}$ & $\begin{array}{c}0.02 \\
(0.03)\end{array}$ & $\begin{array}{c}0.02 \\
(0.03)\end{array}$ & $\begin{array}{c}0.01 \\
(0.04)\end{array}$ & $\begin{array}{c}0.01 \\
(0.08)\end{array}$ \\
\hline $\begin{array}{l}\text { Dummy for same } \\
\text { material comfort of } \\
\text { respondent }\end{array}$ & $\begin{array}{l}-0.01 \\
(0.01)\end{array}$ & $\begin{array}{l}-0.03 \\
(0.02)\end{array}$ & $\begin{array}{l}-0.03 \\
(0.03)\end{array}$ & $\begin{array}{l}-0.04 \\
(0.02)\end{array}$ & $\begin{array}{l}-0.00 \\
(0.03)\end{array}$ & $\begin{array}{l}-0.03 \\
(0.04)\end{array}$ & $\begin{array}{l}-0.05 \\
(0.04)\end{array}$ \\
\hline $\begin{array}{l}\text { Dummy for same } \\
\text { household type and } \\
\text { material comfort of } \\
\text { respondent }\end{array}$ & $\begin{array}{l}-0.06 \\
(0.04)\end{array}$ & $\begin{array}{l}0.13 \\
(0.11)\end{array}$ & $\begin{array}{l}-0.03 \\
(0.11)\end{array}$ & $\begin{array}{l}0.05 \\
(0.05)\end{array}$ & $\begin{array}{l}-0.16^{*} \\
(0.07)\end{array}$ & $\begin{array}{l}-0.02 \\
(0.08)\end{array}$ & $\begin{array}{l}-0.04 \\
(0.14)\end{array}$ \\
\hline Adjusted $\mathrm{R}^{2}$ & 0.46 & 0.53 & 0.54 & 0.30 & 0.46 & 0.52 & 0.54 \\
\hline $\begin{array}{l}\text { F test statistic for } \\
\text { exclusion of all } \\
\text { reference income } \\
\text { dummy variables } \\
\end{array}$ & $\begin{array}{c}2.36 \\
{[0.07]}\end{array}$ & $\begin{array}{l}3.07^{\star} \\
{[0.03]}\end{array}$ & $\begin{array}{l}3.29 * \\
{[0.02]}\end{array}$ & $\begin{array}{l}3.60^{*} \\
{[0.01]}\end{array}$ & $\begin{array}{l}3.37^{\star} \\
{[0.02]}\end{array}$ & $\begin{array}{l}3.45^{\star} \\
{[0.02]}\end{array}$ & $\begin{array}{l}3.51^{*} \\
{[0.01]}\end{array}$ \\
\hline $\begin{array}{l}\text { F test statistic for } \\
\text { exclusion of the } \\
\text { normalized Likert } \\
\text { scale evaluation }\end{array}$ & $\begin{array}{c}14.79 * \star \star \\
{[0.00]}\end{array}$ & $\begin{array}{c}30.79 * \star \star \\
{[0.00]}\end{array}$ & $\begin{array}{c}37.72^{\star \star \star} \\
{[0.00]}\end{array}$ & $\begin{array}{c}14.37^{\star \star \star} \\
{[0.00]}\end{array}$ & $\begin{array}{c}18.90^{\star * \star} \\
{[0.00]}\end{array}$ & $\begin{array}{c}24.76^{\star \star *} \\
{[0.00]}\end{array}$ & $\begin{array}{c}43.96^{\star \star \star} \\
{[0.00]}\end{array}$ \\
\hline $\begin{array}{l}\text { F test statistic for } \\
\text { exclusion of dummy } \\
\text { for same household } \\
\text { type }\end{array}$ & $\begin{array}{c}2.98 \\
{[0.08]}\end{array}$ & $\begin{array}{c}0.05 \\
{[0.82]}\end{array}$ & $\begin{array}{c}1.28 \\
{[0.26]}\end{array}$ & $\begin{array}{c}0.35 \\
{[0.55]}\end{array}$ & $\begin{array}{c}0.66 \\
{[0.42]}\end{array}$ & $\begin{array}{c}0.02 \\
{[0.88]}\end{array}$ & $\begin{array}{c}0.03 \\
{[0.87]}\end{array}$ \\
\hline $\begin{array}{l}F \text { test statistic for } \\
\text { exclusion of dummy } \\
\text { for same material } \\
\text { comfort }\end{array}$ & $\begin{array}{c}0.31 \\
{[0.58]}\end{array}$ & $\begin{array}{c}3.06 \\
{[0.08]}\end{array}$ & $\begin{array}{c}1.79 \\
{[0.18]}\end{array}$ & $\begin{array}{c}3.09 \\
{[0.08]}\end{array}$ & $\begin{array}{c}0.30 \\
{[0.85]}\end{array}$ & $\begin{array}{c}0.96 \\
{[0.33]}\end{array}$ & $\begin{array}{c}1.28 \\
{[0.26]}\end{array}$ \\
\hline $\begin{array}{l}F \text { test statistic for } \\
\text { exclusion of dummy } \\
\text { for same household } \\
\text { type and material } \\
\text { comfort }\end{array}$ & $\begin{array}{c}1.96 \\
{[0.16]}\end{array}$ & $\begin{array}{c}1.96 \\
{[0.16]}\end{array}$ & $\begin{array}{c}0.01 \\
{[0.91]}\end{array}$ & $\begin{array}{c}1.21 \\
{[0.27]}\end{array}$ & $\begin{array}{l}7.56^{\star \star} \\
{[0.01]}\end{array}$ & $\begin{array}{c}0.09 \\
{[0.77]}\end{array}$ & $\begin{array}{c}0.11 \\
{[0.74]}\end{array}$ \\
\hline
\end{tabular}


Table 2. Summary of ordinary least squares coefficients and F-tests for exclusion referring to personal characteristics of respondents. Endogenous variable: equivalence scales stated by respondents. Number of observations: 2,042. Standard Errors of coefficients in parentheses. P-values of F-tests in brackets. Boldface characters for coefficients that have P-values below 5\%.

*** $\mathrm{P}<0.001,{ }^{* *} \mathrm{P}<0.01,{ }^{*} \mathrm{P}<0.05$.

\begin{tabular}{|c|c|c|c|c|c|c|c|}
\hline \multirow{3}{*}{$\begin{array}{l}\text { Variable } \\
\text { Region }\end{array}$} & \multirow{3}{*}{$\begin{array}{l}\text { Values } \\
\text { 1: Former East Germany } \\
0: \text { Former West Germany }\end{array}$} & \multicolumn{2}{|c|}{$\begin{array}{l}1 \text { adult, } \\
1 \text { child }\end{array}$} & \multicolumn{2}{|c|}{$\begin{array}{c}1 \text { adult, } \\
2 \text { children }\end{array}$} & \multicolumn{2}{|c|}{$\begin{array}{c}1 \text { adult, } \\
3 \text { children }\end{array}$} \\
\hline & & 0.02 & $(0.01)$ & $0.04^{\star}$ & $(0.02)$ & $0.05^{\star}$ & $(0.02)$ \\
\hline & & $F=3.11$ & {$[0.08]$} & $F=4.47$ & {$[0.03]$} & $F=4.81$ & [0.03] \\
\hline \multirow[t]{2}{*}{ Gender } & \multirow{2}{*}{$\begin{array}{l}\text { 1: female } \\
\text { 0: male }\end{array}$} & -0.01 & $(0.01)$ & -0.00 & $(0.02)$ & -0.00 & $(0.02)$ \\
\hline & & $F=0.55$ & {$[0.46]$} & $\mathrm{F}=0.01$ & [0.92] & $\mathrm{F}=0.00$ & [0.96] \\
\hline \multirow[t]{2}{*}{ Education } & \multirow{2}{*}{$\begin{array}{c}\text { 1: no degree } \\
\ldots \\
\text { 6: compl. tech. school/university }\end{array}$} & $0.01^{\star \star \star}$ & $(0.00)$ & $0.02^{\star \star \star}$ & $(0.01)$ & $0.03^{\star \star \star}$ & $(0.01)$ \\
\hline & & $F=13.57$ & {$[0.00]$} & $F=14.26$ & {$[0.00]$} & $F=16.89$ & {$[0.00]$} \\
\hline \multirow{2}{*}{ Self-employed } & \multirow{2}{*}{$\begin{array}{l}\text { 1: yes } \\
0: \text { no }\end{array}$} & -0.00 & $(0.02)$ & -0.00 & $(0.04)$ & -0.02 & $(0.07)$ \\
\hline & & $\mathrm{F}=0.02$ & {$[0.90]$} & $\mathrm{F}=0.00$ & {$[0.98]$} & $F=0.07$ & {$[0.80]$} \\
\hline \multirow[t]{2}{*}{ Civil servant } & \multirow{2}{*}{$\begin{array}{l}\text { 1: yes } \\
0: \text { no }\end{array}$} & 0.01 & $(0.03)$ & 0.01 & $(0.05)$ & 0.01 & $(0.06)$ \\
\hline & & $\mathrm{F}=0.26$ & {$[0.61]$} & $\mathrm{F}=0.08$ & {$[0.78]$} & $\mathrm{F}=0.03$ & {$[0.87]$} \\
\hline \multirow[t]{2}{*}{ Blue-collar } & \multirow{2}{*}{$\begin{array}{l}\text { 1: yes } \\
0: \text { no }\end{array}$} & -0.01 & $(0.02)$ & -0.02 & $(0.03)$ & -0.04 & $(0.04)$ \\
\hline & & $\mathrm{F}=0.13$ & {$[0.72]$} & $\mathrm{F}=0.53$ & {$[0.47]$} & $\mathrm{F}=0.85$ & [0.36] \\
\hline \multirow{2}{*}{$\begin{array}{l}\text { School/higher education } \\
\text { or training }\end{array}$} & \multirow{2}{*}{$\begin{array}{l}\text { 1: yes } \\
0: \text { no }\end{array}$} & 0.02 & $(0.05)$ & 0.06 & $(0.08)$ & 0.07 & $(0.11)$ \\
\hline & & $\mathrm{F}=0.20$ & {$[0.65]$} & $\mathrm{F}=0.75$ & {$[0.39]$} & $\mathrm{F}=0.50$ & [0.48] \\
\hline \multirow[t]{2}{*}{ Working, other } & \multirow{2}{*}{$\begin{array}{l}\text { 1: yes } \\
0: \text { no }\end{array}$} & 0.00 & $(0.03)$ & 0.01 & $(0.05)$ & 0.05 & $(0.08)$ \\
\hline & & $\mathrm{F}=0.01$ & {$[0.92]$} & $\mathrm{F}=0.11$ & {$[0.75]$} & $\mathrm{F}=0.57$ & [0.45] \\
\hline \multirow[t]{2}{*}{ Pensioner } & \multirow{2}{*}{$\begin{array}{l}\text { 1: yes } \\
0: \text { no }\end{array}$} & 0.00 & $(0.02)$ & -0.00 & $(0.02)$ & -0.01 & $(0.03)$ \\
\hline & & $\mathrm{F}=0.08$ & {$[0.78]$} & $\mathrm{F}=0.01$ & [0.92] & $\mathrm{F}=0.04$ & [0.85] \\
\hline \multirow[t]{2}{*}{ Unemployed } & \multirow{2}{*}{$\begin{array}{l}\text { 1: yes } \\
0: \text { no }\end{array}$} & 0.01 & $(0.02)$ & -0.00 & $(0.03)$ & -0.02 & $(0.04)$ \\
\hline & & $\mathrm{F}=0.22$ & {$[0.64]$} & $\mathrm{F}=0.01$ & {$[0.93]$} & $\mathrm{F}=0.29$ & [0.59] \\
\hline \multirow{2}{*}{$\begin{array}{l}\text { Homemaker } \\
\text { (Housewife/man) }\end{array}$} & \multirow{2}{*}{$\begin{array}{l}\text { 1: yes } \\
0: \text { no }\end{array}$} & -0.01 & $(0.01)$ & -0.02 & $(0.02)$ & -0.03 & $(0.03)$ \\
\hline & & $\mathrm{F}=0.85$ & {$[0.36]$} & $\mathrm{F}=1.17$ & {$[0.28]$} & $F=1.00$ & [0.32] \\
\hline \multirow{2}{*}{$\begin{array}{l}\text { Obligatory military / } \\
\text { public service }\end{array}$} & \multirow{2}{*}{$\begin{array}{l}\text { 1: yes } \\
0: \text { no }\end{array}$} & 0.03 & $(0.03)$ & 0.03 & $(0.04)$ & 0.02 & $(0.06)$ \\
\hline & & $\mathrm{F}=1.93$ & {$[0.17]$} & $\mathrm{F}=0.67$ & [0.41] & $\mathrm{F}=0.10$ & [0.75] \\
\hline \multirow[t]{2}{*}{ Non-working, other } & 1: yes & 0.03 & $(0.03)$ & 0.04 & $(0.04)$ & 0.03 & $(0.06)$ \\
\hline & $0:$ no & $\mathrm{F}=1.88$ & [0.17] & $\mathrm{F}=1.18$ & {$[0.28]$} & $\mathrm{F}=0.38$ & {$[0.54]$} \\
\hline $\begin{array}{l}\text { Number of adults in the } \\
\text { respondent's household }\end{array}$ & 1: one adu & 0.00 & $(0.01)$ & -0.01 & $(0.02)$ & -0.02 & $(0.03)$ \\
\hline & & $\mathrm{F}=0.08$ & {$[0.78]$} & $\mathrm{F}=0.08$ & {$[0.78]$} & $\mathrm{F}=0.60$ & [0.44] \\
\hline Number of children in the & 0: no children & 0.01 & $(0.01)$ & 0.01 & $(0.01)$ & 0.02 & $(0.01)$ \\
\hline & 3: three or more children & $F=1.10$ & {$[0.30]$} & $F=2.61$ & {$[0.11]$} & $F=3.67$ & {$[0.06]$} \\
\hline Family after-tax income & 1: lowest income class & 0.00 & $(0.00)$ & 0.00 & $(0.00)$ & 0.00 & $(0.01)$ \\
\hline & 10: highest income class & $F=0.06$ & {$[0.81]$} & $F=0.04$ & {$[0.84]$} & $F=0.01$ & [0.93] \\
\hline Age & & -0.00 & $(0.00)$ & -0.00 & $(0.00)$ & -0.00 & $(0.00)$ \\
\hline & & $\mathrm{F}=0.53$ & {$[0.47]$} & $\mathrm{F}=0.08$ & {$[0.77]$} & $F=0.04$ & [0.85] \\
\hline
\end{tabular}


Table 2 (continued).

\begin{tabular}{|c|c|c|c|c|c|c|c|c|c|}
\hline \multirow{2}{*}{$\begin{array}{l}\text { Variable } \\
\text { Region }\end{array}$} & \multirow{2}{*}{$\begin{array}{l}\text { Values } \\
\text { 1: Former East Germany } \\
\text { 0: Former West Germany }\end{array}$} & \multicolumn{2}{|c|}{$\begin{array}{l}2 \text { adults, } \\
0 \text { children }\end{array}$} & \multicolumn{2}{|c|}{$\begin{array}{l}2 \text { adults, } \\
1 \text { child }\end{array}$} & \multicolumn{2}{|c|}{$\begin{array}{l}2 \text { adults, } \\
2 \text { children }\end{array}$} & \multicolumn{2}{|c|}{$\begin{array}{l}2 \text { adults, } \\
3 \text { children }\end{array}$} \\
\hline & & $0.04^{\star}$ & $(0.02)$ & $0.06^{*}$ & $(0.02)$ & $0.08^{\star \star}$ & $(0.03)$ & $0.10^{\star \star}$ & $(0.04)$ \\
\hline \multirow[t]{2}{*}{ Gender } & \multirow{2}{*}{$\begin{array}{l}\text { 1: female } \\
0: \text { male }\end{array}$} & -0.01 & $(0.02)$ & -0.01 & $(0.02)$ & -0.01 & $(0.03)$ & -0.01 & $(0.04)$ \\
\hline & & $F=0.55$ & {$[0.46]$} & $F=0.21$ & {$[0.64]$} & $F=0.11$ & {$[0.74]$} & $F=0.05$ & [0.83] \\
\hline Education & $\begin{array}{c}\text { 1: no degree } \\
\ldots . \\
\text { 6: compl. tech. School } \\
\text { or university }\end{array}$ & $F=2.54$ & {$[0.11]$} & $F=7.52$ & {$[0.01]$} & $F=6.88$ & {$[0.01]$} & $F=7.54$ & {$[0.01]$} \\
\hline \multirow[t]{2}{*}{ Self-employed } & \multirow{2}{*}{$\begin{array}{c}\text { 1: yes } \\
0: \text { no }\end{array}$} & 0.05 & $(0.05)$ & 0.04 & $(0.08)$ & 0.00 & $(0.10)$ & -0.03 & $(0.12)$ \\
\hline & & $F=0.85$ & {$[0.36]$} & $\mathrm{F}=0.31$ & [0.58] & $F=0.00$ & {$[0.97]$} & $\mathrm{F}=0.07$ & {$[0.80]$} \\
\hline Civil servant & $\begin{array}{l}\text { 1: yes } \\
0: \text { no }\end{array}$ & -0.02 & $(0.05)$ & 0.01 & $(0.06)$ & 0.00 & $(0.07)$ & 0.00 & $(0.09)$ \\
\hline $\begin{array}{l}\text { School/higher } \\
\text { education or training }\end{array}$ & $\begin{array}{l}\text { 1: yes } \\
0: \text { no }\end{array}$ & $\mathrm{F}=0.13$ & [0.72] & $\mathrm{F}=0.38$ & [0.54] & $\mathrm{F}=1.04$ & [0.31] & $\mathrm{F}=0.71$ & {$[0.40]$} \\
\hline \multirow[t]{2}{*}{ Working, other } & \multirow{2}{*}{$\begin{array}{l}\text { 1: yes } \\
0: \text { no }\end{array}$} & 0.04 & $(0.05)$ & 0.06 & $(0.07)$ & 0.08 & $(0.10)$ & 0.11 & $(0.12)$ \\
\hline & & $F=0.56$ & [0.45] & $\mathrm{F}=1.03$ & [0.31] & $\mathrm{F}=1.17$ & {$[0.28]$} & $\mathrm{F}=1.38$ & {$[0.24]$} \\
\hline \multirow[t]{2}{*}{ Pensioner } & \multirow{2}{*}{$\begin{array}{l}\text { 1: yes } \\
0: \text { no }\end{array}$} & 0.01 & $(0.03)$ & 0.01 & $(0.04)$ & -0.02 & $(0.04)$ & -0.01 & $(0.05)$ \\
\hline & & $F=0.05$ & [0.82] & $\mathrm{F}=0.08$ & {$[0.78]$} & $F=0.18$ & {$[0.67]$} & $\mathrm{F}=0.01$ & {$[0.92]$} \\
\hline \multirow[t]{2}{*}{ Unemployed } & \multirow{2}{*}{$\begin{array}{l}\text { 1: yes } \\
0: \text { no } \\
\end{array}$} & -0.05 & $(0.03)$ & -0.04 & $(0.04)$ & -0.07 & $(0.05)$ & -0.06 & $(0.07)$ \\
\hline & & $\mathrm{F}=2.77$ & {$[0.10]$} & $\mathrm{F}=1.21$ & {$[0.27]$} & $F=1.86$ & {$[0.17]$} & $\mathrm{F}=1.02$ & {$[0.31]$} \\
\hline \multirow{2}{*}{$\begin{array}{l}\text { Homemaker } \\
\text { (Housewife/man) }\end{array}$} & \multirow{2}{*}{$\begin{array}{l}\text { 1: yes } \\
0: \text { no }\end{array}$} & -0.03 & $(0.02)$ & -0.04 & $(0.03)$ & -0.05 & $(0.04)$ & -0.06 & $(0.04)$ \\
\hline & & $\mathrm{F}=1.80$ & [0.18] & $\mathrm{F}=1.82$ & [0.18] & $\mathrm{F}=1.91$ & {$[0.17]$} & $\mathrm{F}=1.83$ & {$[0.18]$} \\
\hline \multirow{2}{*}{$\begin{array}{l}\text { Obligatory military / } \\
\text { public service }\end{array}$} & 1: yes & -0.01 & $(0.04)$ & -0.03 & $(0.05)$ & -0.01 & $(0.07)$ & -0.01 & $(0.08)$ \\
\hline & 0: no & $\mathrm{F}=0.07$ & [0.79] & $\mathrm{F}=0.44$ & [0.51] & $F=0.05$ & [0.82] & $\mathrm{F}=0.04$ & {$[0.84]$} \\
\hline Number of adults in the & 1: one adult & 0.01 & $(0.02)$ & 0.01 & $(0.02)$ & 0.00 & $(0.03)$ & 0.01 & $(0.04)$ \\
\hline $\begin{array}{l}\text { respondent's } \\
\text { household }\end{array}$ & 2: two adults & $F=0.31$ & {$[0.58]$} & $F=0.20$ & [0.65] & $F=0.01$ & [0.93] & $F=0.03$ & {$[0.85]$} \\
\hline Number of children in & 0: no children & -0.01 & $(0.01)$ & -0.01 & $(0.01)$ & 0.00 & $(0.02)$ & 0.01 & $(0.02)$ \\
\hline $\begin{array}{l}\text { the respondent's } \\
\text { household }\end{array}$ & 3: three or more children & $F=0.69$ & [0.41] & $F=0.77$ & [0.38] & $F=0.00$ & [0.95] & $F=0.23$ & [0.63] \\
\hline Family after-tax & 1: lowest income class & -0.00 & $(0.00)$ & 0.00 & $(0.01)$ & 0.00 & $(0.01)$ & -0.00 & $(0.01)$ \\
\hline income & $\begin{array}{c}\ldots \\
10: \text { highest income class }\end{array}$ & $F=0.12$ & [0.73] & $F=0.05$ & [0.83] & $F=0.02$ & [0.89] & $F=0.00$ & [0.98] \\
\hline Age & & $-0.00^{*}$ & $(0.00)$ & $-0.00^{*}$ & $(0.00)$ & -0.00 & $(0.00)$ & -0.00 & $(0.00)$ \\
\hline & & $F=5.20$ & {$[0.02]$} & $\mathrm{F}=4.83$ & {$[0.03]$} & $F=2.86$ & [0.09] & $\mathrm{F}=2.53$ & {$[0.11]$} \\
\hline
\end{tabular}


Table 3. Summary of seemingly unrelated regressions. Endogenous variable: equivalence scales stated by respondents. Standard errors in parentheses. P-values of F-tests in brackets.

*** $\mathrm{P}<0.001$, ** $\mathrm{P}<0.01,{ }^{*} \mathrm{P}<0.05$.

\begin{tabular}{|c|c|c|c|c|c|c|c|}
\hline & \multicolumn{7}{|c|}{ Germany (835 observations) } \\
\hline & $\begin{array}{l}1 \text { adult, } \\
1 \text { child }\end{array}$ & $\begin{array}{c}1 \text { adult, } \\
2 \text { children }\end{array}$ & $\begin{array}{c}1 \text { adult, } \\
3 \text { children }\end{array}$ & $\begin{array}{l}2 \text { adults, } \\
0 \text { children }\end{array}$ & $\begin{array}{l}2 \text { adults, } \\
1 \text { child }\end{array}$ & $\begin{array}{l}2 \text { adults, } \\
2 \text { children }\end{array}$ & $\begin{array}{l}2 \text { adults, } \\
3 \text { children }\end{array}$ \\
\hline Constant & $\begin{array}{l}0.99^{\star \star \star} \\
(0.02)\end{array}$ & $\begin{array}{l}1.03^{\star \star \star} \\
(0.04)\end{array}$ & $\begin{array}{l}1.09^{\star * \star} \\
(0.06)\end{array}$ & $\begin{array}{l}1.27^{\star \star \star} \\
(0.04)\end{array}$ & $\begin{array}{l}1.26^{\star \star \star} \\
(0.06)\end{array}$ & $\begin{array}{l}1.30^{\star \star \star} \\
(0.07)\end{array}$ & $\begin{array}{l}1.36^{\star \star \star} \\
(0.09)\end{array}$ \\
\hline $\begin{array}{l}\text { Reciprocal of } \\
\text { reference income }\end{array}$ & $\begin{array}{c}271.22^{\star \star \star} \\
(8.70)\end{array}$ & $\begin{array}{c}482.93^{\star \star \star} \\
(14.83)\end{array}$ & $\begin{array}{c}698.54^{\star \star \star} \\
(22.10)\end{array}$ & $\begin{array}{c}215.65^{\star \star \star} \\
(16.25)\end{array}$ & $\begin{array}{c}460.07^{\star \star \star} \\
(20.27)\end{array}$ & $\begin{array}{c}674.65^{* \star \star} \\
(25.43)\end{array}$ & $\begin{array}{c}886.86^{\star \star \star} \\
(32.62)\end{array}$ \\
\hline $\begin{array}{l}\text { Dummy reference } \\
\text { income } 1,270 \text { Euros }\end{array}$ & $\begin{array}{r}-0.01 \\
(0.01)\end{array}$ & $\begin{array}{l}-0.01 \\
(0.02)\end{array}$ & $\begin{array}{r}-0.02 \\
(0.03)\end{array}$ & $\begin{array}{r}-0.00 \\
(0.02)\end{array}$ & $\begin{array}{r}-0.01 \\
(0.03)\end{array}$ & $\begin{array}{r}-0.01 \\
(0.04)\end{array}$ & $\begin{array}{r}-0.01 \\
(0.05)\end{array}$ \\
\hline $\begin{array}{l}\text { Dummy reference } \\
\text { income } 2,032 \text { Euros }\end{array}$ & $\begin{array}{r}0.01 \\
(0.01)\end{array}$ & $\begin{array}{r}0.01 \\
(0.02)\end{array}$ & $\begin{array}{r}0.01 \\
(0.04)\end{array}$ & $\begin{array}{r}0.03 \\
(0.03)\end{array}$ & $\begin{array}{r}0.02 \\
(0.03)\end{array}$ & $\begin{array}{r}0.03 \\
(0.04)\end{array}$ & $\begin{array}{r}0.02 \\
(0.05)\end{array}$ \\
\hline $\begin{array}{l}\text { Dummy reference } \\
\text { income } 2,794 \text { Euros }\end{array}$ & $\begin{array}{r}-0.00 \\
(0.01)\end{array}$ & $\begin{array}{r}-0.01 \\
(0.02)\end{array}$ & $\begin{array}{r}-0.01 \\
(0.04)\end{array}$ & $\begin{array}{r}-0.02 \\
(0.03)\end{array}$ & $\begin{array}{r}-0.02 \\
(0.03)\end{array}$ & $\begin{array}{r}-0.02 \\
(0.04)\end{array}$ & $\begin{array}{r}-0.02 \\
(0.05)\end{array}$ \\
\hline Adjusted $\mathrm{R}^{2}$ & 0.61 & 0.63 & 0.62 & 0.24 & 0.46 & 0.53 & 0.54 \\
\hline $\begin{array}{l}\text { F test statistic for } \\
\text { exclusion of all } \\
\text { reference income } \\
\text { dummy variables }\end{array}$ & $\begin{array}{c}0.30 \\
{[0.83]}\end{array}$ & $\begin{array}{c}0.30 \\
{[0.82]}\end{array}$ & $\begin{array}{c}0.22 \\
{[0.88]}\end{array}$ & $\begin{array}{c}0.87 \\
{[0.46]}\end{array}$ & $\begin{array}{c}0.54 \\
{[0.66]}\end{array}$ & $\begin{array}{c}0.46 \\
{[0.71]}\end{array}$ & $\begin{array}{c}0.22 \\
{[0.88]}\end{array}$ \\
\hline
\end{tabular}

\begin{tabular}{|c|c|c|c|c|c|c|c|}
\hline & \multicolumn{7}{|c|}{ France (1,115 observations) } \\
\hline & $\begin{array}{l}1 \text { adult, } \\
1 \text { child }\end{array}$ & $\begin{array}{c}1 \text { adult, } \\
2 \text { children }\end{array}$ & $\begin{array}{c}1 \text { adult, } \\
3 \text { children }\end{array}$ & $\begin{array}{l}2 \text { adults, } \\
0 \text { children }\end{array}$ & $\begin{array}{c}2 \text { adults, } \\
1 \text { child }\end{array}$ & $\begin{array}{l}2 \text { adults, } \\
2 \text { children }\end{array}$ & $\begin{array}{l}2 \text { adults, } \\
3 \text { children }\end{array}$ \\
\hline Constant & $\begin{array}{l}1.03^{\star \star \star} \\
(0.03)\end{array}$ & $\begin{array}{l}1.07^{* * *} \\
(0.05)\end{array}$ & $\begin{array}{l}1.08^{* \star *} \\
(0.07)\end{array}$ & $\begin{array}{l}1.26^{\star * *} \\
(0.04)\end{array}$ & $\begin{array}{l}1.26^{* * *} \\
(0.06)\end{array}$ & $\begin{array}{l}1.25^{\star * *} \\
(0.08)\end{array}$ & $\begin{array}{l}1.24^{\star * \star} \\
(0.10)\end{array}$ \\
\hline $\begin{array}{l}\text { Reciprocal of } \\
\text { reference income }\end{array}$ & $\begin{array}{c}234.33^{\star \star \star} \\
(10.56)\end{array}$ & $\begin{array}{c}437.75^{\star \star \star} \\
(17.86)\end{array}$ & $\begin{array}{c}621.02^{\star \star \star} \\
(25.08)\end{array}$ & $\begin{array}{c}202.54^{\star \star \star} \\
(14.63)\end{array}$ & $\begin{array}{c}411.23^{\star \star \star} \\
(19.94)\end{array}$ & $\begin{array}{c}604.04^{\star \star \star} \\
(26.93)\end{array}$ & $\begin{array}{c}786.70^{\star \star \star} \\
(34.67)\end{array}$ \\
\hline $\begin{array}{l}\text { Dummy reference } \\
\text { income 1,312 Euros }\end{array}$ & $\begin{array}{r}-0.01 \\
(0.02)\end{array}$ & $\begin{array}{r}-0.02 \\
(0.03)\end{array}$ & $\begin{array}{r}-0.02 \\
(0.04)\end{array}$ & $\begin{array}{r}0.00 \\
(0.02)\end{array}$ & $\begin{array}{r}0.01 \\
(0.03)\end{array}$ & $\begin{array}{r}0.00 \\
(0.04)\end{array}$ & $\begin{array}{l}-0.01 \\
(0.05)\end{array}$ \\
\hline $\begin{array}{l}\text { Dummy reference } \\
\text { income } 2,100 \text { Euros }\end{array}$ & $\begin{array}{r}0.01 \\
(0.02)\end{array}$ & $\begin{array}{r}0.01 \\
(0.03)\end{array}$ & $\begin{array}{r}0.01 \\
(0.04)\end{array}$ & $\begin{array}{r}-0.00 \\
(0.02)\end{array}$ & $\begin{array}{r}-0.00 \\
(0.03)\end{array}$ & $\begin{array}{r}-0.00 \\
(0.04)\end{array}$ & $\begin{array}{r}-0.00 \\
(0.05)\end{array}$ \\
\hline $\begin{array}{l}\text { Dummy reference } \\
\text { income } 2,887 \text { Euros }\end{array}$ & $\begin{array}{r}-0.00 \\
(0.02)\end{array}$ & $\begin{array}{r}-0.00 \\
(0.03)\end{array}$ & $\begin{array}{r}-0.01 \\
(0.04)\end{array}$ & $\begin{array}{r}-0.02 \\
(0.02)\end{array}$ & $\begin{array}{l}-0.01 \\
(0.03)\end{array}$ & $\begin{array}{l}-0.01 \\
(0.04)\end{array}$ & $\begin{array}{r}-0.02 \\
(0.06)\end{array}$ \\
\hline Adjusted $\mathrm{R}^{2}$ & 0.38 & 0.42 & 0.43 & 0.20 & 0.35 & 0.39 & 0.40 \\
\hline $\begin{array}{l}\text { F test statistic for } \\
\text { exclusion of all } \\
\text { reference income } \\
\text { dummy variables }\end{array}$ & $\begin{array}{c}0.43 \\
{[0.73]}\end{array}$ & $\begin{array}{c}0.36 \\
{[0.78]}\end{array}$ & $\begin{array}{c}0.26 \\
{[0.85]}\end{array}$ & $\begin{array}{c}0.21 \\
{[0.89]}\end{array}$ & $\begin{array}{c}0.16 \\
{[0.92]}\end{array}$ & $\begin{array}{c}0.05 \\
{[0.98]}\end{array}$ & $\begin{array}{c}0.04 \\
{[0.99]}\end{array}$ \\
\hline
\end{tabular}

\begin{tabular}{|c|c|c|c|c|c|c|c|}
\hline & \multicolumn{7}{|c|}{ Cyprus (650 observations) } \\
\hline & $\begin{array}{l}1 \text { adult, } \\
1 \text { child }\end{array}$ & $\begin{array}{c}1 \text { adult, } \\
2 \text { children }\end{array}$ & $\begin{array}{c}1 \text { adult, } \\
3 \text { children }\end{array}$ & $\begin{array}{l}2 \text { adults, } \\
0 \text { children }\end{array}$ & $\begin{array}{l}2 \text { adults, } \\
1 \text { child }\end{array}$ & $\begin{array}{l}2 \text { adults, } \\
2 \text { children }\end{array}$ & $\begin{array}{c}2 \text { adults, } \\
3 \text { children }\end{array}$ \\
\hline Constant & $\begin{array}{l}1.08^{\star \star \star} \\
(0.05)\end{array}$ & $\begin{array}{l}1.19^{\star \star \star} \\
(0.09)\end{array}$ & $\begin{array}{l}1.28^{\star \star \star} \\
(0.14)\end{array}$ & $\begin{array}{l}1.24^{\star \star \star} \\
(0.07)\end{array}$ & $\begin{array}{l}1.31^{\star \star \star} \\
(0.10)\end{array}$ & $\begin{array}{l}1.43^{\star \star \star} \\
(0.14)\end{array}$ & $\begin{array}{l}1.52^{\star \star \star} \\
(0.17)\end{array}$ \\
\hline $\begin{array}{l}\text { Reciprocal of } \\
\text { reference income }\end{array}$ & $\begin{array}{c}192.68^{\star * \star} \\
(9.22)\end{array}$ & $\begin{array}{c}351.77^{\star \star \star} \\
(15.89)\end{array}$ & $\begin{array}{c}519.77^{\star \star \star} \\
(23.82)\end{array}$ & $\begin{array}{c}168.68^{\star \star \star} \\
(12.35)\end{array}$ & $\begin{array}{c}321.83^{\star \star *} \\
(16.84)\end{array}$ & $\begin{array}{c}499.02^{\star \star \star} \\
(23.29)\end{array}$ & $\begin{array}{l}661.18^{\text {}} \\
(29.20)\end{array}$ \\
\hline $\begin{array}{l}\text { Dummy reference } \\
\text { income } 774 \text { Euros }\end{array}$ & $\begin{array}{r}-0.03 \\
(0.02)\end{array}$ & $\begin{array}{r}-0.04 \\
(0.04)\end{array}$ & $\begin{array}{l}-0.07 \\
(0.06)\end{array}$ & $\begin{array}{r}0.01 \\
(0.03)\end{array}$ & $\begin{array}{r}-0.02 \\
(0.04)\end{array}$ & $\begin{array}{l}-0.03 \\
(0.06)\end{array}$ & $\begin{array}{l}-0.06 \\
(0.07)\end{array}$ \\
\hline $\begin{array}{l}\text { Dummy reference } \\
\text { income } 1,238 \text { Euros }\end{array}$ & $\begin{array}{r}-0.00 \\
(0.02)\end{array}$ & $\begin{array}{r}0.00 \\
(0.04)\end{array}$ & $\begin{array}{r}-0.00 \\
(0.06)\end{array}$ & $\begin{array}{r}0.02 \\
(0.03)\end{array}$ & $\begin{array}{r}0.01 \\
(0.04)\end{array}$ & $\begin{array}{r}0.01 \\
(0.06)\end{array}$ & $\begin{array}{r}0.01 \\
(0.08)\end{array}$ \\
\hline $\begin{array}{l}\text { Dummy reference } \\
\text { income 1,702 Euros }\end{array}$ & $\begin{array}{r}0.01 \\
(0.02)\end{array}$ & $\begin{array}{r}0.02 \\
(0.04)\end{array}$ & $\begin{array}{r}0.02 \\
(0.06)\end{array}$ & $\begin{array}{r}0.02 \\
(0.03)\end{array}$ & $\begin{array}{r}0.02 \\
(0.05)\end{array}$ & $\begin{array}{r}0.03 \\
(0.06)\end{array}$ & $\begin{array}{r}0.03 \\
(0.08)\end{array}$ \\
\hline Adjusted $\mathrm{R}^{2}$ & 0.48 & 0.51 & 0.50 & 0.30 & 0.45 & 0.49 & 0.52 \\
\hline $\begin{array}{l}\text { F test statistic for } \\
\text { exclusion of all } \\
\text { reference income } \\
\text { dummy variables }\end{array}$ & $\begin{array}{c}0.76 \\
{[0.52]}\end{array}$ & $\begin{array}{c}0.73 \\
{[0.53]}\end{array}$ & $\begin{array}{c}0.76 \\
{[0.52]}\end{array}$ & $\begin{array}{c}0.15 \\
{[0.93]}\end{array}$ & $\begin{array}{c}0.26 \\
{[0.85]}\end{array}$ & $\begin{array}{c}0.30 \\
{[0.82]}\end{array}$ & $\begin{array}{c}0.40 \\
{[0.75]}\end{array}$ \\
\hline
\end{tabular}


Table 3 (continued).

\begin{tabular}{|c|c|c|c|c|c|c|c|}
\hline & \multicolumn{7}{|c|}{ India ( 1,070 observations) } \\
\hline & $\begin{array}{l}1 \text { adult, } \\
1 \text { child }\end{array}$ & $\begin{array}{c}1 \text { adult, } \\
2 \text { children }\end{array}$ & $\begin{array}{c}1 \text { adult, } \\
3 \text { children }\end{array}$ & $\begin{array}{l}2 \text { adults, } \\
0 \text { children }\end{array}$ & $\begin{array}{l}2 \text { adults, } \\
1 \text { child }\end{array}$ & $\begin{array}{l}2 \text { adults, } \\
2 \text { children }\end{array}$ & $\begin{array}{l}2 \text { adults, } \\
3 \text { children }\end{array}$ \\
\hline Constant & $\begin{array}{l}1.09^{\star * \star} \\
(0.10)\end{array}$ & $\begin{array}{l}1.25^{\star \star *} \\
(0.15)\end{array}$ & $\begin{array}{l}1.39^{* * *} \\
(0.22)\end{array}$ & $\begin{array}{l}1.19^{\star \star \star} \\
(0.11)\end{array}$ & $\begin{array}{l}1.19^{\star \star \star} \\
(0.16)\end{array}$ & $\begin{array}{l}1.32^{\star \star \star} \\
(0.22)\end{array}$ & $\begin{array}{l}1.31^{* \star *} \\
(0.29)\end{array}$ \\
\hline $\begin{array}{l}\text { Reciprocal of } \\
\text { reference income }\end{array}$ & $\begin{array}{c}110.65^{\star \star \star} \\
(6.69)\end{array}$ & $\begin{array}{c}200.92^{\star \star \star} \\
(9.67)\end{array}$ & $\begin{array}{c}308.39^{\star * \star} \\
(14.48)\end{array}$ & $\begin{array}{c}134.11^{\star \star \star} \\
(7.39)\end{array}$ & $\begin{array}{c}245.18^{\star \star \star} \\
(10.72)\end{array}$ & $\begin{array}{c}357.38^{\star \star \star} \\
(14.45)\end{array}$ & $\begin{array}{c}467.95^{\star \star \star} \\
(18.95)\end{array}$ \\
\hline $\begin{array}{l}\text { Dummy reference } \\
\text { income } 552 \text { Euros }\end{array}$ & $\begin{array}{l}-0.01 \\
(0.04)\end{array}$ & $\begin{array}{l}-0.01 \\
(0.06)\end{array}$ & $\begin{array}{r}-0.02 \\
(0.09)\end{array}$ & $\begin{array}{r}0.01 \\
(0.05)\end{array}$ & $\begin{array}{r}-0.00 \\
(0.07)\end{array}$ & $\begin{array}{r}-0.02 \\
(0.09)\end{array}$ & $\begin{array}{r}-0.02 \\
(0.12)\end{array}$ \\
\hline $\begin{array}{l}\text { Dummy reference } \\
\text { income } 967 \text { Euros }\end{array}$ & $\begin{array}{r}-0.02 \\
(0.04)\end{array}$ & $\begin{array}{r}-0.02 \\
(0.06)\end{array}$ & $\begin{array}{l}-0.03 \\
(0.09)\end{array}$ & $\begin{array}{r}-0.02 \\
(0.05)\end{array}$ & $\begin{array}{r}-0.02 \\
(0.07)\end{array}$ & $\begin{array}{l}-0.03 \\
(0.09)\end{array}$ & $\begin{array}{r}-0.04 \\
(0.12)\end{array}$ \\
\hline $\begin{array}{l}\text { Dummy reference } \\
\text { income } 1,381 \text { Euros }\end{array}$ & $\begin{array}{r}0.01 \\
(0.04)\end{array}$ & $\begin{array}{r}0.01 \\
(0.06)\end{array}$ & $\begin{array}{c}0.02 \\
(0.10)\end{array}$ & $\begin{array}{r}0.01 \\
(0.05)\end{array}$ & $\begin{array}{r}0.01 \\
(0.07)\end{array}$ & $\begin{array}{r}0.01 \\
(0.10)\end{array}$ & $\begin{array}{r}0.01 \\
(0.13)\end{array}$ \\
\hline Adjusted $\mathrm{R}^{2}$ & 0.28 & 0.38 & 0.39 & 0.31 & 0.42 & 0.46 & 0.47 \\
\hline $\begin{array}{l}\text { F test statistic for } \\
\text { exclusion of all } \\
\text { reference income } \\
\text { dummy variables }\end{array}$ & $\begin{array}{c}0.15 \\
{[0.93]}\end{array}$ & $\begin{array}{c}0.07 \\
{[0.97]}\end{array}$ & $\begin{array}{c}0.08 \\
{[0.97]}\end{array}$ & $\begin{array}{c}0.15 \\
{[0.93]}\end{array}$ & $\begin{array}{c}0.07 \\
{[0.98]}\end{array}$ & $\begin{array}{c}0.09 \\
{[0.96]}\end{array}$ & $\begin{array}{c}0.05 \\
{[0.99]}\end{array}$ \\
\hline
\end{tabular}

\begin{tabular}{|c|c|c|c|c|c|c|c|}
\hline & \multicolumn{7}{|c|}{ China (980 observations) } \\
\hline & $\begin{array}{l}1 \text { adult, } \\
1 \text { child }\end{array}$ & $\begin{array}{c}1 \text { adult, } \\
2 \text { children }\end{array}$ & $\begin{array}{c}1 \text { adult, } \\
3 \text { children }\end{array}$ & $\begin{array}{l}2 \text { adults, } \\
0 \text { children }\end{array}$ & $\begin{array}{c}2 \text { adults, } \\
1 \text { child }\end{array}$ & $\begin{array}{l}2 \text { adults, } \\
2 \text { children }\end{array}$ & $\begin{array}{l}2 \text { adults, } \\
3 \text { children }\end{array}$ \\
\hline Constant & $\begin{array}{l}1.47^{\star \star \star} \\
(0.11)\end{array}$ & $\begin{array}{l}1.67^{* \star *} \\
(0.22)\end{array}$ & $\begin{array}{l}1.93^{* \star \star} \\
(0.37)\end{array}$ & $\begin{array}{l}1.49^{\star * \star} \\
(0.12)\end{array}$ & $\begin{array}{l}1.80^{* * \star} \\
(0.20)\end{array}$ & $\begin{array}{l}2.13^{\star * \star} \\
(0.31)\end{array}$ & $\begin{array}{l}2.68^{\star \star \star} \\
(0.44)\end{array}$ \\
\hline $\begin{array}{l}\text { Reciprocal of } \\
\text { reference income }\end{array}$ & $\begin{array}{c}139.39^{\star \star \star} \\
(8.09)\end{array}$ & $\begin{array}{c}295.82^{\star \star \star} \\
(16.83)\end{array}$ & $\begin{array}{l}411.41^{\star \star \star} \\
(27.73)\end{array}$ & $\begin{array}{c}78.42^{\star \star \star} \\
(9.27)\end{array}$ & $\begin{array}{c}227.80^{\star \star \star} \\
(15.01)\end{array}$ & $\begin{array}{c}386.69^{\star \star \star} \\
(23.30)\end{array}$ & $\begin{array}{c}529.31^{\text {***}} \\
(33.52)\end{array}$ \\
\hline $\begin{array}{l}\text { Dummy reference } \\
\text { income } 497 \text { Euros }\end{array}$ & $\begin{array}{r}0.03 \\
(0.03)\end{array}$ & $\begin{array}{r}0.01 \\
(0.06)\end{array}$ & $\begin{array}{l}-0.05 \\
(0.09)\end{array}$ & $\begin{array}{r}0.02 \\
(0.03)\end{array}$ & $\begin{array}{r}-0.02 \\
(0.05)\end{array}$ & $\begin{array}{r}-0.09 \\
(0.08)\end{array}$ & $\begin{array}{l}-0.17 \\
(0.11)\end{array}$ \\
\hline $\begin{array}{l}\text { Dummy reference } \\
\text { income } 993 \text { Euros }\end{array}$ & $\begin{array}{r}0.01 \\
(0.03)\end{array}$ & $\begin{array}{r}-0.04 \\
(0.06)\end{array}$ & $\begin{array}{c}-0.19^{*} \\
(0.10)\end{array}$ & $\begin{array}{r}-0.01 \\
(0.03)\end{array}$ & $\begin{array}{r}-0.08 \\
(0.05)\end{array}$ & $\begin{array}{l}-0.16^{*} \\
(0.08)\end{array}$ & $\begin{array}{l}-0.23^{*} \\
(0.12)\end{array}$ \\
\hline $\begin{array}{l}\text { Dummy reference } \\
\text { income } 1,987 \text { Euros }\end{array}$ & $\begin{array}{r}0.00 \\
(0.03)\end{array}$ & $\begin{array}{r}-0.02 \\
(0.06)\end{array}$ & $\begin{array}{l}-0.16 \\
(0.10)\end{array}$ & $\begin{array}{l}-0.03 \\
(0.03)\end{array}$ & $\begin{array}{l}-0.09 \\
(0.05)\end{array}$ & $\begin{array}{r}-0.15 \\
(0.09)\end{array}$ & $\begin{array}{l}-0.19 \\
(0.12)\end{array}$ \\
\hline Adjusted $\mathrm{R}^{2}$ & 0.31 & 0.32 & 0.27 & 0.15 & 0.29 & 0.32 & 0.29 \\
\hline $\begin{array}{l}\text { F test statistic for } \\
\text { exclusion of all } \\
\text { reference income } \\
\text { dummy variables }\end{array}$ & $\begin{array}{c}0.32 \\
{[0.81]}\end{array}$ & $\begin{array}{c}0.24 \\
{[0.87]}\end{array}$ & $\begin{array}{c}1.56 \\
{[0.20]}\end{array}$ & $\begin{array}{c}0.56 \\
{[0.64]}\end{array}$ & $\begin{array}{c}1.10 \\
{[0.35]}\end{array}$ & $\begin{array}{c}1.68 \\
{[0.17]}\end{array}$ & $\begin{array}{c}1.75 \\
{[0.16]}\end{array}$ \\
\hline
\end{tabular}

\begin{tabular}{|c|c|c|c|c|c|c|c|}
\hline & \multicolumn{7}{|c|}{ Botswana (477 observations) } \\
\hline & $\begin{array}{l}1 \text { adult, } \\
1 \text { child }\end{array}$ & $\begin{array}{c}1 \text { adult, } \\
2 \text { children }\end{array}$ & $\begin{array}{c}1 \text { adult, } \\
3 \text { children }\end{array}$ & $\begin{array}{l}2 \text { adults, } \\
0 \text { children }\end{array}$ & $\begin{array}{l}2 \text { adults, } \\
1 \text { child }\end{array}$ & $\begin{array}{l}2 \text { adults, } \\
2 \text { children }\end{array}$ & $\begin{array}{l}2 \text { adults, } \\
3 \text { children }\end{array}$ \\
\hline Constant & $\begin{array}{l}1.40^{\star \star \star} \\
(0.15)\end{array}$ & $\begin{array}{l}1.56^{* * *} \\
(0.28)\end{array}$ & $\begin{array}{l}1.61^{\star \star *} \\
(0.44)\end{array}$ & $\begin{array}{l}1.15^{\star \star \star} \\
(0.24)\end{array}$ & $\begin{array}{l}1.47^{\star \star \star} \\
(0.31)\end{array}$ & $\begin{array}{l}1.56^{\star \star *} \\
(0.43)\end{array}$ & $\begin{array}{l}1.75^{\star \star \star} \\
(0.59)\end{array}$ \\
\hline $\begin{array}{l}\text { Reciprocal of } \\
\text { reference income }\end{array}$ & $\begin{array}{c}115.85^{\star \star \star} \\
(9.75)\end{array}$ & $\begin{array}{c}233.90^{\star \star \star} \\
(17.48)\end{array}$ & $\begin{array}{c}351.55^{\star \star \star} \\
(26.97)\end{array}$ & $\begin{array}{c}122.06^{\star \star \star} \\
(14.57)\end{array}$ & $\begin{array}{c}249.05^{\star \star \star} \\
(19.01)\end{array}$ & $\begin{array}{c}388.31^{\star \star \star} \\
(26.73)\end{array}$ & $\begin{array}{c}527.51^{\star \star \star} \\
(36.21)\end{array}$ \\
\hline $\begin{array}{l}\text { Dummy reference } \\
\text { income } 381 \text { Euros }\end{array}$ & $\begin{array}{r}0.03 \\
(0.04)\end{array}$ & $\begin{array}{c}0.07 \\
(0.08)\end{array}$ & $\begin{array}{r}0.10 \\
(0.12)\end{array}$ & $\begin{array}{r}0.01 \\
(0.07)\end{array}$ & $\begin{array}{r}0.01 \\
(0.09)\end{array}$ & $\begin{array}{r}0.03 \\
(0.12)\end{array}$ & $\begin{array}{c}0.01 \\
(0.16)\end{array}$ \\
\hline Adjusted $\mathrm{R}^{2}$ & 0.31 & 0.32 & 0.32 & 0.18 & 0.33 & 0.38 & 0.38 \\
\hline $\begin{array}{l}\text { F test statistic for } \\
\text { exclusion of all } \\
\text { reference income } \\
\text { dummy variables }\end{array}$ & $\begin{array}{c}0.69 \\
{[0.41]}\end{array}$ & $\begin{array}{c}0.68 \\
{[0.41]}\end{array}$ & $\begin{array}{c}0.63 \\
{[0.43]}\end{array}$ & $\begin{array}{c}0.01 \\
{[0.91]}\end{array}$ & $\begin{array}{c}0.02 \\
{[0.88]}\end{array}$ & $\begin{array}{c}0.08 \\
{[0.78]}\end{array}$ & $\begin{array}{c}0.01 \\
{[0.93]}\end{array}$ \\
\hline
\end{tabular}


Figure 1. Scatter plots of stated Els in Part A of the survey for each RI and each family type.

$6^{\text {th }}$ degree polynomial fit.

--- linear regression.
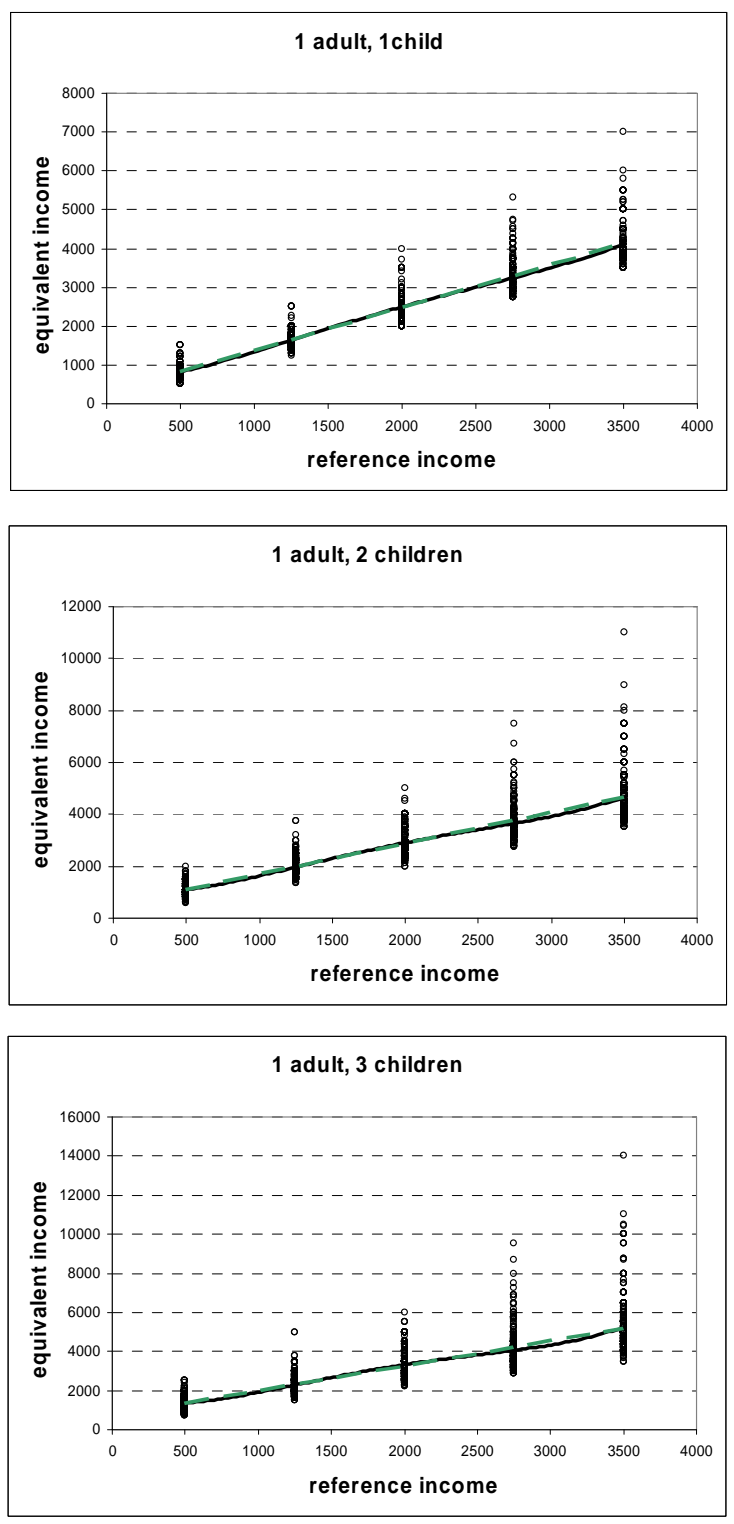
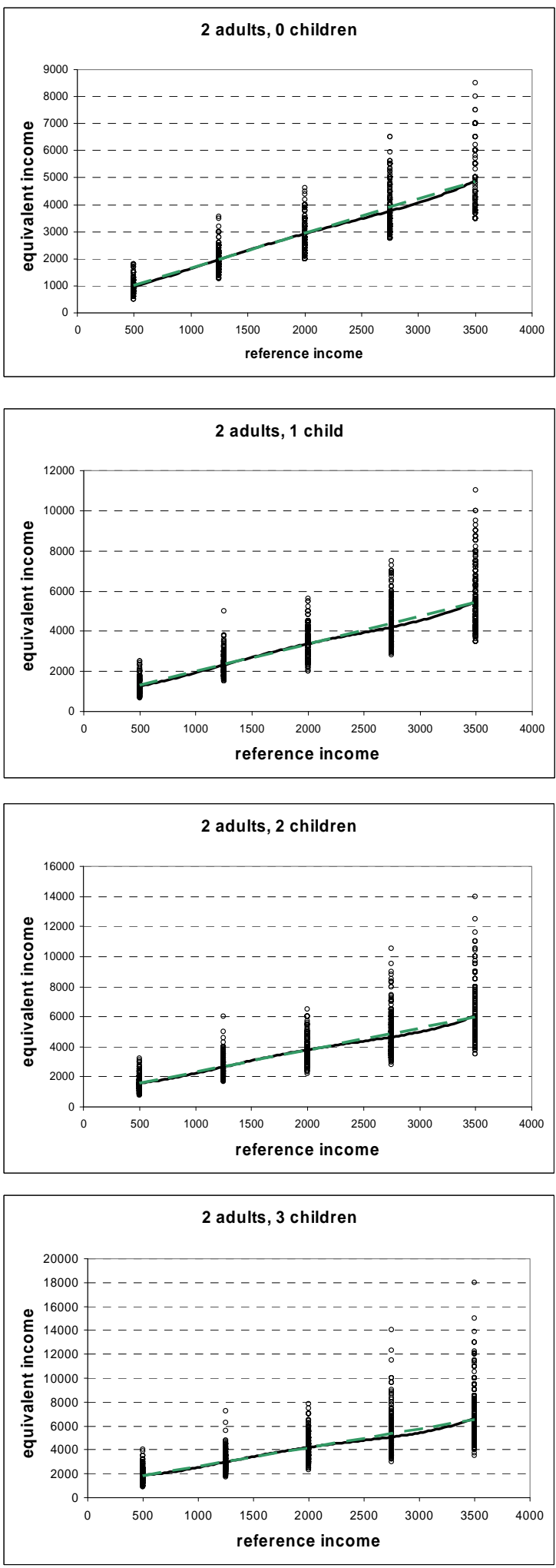
Figure 2. Scatter plots of stated equivalent incomes.

$6^{\text {th }}$ degree polynomial fit

France

China

Germany
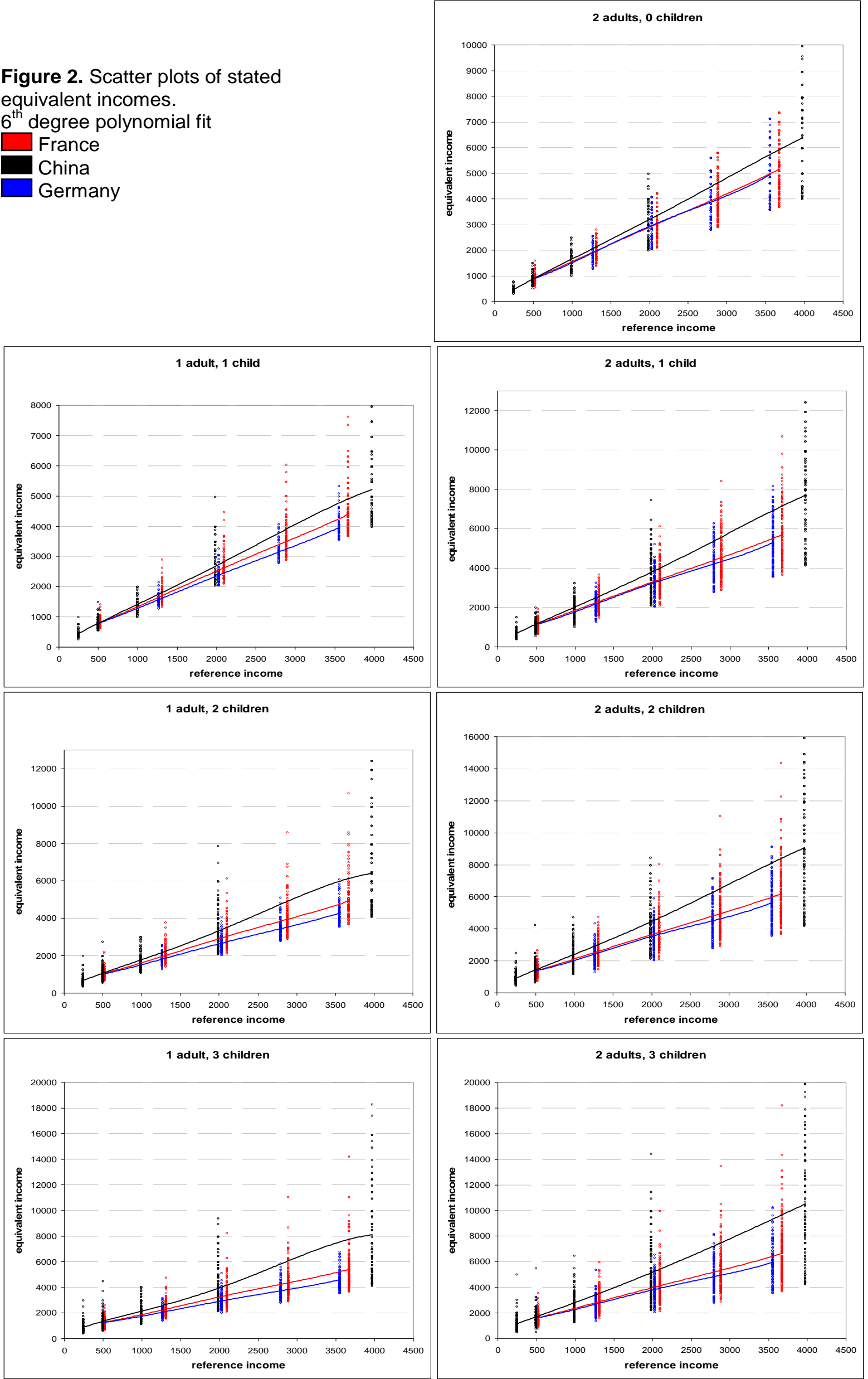
Figure 3. Scatter plots of stated equivalent incomes.

$6^{\text {th }}$ degree polynomial fit

Cyprus

Botswana

India
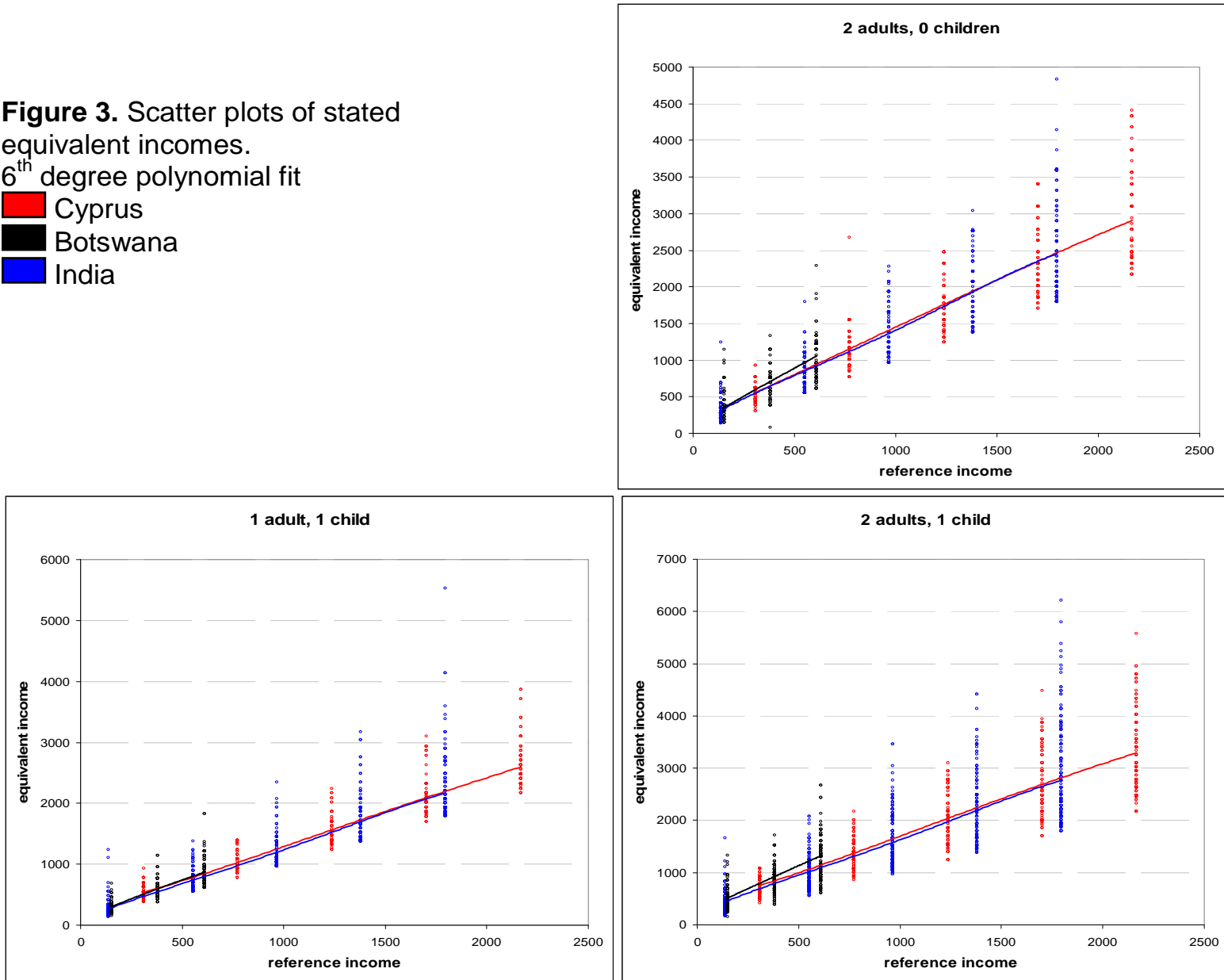

2 adults, 1 child
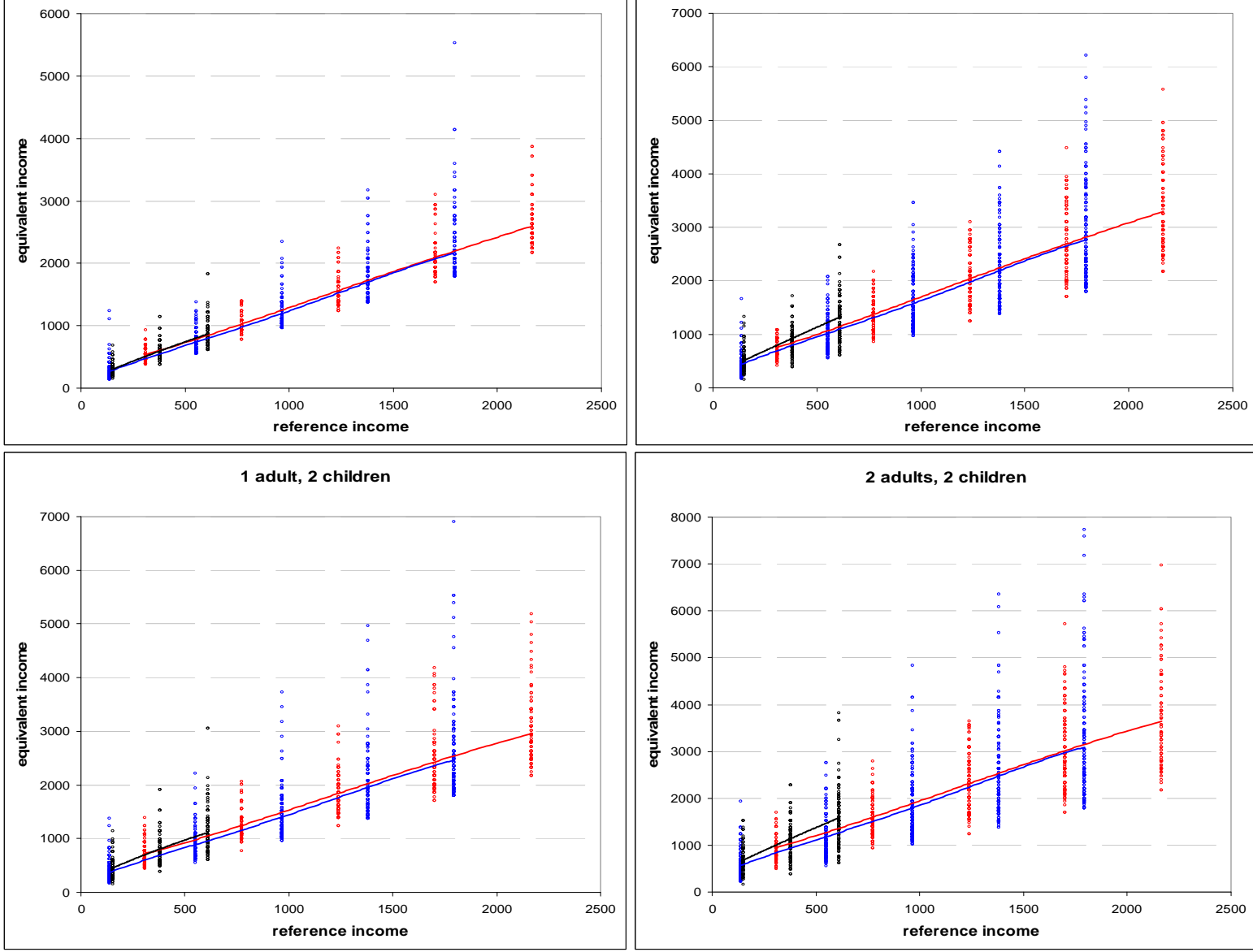

2 adults, 2 children
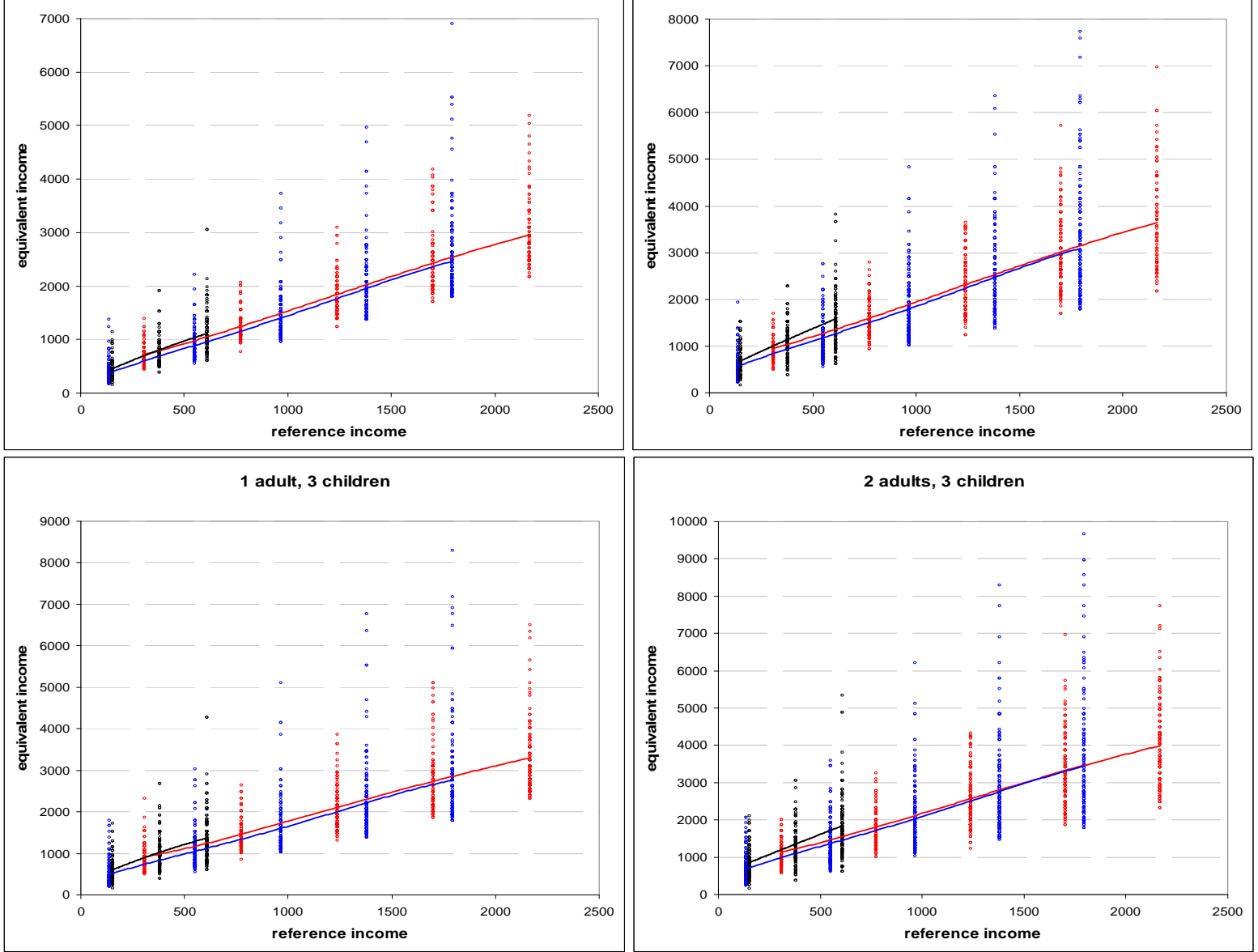


\title{
Additional Appendices (Online) for
}

\section{Do Demographics Prevent Consumption Aggregates From Reflecting Micro-Level Preferences?}

\author{
Christos Koulovatianos \\ Department of Economics, University of Luxembourg, and CFS, Frankfurt \\ christos.koulovatianos@uni.lu \\ Carsten Schröder \\ Department of Economics, Free University of Berlin, and SOEP at DIW Berlin \\ cschroeder@diw.de \\ Ulrich Schmidt \\ Department of Economics, University of Kiel, Kiel Institute for the World Economy, and \\ University of Johannesburg, Johannesburg, South Africa \\ uschmidt@bwl.uni-kiel.de
}

April 2018 


\section{Appendix A - Common Choice-Independent Rates of Time Preference and Time-Invariant Momentary Utility Functions}

Household preferences of each $i \in \mathcal{I}$, are given by the general additively-separable utility function with a common across households rate of time preference captured by the positivelyvalued function $\rho: \mathbb{R}_{+} \rightarrow \mathbb{R}_{++}$, where

$$
U^{i}\left(\left(c^{i}(t)\right)_{t \geq 0}\right)=\int_{0}^{\infty} e^{-\int_{0}^{t} \rho(\tau) d \tau} u^{i}\left(c^{i}(t)\right) d t
$$

Assumption A.1 For all $i \in \mathcal{I}, u^{i}: \mathbb{R}_{+} \rightarrow \mathbb{R}$, is twice-continuously differentiable and such that $u_{1}^{i}(c)>0$ and $u_{11}^{i}(c)<0$ on some interval, $\mathbb{C}^{i} \subseteq \mathbb{R}_{+}$, with both $u_{1}^{i}(c)<\infty$ and $-\infty<u_{11}^{i}(c)$ for all $c \in \mathbb{C}^{i} \subseteq \mathbb{R}_{+}$, with $\underline{c}^{i} \equiv \inf \left(\mathbb{C}^{i}\right)<\sup \left(\mathbb{C}^{i}\right) \equiv \bar{c}^{i}$.

Assumption A.1 secures that, for all $i \in \mathcal{I}$, there is a choice domain, $\mathbb{C}^{i} \subseteq \mathbb{R}_{+}$, which is an interval, and where standard desirable properties of momentary utility functions are present.

Assumption A.2 $\underset{i \in \mathcal{I}}{\cap} \mathbb{C}^{i}$ is non-empty and not a singleton.

Assumption A.2 places a weak constraint on the scope of preference heterogeneity. It says that nobody's bliss point (if any), should be lower than or equal to anyone else's subsistence level of consumption (if any), hence $\cap \mathbb{C}_{i \in \mathcal{I}}^{i}$ is an interval. Since the consumable good is considered to be a composite good (a consumer basket), Assumption A.1 is not unreasonably restrictive. 
Theorem A.1 Under Assumptions A.1 and A.2, and Asumptions 2 and 3 in the paper, a representative consumer exists if and only if

$$
u^{i}(c)=\left\{\begin{array}{cc}
\frac{\left(\alpha c+\beta_{i}\right)^{1-\frac{1}{\alpha}}-1}{\alpha\left(1-\frac{1}{\alpha}\right)} & \text { with } \alpha>0 \text { and } \beta_{i} \in \mathbb{R} \text { or } \alpha<0 \text { and } \beta_{i}>0 \\
\text { or } & \text { with } \beta_{i}>0 \\
-e^{-\frac{1}{\beta_{i}} c} & \text {, }
\end{array},\right.
$$

for all $i \in \mathcal{I}$. The representative consumer has the common, across households, rate of time preference, $\rho(t)$, at all times, and momentary utility function given by,

$$
u^{R C}(c)=\left\{\begin{array}{cc}
\frac{\left(\alpha c+\beta_{R C}\right)^{1-\frac{1}{\alpha}}-1}{\alpha\left(1-\frac{1}{\alpha}\right)} & \text { for } \alpha \neq 0 \\
-e^{-\frac{1}{\beta_{R C}} c} & \text { else }
\end{array}\right.
$$

with

$$
\beta_{R C}=\int_{\mathcal{I}} \beta_{i} d \mu(i) .
$$

\section{Proof of Theorem A.1}

Part 1: Necessity

Fix any function $\rho: \mathbb{R}_{+} \rightarrow \mathbb{R}_{++}$, and any collection $\left(u^{i}\right)_{i \in \mathcal{I}}$, with properties complying with Assumptions A.1 and A.2, and Assumption 2 in the paper. Assume that a representative consumer exists with some momentary utility function $v^{R C}: \mathbb{C}^{R C} \times \mathbb{R}_{+} \rightarrow \mathbb{R}$, of the form $v^{R C}(c(t), t)$, at each point in time. Under Assumption 3 in the paper, from Definition 1 
and the necessary condition,

$$
\dot{c}^{i}(t)=-\frac{u_{1}^{i}\left(c^{i}(t)\right)}{u_{11}^{i}\left(c^{i}(t)\right)}[r(t)-\rho(t)]
$$

it must be,

$$
\frac{v_{1}^{R C}\left(\int_{\mathcal{I}} c^{i}(t) d \mu(i), t\right)}{v_{11}^{R C}\left(\int_{\mathcal{I}} c^{i}(t) d \mu(i), t\right)}\left[r(t)+\frac{v_{12}^{R C}\left(\int_{\mathcal{I}} c^{i}(t) d \mu(i), t\right)}{v_{1}^{R C}\left(\int_{\mathcal{I}} c^{i}(t) d \mu(i), t\right)}\right]=\int_{\mathcal{I}} \mu(i) \frac{u_{1}^{i}\left(c^{i}(t)\right)}{u_{11}^{i}\left(c^{i}(t)\right)} d i[r(t)-\rho(t)]
$$

in which the term

$$
-\frac{v_{12}^{R C}\left(\int_{\mathcal{I}} c^{i}(t) d \mu(i), t\right)}{v_{1}^{R C}\left(\int_{\mathcal{I}} c^{i}(t) d \mu(i), t\right)}
$$

is the temporal rate of time preference of the representative consumer.

(Necessity) Step 1: preliminary characterization of the function $\int_{0}^{\infty} v^{R C}(c(t), t) d t$.

According to Definition 1 in the paper, the existence (and the implied preference primitives) of the representative consumer should be independent from any price regime. The case where $r(t)=\rho(t)$ for all $t \geq 0$, should always be included in the price domain. To see this, fix any moment in time, $t \in \mathbb{R}_{+}$, pick any household $i \in \mathcal{I}$, and multiply its budget constraint (this is equation (4) in the paper), by the integrating factor $e^{-\int_{t}^{\tau} r(s) d s}$, integrate over all $\tau \in[t, \infty)$, and apply the transversality condition, to obtain,

$$
\int_{t}^{\infty} e^{-\int_{t}^{\tau} r(s) d s} c^{i}(t) d \tau=a^{i}(t)+\int_{t}^{\infty} e^{-\int_{t}^{\tau} r(s) d s} \theta^{i}(\tau) w(\tau) d \tau
$$

For the case $r(t)=\rho(t)$ for all $t \geq 0$, under Assumption 3 in the paper, (4) implies that $\dot{c}^{i}(t)=0$ for all $t \in \mathbb{R}_{+}$, and all $i \in \mathcal{I}$, so, (6) implies that

$$
c^{i}(t)=\hat{c}^{i}=\frac{a^{i}(t)+\int_{t}^{\infty} e^{-\int_{t}^{\tau} \rho(s) d s} \theta^{i}(\tau) w(\tau) d \tau}{\int_{t}^{\infty} e^{-\int_{t}^{\tau} \rho(s) d s} d \tau}, \text { for all } t \geq 0
$$


For the given preference profile, $\left(u^{i}\right)_{i \in \mathcal{I}},(7)$ implies that there are always $\left(a_{0}^{i}, \theta^{i}\right)_{i \in \mathcal{I}}$ and $(w(t))_{t \geq 0}$ securing that $\hat{c}^{i} \in \mathbb{C}^{i}$ for all $i \in \mathcal{I}$, and for all $t \geq 0$. So, the case $r(t)=\rho(t)$ for all $t \geq 0$, is always part of the domain complying with Assumption 3 in the paper, for any $\left(u^{i}\right)_{i \in \mathcal{I}}$ that satisfies Assumptions A.1 and A.2, and also Assumption 2 in the paper.

Thus, set $r(t)=\rho(t)$ for all $t \geq 0$ and pick an appropriate $\left(a_{0}^{i}, \theta^{i}\right)_{i \in \mathcal{I}}$ and $(w(t))_{t \geq 0}$ securing that $\hat{c}^{i}>\underline{c}^{i}$ for all $i \in \mathcal{I}$, and for all $t \geq 0$, and also set

$$
c \equiv \int_{\mathcal{I}} \hat{c}^{i} d \mu(i)
$$

Equations (5) and (7) imply that the necessary optimality conditions of the representative consumer are,

$$
-\frac{v_{12}^{R C}(c, t)}{v_{1}^{R C}(c, t)}=\rho(t)
$$

So, standard Riemann integration with respect to $t$ over the time interval $[0, t]$ implies that

$$
v_{1}^{R C}(c, t)=e^{-\int_{0}^{t} \rho(\tau) d \tau} v_{1}^{R C}(c, 0)
$$

or,

$$
v^{R C}(c, t)=e^{-\int_{0}^{t} \rho(\tau) d \tau} v^{R C}(c, 0)
$$

ignoring the constant, since this is a utility function. Setting

$$
u^{R C}(c) \equiv v^{R C}(c, 0)
$$

we conclude that the objective of the representative consumer must be of the form

$$
U^{R C}\left((c(t))_{t \geq 0}\right)=\int_{0}^{\infty} e^{-\int_{0}^{t} \rho(\tau) d \tau} u^{R C}(c(t)) d t
$$

For notational ease, let $f^{R C}: \mathbb{C}^{R C} \rightarrow \mathbb{R}_{++}$and $\left(f^{i}: \mathbb{C}^{i} \rightarrow \mathbb{R}_{++}\right)_{i \in \mathcal{I}}$, with

$$
f^{R C}(\cdot)=-\frac{v_{1}^{R C}(\cdot)}{v_{11}^{R C}(\cdot)} \quad \text { and } \quad f^{i}(\cdot)=-\frac{u_{1}^{i}(\cdot)}{u_{11}^{i}(\cdot)} \quad \text { for all } i \in \mathcal{I} \text {. }
$$


Combining (8) with (5), it is,

$$
f^{R C}\left(\int_{\mathcal{I}} c^{i}(t) d \mu(i)\right)=\int_{\mathcal{I}} f^{i}\left(c^{i}(t)\right) d \mu(i)
$$

for all $\left(c^{i}(t) \in \mathbb{C}^{i}\right)_{i \in \mathcal{I}}$ that are consumer-equilibrium choices and $t \geq 0$.

(Necessity) Step 2: characterization of $f^{R C}: \mathbb{R}_{+} \rightarrow \mathbb{R}_{++}$and $\left(f^{i}: \mathbb{R}_{+} \rightarrow \mathbb{R}_{++}\right)_{i \in \mathcal{I}}$. In this step we show that,

$$
(9) \Leftrightarrow\left\{\begin{array}{c}
f^{i}(c)=\alpha c+\beta_{i}, \text { and, } \\
f^{R C}(c)=\alpha c+\int_{\mathcal{I}} \beta_{i} d \mu(i), \\
\text { for some } \alpha \in \mathbb{R} \text { and some } \beta_{i} \in \mathbb{R}, \text { for all } i \in \mathcal{I}
\end{array}\right\} .
$$

The sufficiency part of (10) is straightforward. For the necessity part of (10), let (9) hold, being the only information available concerning $f^{R C}: \mathbb{R}_{+} \rightarrow \mathbb{R}_{++}$and the collection $\left(f^{i}: \mathbb{R}_{+} \rightarrow \mathbb{R}_{++}\right)_{i \in \mathcal{I}}$. Suppose that $r(t)=\rho(t)$ for all $t \geq 0$, and, given $(7)$, find a common distribution of $\left(a_{0}^{i}, \theta^{i}\right)_{i \in \mathcal{I}}$ and $(w(t))_{t \geq 0}$, where $a_{0}^{i}=a_{0}$ and $\theta^{i}=\theta$, so that $c^{i}(t)=\tilde{c}$ for all $i \in \mathcal{I}$, and all $t \geq 0$, also with $\tilde{c} \in \cap_{i \in \mathcal{I}} \mathbb{C}^{i}$.

Let

$$
\Phi^{R C}(c) \equiv f^{R C}(c)-f^{R C}(\tilde{c})
$$

and,

$$
\Phi^{i}(c) \equiv f^{i}(c)-f^{i}(\tilde{c}), \text { for all } i \in \mathcal{I}
$$

For this distribution, (9) implies that,

$$
f^{R C}(\tilde{c})=\int_{\mathcal{I}} f^{i}(\tilde{c}) d \mu(i)
$$


Given that $\inf \{d \mu(i) \mid i \in \mathcal{I}\}>0$, set $\underline{\mu}$ such that,

$$
0<\underline{\mu} \leq \inf \{d \mu(i) \mid i \in \mathcal{I}\}
$$

Pick any arbitrary household type $i \in \mathcal{I}$, keep prices as before, and modify the previous distribution by adding to $\underline{\mu}$ of this household type different wealth or productivity that yields $c^{i}(t)=(\tilde{c}+\Delta c) \in \underset{i \in \mathcal{I}}{\cap} \mathbb{C}^{i}$, for all $t \geq 0$. Since prices are the same, $c^{j}(t)=\tilde{c}$, for all $j \in \mathcal{I} \backslash\{i\}$ and for some households of type $i$ with density $d \mu(i)-\underline{\mu}$, and for all $t \geq 0$. Combining (9), (13), (11) and (12), it is,

$$
\Phi^{R C}(\underline{\mu} \Delta c+\tilde{c})=\underline{\mu} \Phi^{i}(\Delta c+\tilde{c})
$$

Since the choices of $i \in \mathcal{I}, \Delta c$, and $\tilde{c} \in \underset{i \in \mathcal{I}}{\cap} \mathbb{C}^{i}$, were arbitrary, and since we can construct the same distribution of consumption choices for all $i \in \mathcal{I}$, (15) holds for all $i \in \mathcal{I}$, so,

$$
\Phi^{i}(c)=\Phi(c) \text { for all } c \in \underset{i \in \mathcal{I}}{\cap} \mathbb{C}^{i} \text { and for all } i \in \mathcal{I} \text {. }
$$

Given (7), we are able to construct any interior optimal path with distribution of consumptions with $c^{i}(t)=c \in \underset{i \in \mathcal{I}}{\cap} \mathbb{C}^{i}$ for all $i \in \mathcal{I}$, and all $t \geq 0$. Therefore, (9), (13), and (16) imply that,

$$
\Phi^{R C}(c)=\Phi^{i}(c)=\Phi(c) \quad \text { for all } c \in \bigcap_{i \in \mathcal{I}} \mathbb{C}^{i} \text { and for all } i \in \mathcal{I}
$$

and,

$$
\Phi\left(\int_{\mathcal{I}} c^{i}(t) d \mu(i)\right)=\int_{\mathcal{I}} \Phi\left(c^{i}(t)\right) d \mu(i), \quad \text { for all }\left(c^{i}(t) \in \underset{i \in \mathcal{I}}{\cap \mathbb{C}^{i}}\right)_{i \in \mathcal{I}}, \text { and } t \geq 0
$$

holding for the whole domain of wealth/labor-productivity heterogeneity and prices where household choices fall in the interval $\underset{i \in \mathcal{I}}{\cap} \mathbb{C}^{i}$ (see Assumption A.2) and are interior. Equation (18) enables us to further characterize $\Phi$. In particular,

$$
(18) \Leftrightarrow \Phi \text { is affine on } \bigcap_{i \in \mathcal{I}} \mathbb{C}^{i} \text {. }
$$


The sufficiency part of (19) is straightforward, so for the necessity part of (19) set,

$$
z^{i} \equiv c^{i}-\tilde{c}
$$

with $\tilde{c}$ defined as above for an arbitrary $\tilde{c} \in \cap \underset{i \in \mathcal{I}}{\cap} \mathbb{C}^{i}$, in the case where $r(t)=\rho(t)$ for all $t \geq 0$. Since we know that for the transformed variable, $z$, the choice of 0 falls in the class of interior solutions to a distribution in the domain of $\left(u^{i}\right)_{i \in \mathcal{I}}$, namely the case where all households choose $\tilde{c} \in \underset{i \in \mathcal{I}}{\cap} \mathbb{C}^{i}$ at all times, fix $\tilde{c}$ and set,

$$
\Psi(z) \equiv \Phi(z)-\Phi(0)
$$

We now show that $\Psi$ is a linear functional. For any partition of households, irrespective of their household types, say, $\mathcal{I}_{1}, \mathcal{I}_{2} \subset \mathcal{I}$, with $\mathcal{I}_{1} \cap \mathcal{I}_{2}=\emptyset$, and $\int_{\mathcal{I}_{1}} d \mu(i)=\mu$, retaining $r(t)=\rho(t)$ for all $t \geq 0$, provide the same $a_{0}$ and a labor-productivity function $\theta$ to all $i \in \mathcal{I}_{1}$, so that consumption is equal to $(\Delta c+\tilde{c}) \in \cap \cap_{i \in \mathcal{I}} \mathbb{C}^{i}$ for all $i \in \mathcal{I}_{1}$ at all times, provide to the remaining households $\tilde{a}_{0}$ and a labor-productivity $\tilde{\theta}$, so that their consumption is equal

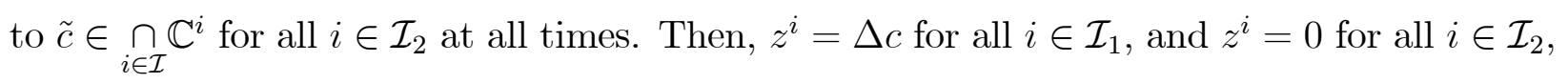
so,

$$
\Phi(\mu \Delta c)=\Phi(\mu \Delta c+(1-\mu) 0)
$$

and (18) and (21) imply that,

$$
\Phi(\mu \Delta c)=\mu \Phi(\Delta c)+(1-\mu) \Phi(0)
$$

or,

$$
\Psi(\mu \Delta c)=\mu \Psi(\Delta c)
$$

Notice that the choices of $\Delta c$ and $\mu$ were arbitrary. So, we can take any $\mu_{1}, \mu_{2} \in(0,1)$ with $\left(\mu_{1} \Delta c+\tilde{c}\right),\left(\mu_{1} \Delta c+\tilde{c}\right) \in \underset{i \in \mathcal{I}}{\cap} \mathbb{C}^{i}$ and $\frac{\mu_{2}}{\mu_{1}}=\xi \in \mathbb{R}_{+}$. Repeating the same steps, (22) yields 
$\Psi\left(\mu_{1} \Delta c\right)=\mu_{1} \Psi(\Delta c)$ and $\Psi\left(\xi \mu_{1} \Delta c\right)=\xi \mu_{1} \Psi(\Delta c)$, or

$$
\Psi\left(\xi \mu_{1} \Delta c\right)=\xi \Psi\left(\mu_{1} \Delta c\right), \text { for all } \xi \in \mathbb{R}_{+}
$$

Since $\Psi$ is a univariate function, (23) is sufficient to prove that $\Psi$ is linear. So, let,

$$
\Psi(z)=\alpha z, \quad \alpha \in \mathbb{R}
$$

and, due to the linearity of $\Psi$, the transformation (20) can be ignored, having (21) and (17) implying that, $\Phi(c)=\alpha c+\Phi(0)$. But since (11) and (12) imply that $\Phi(\tilde{c})=0, \Phi(0)=-\alpha \tilde{c}$, so,

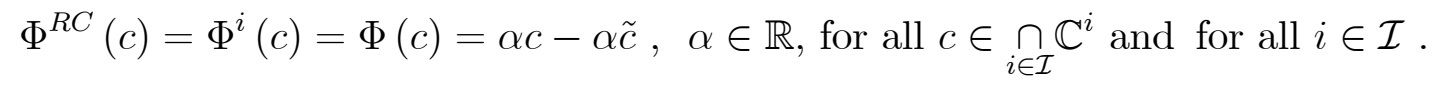

Using (24) we show that,

$$
\Phi^{i}(c)=\Phi(c)=\alpha c-\alpha \tilde{c}, \quad \alpha \in \mathbb{R} \text {, for all } c \in \mathbb{C}^{i} \text { and for all } i \in \mathcal{I} \text {. }
$$

To prove (25), consider the case where an arbitrary $c^{j} \in \mathbb{C}^{j}$ is such that $c^{j} \leq \inf \left(\cap_{i \in \mathcal{I}} \mathbb{C}^{i}\right)$ or $c^{j} \geq \sup \left(\cap_{i \in \mathcal{I}} \mathbb{C}^{i}\right)$ for some $j \in \mathcal{I}$, whenever any of the two is possible (i.e., whenever $\inf \left(\underset{i \in \mathcal{I}}{\cap \mathbb{C}^{i}}\right)>0$, or sup $\left.\left(\underset{i \in \mathcal{I}}{\cap \mathbb{C}^{i}}\right)<\infty\right)$. There always exists some $\mu \in(0,1)$, with $\mu \leq d \mu(j)$, such that $\left(\mu c^{j}+(1-\mu) \tilde{c}\right) \in \cap \cap_{i \in \mathcal{I}} \mathbb{C}^{i}$. So, retaining $r(t)=\rho(t)$ for all $t \geq 0$, provide a level $a_{0}$ and a labor-productivity function $\theta$ to a mass $\mu$ of type $j \in \mathcal{I}$, so that consumption is equal to $c^{j}$ at all times, and also provide to the remaining households $\tilde{a}_{0}$ and a labor-productivity $\tilde{\theta}$, so that their consumption is equal to $\tilde{c} \in \underset{i \in \mathcal{I}}{\cap} \mathbb{C}^{i}$ at all times. Combining (9), (11), (12) and (13), it is

$$
\mu \Phi^{j}\left(c^{j}\right)=\Phi^{R C}\left(\mu c^{j}+(1-\mu) \tilde{c}\right)
$$


But since $\left(\mu c^{j}+(1-\mu) \tilde{c}\right) \in \underset{i \in \mathcal{I}}{\cap} \mathbb{C}^{i},(24)$ implies that $\Phi^{R C}\left(\mu c^{j}+(1-\mu) \tilde{c}\right)=\alpha\left(\mu c^{j}+(1-\mu) \tilde{c}\right)-$ $\alpha \tilde{c}$, or

$$
\Phi^{j}\left(c^{j}\right)=\alpha c^{j}-\alpha \tilde{c}
$$

Since the choices of $j \in \mathcal{I}$ and $c^{j} \in \mathbb{C}^{j}$ were arbitrary, (25) is proved.

Combining (12) with (25) it is,

$$
f^{i}(c)=\alpha c-\alpha \tilde{c}+f^{i}(\tilde{c}) \text { for all } c \in \mathbb{C}^{i} \text { and all } i \in \mathcal{I} .
$$

Now that all $f^{i}$ 's are completely characterized over their domains, $\mathbb{C}^{i}$, we can consider the case of $c=0$, irrespective from whether $0 \in \mathbb{C}^{i}$ or not, in order to set the intercepts of all $f^{i}$ s. Equation (26) implies,

$$
f^{i}(\tilde{c})=\alpha \tilde{c}+f^{i}(0)
$$

Setting $f^{i}(0)=\beta_{i}$ for some $\beta_{i} \in \mathbb{R}$, for all $i \in \mathcal{I}$, a final combination of (26) with (27), and also setting $\beta_{R C}=\int_{\mathcal{I}} \beta_{i} d \mu(i)$ (consistently with (9)), completes the proof of (10).

(Necessity) Step 3: characterization of $\left(u^{i}: \mathbb{R}_{+} \rightarrow \mathbb{R}\right)_{i \in \mathcal{I}}$ and $u^{R C}: \mathbb{R}_{+} \rightarrow \mathbb{R}$.

In light of (10), we derive the functional forms of utility for all household types through Riemann integration. There are two general cases, those of $\alpha \neq 0$ and $\alpha=0$. (The case where $\alpha=1$ is also of special interest, but the particular functional form of $\left(u^{i}\right)_{i \in \mathcal{I}}$ and $u^{R C}$ that result in this case can be derived from the more general functional forms that apply to $\alpha \neq 0$.

For the case where $\alpha \neq 0,(10)$ implies that,

$$
\frac{u_{11}^{i}(c)}{u_{1}^{i}(c)}=-\frac{1}{\alpha c+\beta_{i}}
$$


and the indefinite Riemann integral of this expression with respect to $c$ yields,

$$
\ln \left[u_{1}^{i}(c)\right]=-\frac{1}{\alpha} \ln \left(\alpha c+\beta_{i}\right)+\kappa_{i},
$$

where $\kappa_{i}$ is some constant in $\mathbb{R}$, that can be household-specific, and integrating once more, it is,

$$
u^{i}(c)=e^{\kappa_{i}} \frac{\left(\alpha c+\beta_{i}\right)^{1-\frac{1}{\alpha}}}{\alpha\left(1-\frac{1}{\alpha}\right)}+\kappa,
$$

where $\kappa$ is, again some constant. Setting $e^{\kappa_{i}}=1$, without loss of generality, and $\kappa$ accordingly, we obtain the result of (2). The special case where $\alpha=1$, is known to yield the result that $u^{i}(c)=\ln \left(\alpha c+\beta_{i}\right)+\kappa$, through computing the limit of the above expression for $\alpha \rightarrow 1$ using L'Hôpital's rule. The preferences of the representative consumer are derived in the same way.

For the case where $\alpha=0$,

$$
\frac{u_{11}^{i}(c)}{u_{1}^{i}(c)}=-\frac{1}{\beta_{i}}
$$

and in order for $u_{1}^{i}>0$ and $u_{11}^{i}<0$ to hold, it must be that $\beta_{i}>0$. So,

$$
\ln \left[u_{1}^{i}(c)\right]=-\frac{1}{\beta_{i}} c+\kappa_{i}
$$

and

$$
u^{i}(c)=-e^{\kappa_{i}} \beta_{i} e^{-\frac{1}{\beta_{i}} c}+\kappa
$$

so, setting $e^{\kappa_{i}} \beta_{i}=1$ and $\kappa=0$ yields the corresponding function in (2). With the same reasoning for the representative consumer, the proof of the necessity part is complete. 


\section{Part 2: Sufficiency}

The particular functional forms given by (2) enable a complete analytical characterization of the demand functions of all households at all times. Again, two cases must be examined separately, that of $\alpha \neq 0$ and the case where $\alpha=0$.

Under the assumption that $\alpha \neq 0,(4)$, implies

$$
\dot{c}^{i}(t)=\left[\alpha c^{i}(t)+\beta_{i}\right][r(t)-\rho(t)]
$$

so, multiplying this expression by the integrating factor $e^{-\alpha \int_{t}^{T}[r(s)-\rho(s)] d s}$ and integrating over the interval $[t, \tau]$ for any $\tau \in[t, \infty)$, yields

$$
c^{i}(\tau)=c^{i}(t) e^{\alpha \int_{t}^{\tau}[r(s)-\rho(s)] d s}+\beta_{i} e^{\alpha \int_{t}^{\tau}[r(s)-\rho(s)] d s} \int_{t}^{\tau} e^{-\alpha \int_{t}^{\tau}[r(s)-\rho(s)] d s}[r(s)-\rho(s)] d s .
$$

Multiplying this last expression by $e^{-\int_{t}^{\tau} r(s) d s}$, integrating over all $\tau \in[t, \infty)$, and combining the result with (6), gives

$$
\begin{aligned}
c^{i}(t)=\frac{a^{i}(t)+\int_{t}^{\infty} e^{-\int_{t}^{\tau} r(s) d s} \theta^{i}(\tau) w(\tau) d \tau}{\int_{t}^{\infty} e^{\int_{t}^{\tau}[(\alpha-1) r(s)-\alpha \rho(s)] d s} d \tau} & \\
& -\frac{\beta_{i} \int_{t}^{\infty} e^{\int_{t}^{\tau}[(\alpha-1) r(s)-\alpha \rho(s)] d s} \int_{t}^{\tau} e^{-\alpha \int_{t}^{\tau}[r(s)-\rho(s)] d s}[r(s)-\rho(s)] d s d \tau}{\int_{t}^{\infty} e^{\int_{t}^{\tau}[(\alpha-1) r(s)-\alpha \rho(s)] d s} d \tau},
\end{aligned}
$$

which can be linearly aggregated across all $a^{i}$ 's, $\theta^{i}$ 's and $\beta_{i}$ 's, proving that a representative consumer exists, as long as Assumption A.1 holds, which keeps all individual demands taking the form of (34).

For the case where $\alpha=0$, when all individual utilities fall in the class of $u^{i}(c)=-e^{-\frac{1}{\beta_{i}} c}$, (34) implies that,

$$
c^{i}(t)=\frac{a^{i}(t)+\int_{t}^{\infty} e^{-\int_{t}^{\tau} r(s) d s} \theta^{i}(\tau) w(\tau) d \tau-\beta_{i} \int_{t}^{\infty} e^{-\int_{t}^{\tau} r(s) d s} \int_{t}^{\tau}[r(s)-\rho(s)] d s d \tau}{\int_{t}^{\infty} e^{-\int_{t}^{\tau} r(s) d s} d \tau},
$$

which can also be linearly aggregated across all $a^{i}$ s, $\theta^{i}$, s and $\beta_{i}$ 's, completing the proof of the theorem. Q.E.D. 
Theorem A.1 states that the existence of a representative consumer rests upon particular functional forms and common parameter values: the quasi elasticity of intertemporal substitution, $\alpha$, should be the same across all households; ${ }^{1}$ households can differ only with respect to their subsistence consumption or bliss point of consumption; yet, it can either be that all households have some subsistence consumption, or that all households can have some bliss point, but bliss points and consumption subsistence levels cannot coexist in the same community preference profile.

$\overline{1}$ Note that the elasticity of substitution is equal to $\alpha \cdot\left(1-\beta_{i} / c\right)$. 


\section{Appendix B - Samples}

\subsection{Representative research sample for Germany}

In order to implement Part A of the questionnaire efficiently, it is necessary to examine demographic and descriptive income statistics from the country being studied in order to determine appropriate household types and reference incomes (RIs) to use in Part A. In Germany, the eight household types that were chosen represent $86.05 \%$ of the overall number of households, as seen in Table B1, based on the most recent German Income and Expenditure Survey (EVS) of 2003. ${ }^{2}$ The EVS, provided by the German Statistical Office in five-year intervals, contains representative household-level information on income, wealth, and expenditures for several types of goods. The RIs provided in Part A were determined so as to cover a broad range of the disposable-income distribution for single-childless-adult households in Germany. The amount of EUR 500 per month is the level of total social assistance for a one-member household in Germany. Specifically, the level of monetary social assistance in 2006 for a single, childless adult is EUR 345 per month (see Article 20, Paragraph 2, 2a, 3, Sozialgesetzbuch II (SGB II - "Social Security Code")). ${ }^{3} \quad$ In addition, households receive housing allowances. The level of housing allowances is contingent upon the rent and also upon the income and wealth of the single, childless adult. A reasonable number is ca. EUR 160. The amount of EUR 1,250 corresponds to the 41st percentile of the one-memberhousehold monthly disposable-income distribution, EUR 2,000 to the 76th, EUR 2,750 to the 89th, and EUR 3,500 to the 94th percentile. Each respondent was provided with only one RI to evaluate in Part A (by random assignment).

The survey's sample consists of 2,042 respondents from all regions of Germany, col-

2 See the German Social Science Infrastructure Services at:

http://www.gesis.org/en/social_monitoring/GML/data/inc\&exp/index.htm.

3 For the German Social Security Code see, http://www.sozialgesetzbuchbundessozialhilfegesetz.de/_buch/sgb_ii.htm. 
lected by the research institute "FORSA" ("Gesellschaft für Sozialforschung und statistische Analysen mbH" - Research Institute for Social Research and Statistical Analyses) in 2006. The FORSA institute routinely conducts surveys with a representative online panel of about 10,000 German households. FORSA has stored an extensive set of socioeconomic and demographic variables for each participating household. This enables a pre-screening of respondents' personal and household characteristics. Households were provided with web TVs when Internet was not available. Completion times ranged from about 10 to 25 minutes.

The sampling procedure is designed to obtain enough respondents who live in each of the household types that appear as hypothetical households in Part A. Table B2 shows the breakdown of the large sample from Germany, and Table B3 shows the number of respondents from each family type. Table B3 also compares the percentages of respondents from each household type in the sample with the percentages of household types in the overall German population. This comparison reveals that pre-screening of respondent characteristics is efficient. The household type consisting of one adult with three children is more than six times over-represented in the sample relative to the German population. Even so, there were only 19 respondents from households with one adult and three children. For the other seven household types, respondent numbers are sufficiently high to conduct the tests explained below.

\subsection{Pilot Survey Samples}

The breakdown of the samples in pilot studies appears in Tables B5a and B5b. The complete questionnaire appears in Appendix A.1 of Koulovatianos et al. (2005). In Botswana, the questionnaire consisted of questions about three reference incomes instead of five. Because several languages (mainly Setswana and Kalanga, but also Sekgalagadi) are used in Botswana, interviewers had to resort to oral interviews. The response rate with five refer- 
ence incomes was low, and given our planned budget and time constraints we modified the questionnaire so as to increase the response rate. For the purpose of testing the income dependence of equivalence scales, three reference incomes serve this task well. For testing the linear relationship between EIs and RIs, three reference incomes are marginally sufficient for such a test. Nevertheless, we include this country in this study as complementary information.

The questionnaire, the sampling strategy and sampling regions for Germany, France, and Cyprus appear in previous studies (see Koulovatianos et al. (2005, 2007)). The sampling region in China was the urban area of Hangzhou and several towns in the province of Zhejiang. In India, the sample was collected from cities and villages of three states of south India, Tamil Nadu, Andhra Pradesh, and Karnataka. The cities where our respondents were surveyed are Chennai (Madras) in Tamil Nadu, Hyderabad (Andhra Pradesh), and Bangalore in Karnataka. The questionnaire was provided in the languages of Tamil (Tamil Nadu), Telegu (Andhra Pradesh), in the English language (respondents from Karnataka preferred English instead of our questionnaires provided in the language Kannada) and elderly respondents were given the option of a questionnaire in Hindi. In Botswana, sampling was from the capital Gaborone and villages around it. Apart from questionnaires provided in English, a large part of the respondents were interviewed orally, mainly in the languages Setswana and Kalanga. Sample surveys typically lasted between 20-35 minutes, as respondents had to evaluate five different RIs. 


\section{Appendix C - How NLSE suppresses noise from Heterogeneity in Respondent Perceptions of Verbal Characterizations}

The existence of a common, "cardinal" perception of verbal characterizations such as "good" or "bad" is not guaranteed. ${ }^{4}$ This problem can make stated Likert-scale values in Part B noisy across individuals. We have named the source of such noise Heterogeneity in Respondent Perceptions of Verbal Characterizations (HRPVC). To suppress such inter-respondent noise, we construct the variable "normalized Likert-scale evaluation" (NLSE).

Table $\mathrm{C} 1$ presents the descriptive statistics of Likert-scale values stated in Part B for all household types and RIs. The means and medians across household types for a given reference income are close to each other. This lends support to the results of the pilot survey that was run in advance to define the EIs that were provided in Part $\mathrm{B}:{ }^{5}$ respondents to the present survey also perceive the average incomes stated by the respondents of the pilot survey as EIs.

Figure $\mathrm{C} 1$ depicts information from the first column of Table $\mathrm{C} 1$, which refers to the one-member household. Each box in Figure C1 is defined by the value of the first and third quartile, so each box contains $50 \%$ of the values around the median. A dash within a box represents the median response, while each vertical line spans the range of responses. Except for $\mathrm{RI}=\mathrm{EUR} 2,750$, the range of responses covers the whole Likert-scale interval that was provided (from 1 to 100). In particular, for the distribution of responses corresponding to $\mathrm{RI}=\mathrm{EUR} 1,250$, both the mean and the median lie in the middle of the range, and the two middle quartiles are distanced symmetrically from the median by 20 points in the Likert scale. So, while Figure C1 shows that there is positive correlation between income and

4 See Kahneman and Krueger (2006, pp. 18-21) for a thorough discussion of this difficulty of inter-respondent comparisons of verbal characterizations of well-being.

5 These numbers are taken from Koulovatianos et al. (2005) for Germany. 
subjective perceptions of living standards, the noisiness of the Likert-scale values indicates the presence of HRPVC. Such noisiness justifies concerns about the effectiveness of using 'raw' Likert-scale values for interpersonal comparisons and about their role as conditioning variables in regressions.

The descriptive statistics of NLSE are given in Table C2 and Figures C2 to C6. By the definition of NLSE, noise stemming from HRPVC should be suppressed. Table C2 confirms this suppressive effect of the NLSE. 


\section{Appendix D - Calibration of the Representative Consumer in Germany in year 2003}

In order to calibrate subsistence consumption so as to replicate the numbers appearing in the utility function given by (18) in the paper, we combine equation (15) in the paper with equation (27) appearing in the paper's Appendix under the Assumptions of Proposition 1, and we obtain,

$$
\beta_{j}=\psi_{i, j} \cdot \beta_{i}-\alpha \cdot \chi_{i, j}
$$

Setting $i=O M H$, where "OMH" denotes a one-member household, and aggregating across all household types, equation (D.1) implies,

$$
\sum_{j \in \mathcal{I}} \mu_{j} \beta_{j}=\beta_{O M H} \cdot \sum_{j \in \mathcal{I}} \mu_{j} \psi_{O M H, j}-\alpha \cdot \sum_{j \in \mathcal{I}} \mu_{j} \chi_{O M H, j}
$$

where $\mu_{j}$ is the fraction of households belonging to household type $j \in \mathcal{I}$, in order to obtain

the term $\beta^{R C}(t)$ given by equation (11) in the text for year 2003. Data for the vector $\left\{\mu_{j}\right\}_{j \in \mathcal{I}}$ in equation (D.2) is taken from Table B3 of Appendix B, which are taken from the 2003 German Income and Expenditure Survey. Estimates for the vectors $\left\{\psi_{O M H, j}\right\}_{j \in \mathcal{I}}$ and $\left\{\chi_{O M H, j}\right\}_{j \in \mathcal{I}}$ are taken from the relevant estimated coefficients in Table 1 of the paper, while $\psi_{O M H, O M H}=1$, and $\chi_{O M H, O M H}=0$. Since the estimation appearing in Table 1 of the paper refers to monthly data, we have multiplied the resulting expression for $\Sigma_{j \in \mathcal{I}} \mu_{j} \beta_{j}$ from equation (D.2) by 12, in order to obtain the utility function referring to one year.

Similarly, regarding the case of exponential utility, equation (32) in the paper imply that,

$$
\sum_{j \in \mathcal{I}} \mu_{j} \beta_{j}=\beta_{O M H} \cdot \sum_{j \in \mathcal{I}} \mu_{j} \psi_{O M H, j}
$$

so, together with equation (11) in the paper we obtain equation (19) in the paper.

In aggregative models that use the utility function given by (18) in the paper, the appropriate measure of aggregate income to use is one-member-household equivalent income. A 
distribution of one-member household equivalent incomes (DOMHEI) transforms household income data referring to different household types into comparable incomes of identical (onemember) households. Because these one-member-household EIs retain the original level of material comfort of each individual, they reflect the inequality of living standards among individuals in a country.

The construction of a DOMHEI follows this procedure: consider the household income, $y^{h}$, of a household which is household type $h$ with $n^{h}$ members; based on the estimated values of coefficients $a^{h}$ and $b^{h}$ in equation (17) in the paper, find the RI that corresponds to $y^{h}$, denoted as $y_{R I}^{h}$; assign $y_{R I}^{h}$ to each household member of that household and include $n^{h}$ times the income level $y_{R I}^{h}$ in the DOMHEI. The idea behind the construction of the DOMHEI is to pick each household member from all household types and place him/her in a one-member household (also treating children as adults), providing each individual with the same level of material comfort in this (new) virtual household type as before. The income level $y_{R I}^{h}$ plays this role of making material-comfort levels equal when transforming all household types into one-member households.

Our application appears in Figure D1. We have imposed an upper bound on equivalence scales (ESs) equal to the number of household members. This constraint applies when observed household incomes are exceptionally low. Table D1 presents the average ESs based on estimates from Table 1 in the text, imputed in the income distribution for each household type taken from the German Income and Expenditure Survey in year 2003. The expert-based OECD-modified ESs are presented in the second column of Table D1. ${ }^{6}$ Our average ESs and those of the OECD differ only slightly, justifying the comparison of the two estimates of the DOMHEI appearing in Figure D1. The fact that our ESs fall with RI, shifts poorer ${ }_{6}$ See the link in the OECD website:

http://www.oecd.org/LongAbstract/0,2546,en_2825_497118_35411112_1_1_1_1,00.html 
(richer) multi-member households to lower (higher) one-member-household EIs, thickening the resulting density. This thickening impacts the inequality of one-member-household EIs substantially: the Gini coefficient increases from $27.37 \%$ (OECD ES) to $30.54 \%$ with our ESs. 
Tables for Appendices A - D

Table A1. Distribution of household types in Germany. Data refer to the overall population and are taken from the German Income and Expenditure Survey in 2003.

\begin{tabular}{|l|c|c|c|c|c|c|c|c|c|}
\hline & \multicolumn{9}{|c|}{ Household type } \\
\cline { 2 - 11 } & $\begin{array}{c}1 \text { adult, } \\
0 \\
\text { children }\end{array}$ & $\begin{array}{c}1 \text { adult, } \\
1 \\
\text { child }\end{array}$ & $\begin{array}{c}1 \text { adult, } \\
2 \\
\text { children }\end{array}$ & $\begin{array}{c}1 \text { adult, } \\
3 \\
\text { children }\end{array}$ & $\begin{array}{c}2 \text { adults, } \\
0 \\
\text { children }\end{array}$ & $\begin{array}{c}2 \text { adults, } \\
1 \\
\text { child }\end{array}$ & $\begin{array}{c}2 \text { adults, } \\
2 \\
\text { children }\end{array}$ & $\begin{array}{c}2 \text { adults, } \\
3 \\
\text { children }\end{array}$ & Other \\
\hline $\begin{array}{l}\text { Number of } \\
\text { households } \\
\text { (in } \\
\text { thousands) }\end{array}$ & $14,031.1$ & 931.4 & 356.3 & 45.4 & $11,208.4$ & $2,440.9$ & $2,963.2$ & 808.3 & $5,312.8$ \\
\hline $\begin{array}{l}\% \text { of } \\
\text { population }\end{array}$ & 36.83 & 2.44 & 0.94 & 0.12 & 29.42 & 6.41 & 7.78 & 2.12 & 13.95 \\
\hline
\end{tabular}


Table A2. Description of the personal characteristics of the 2,042 respondents to the survey. ${ }^{a}$ Respondents who have completed schooling sufficient for general qualification to enter a German University; ${ }^{b}$ Respondents who stated that they have an occupation, and they either did not state their occupation type, or their occupation type did not fit into the other working categories; ${ }^{\mathrm{c}}$ Respondents who stated that they are non-working, and they either did not state their status, or their status did not fit into the other categories.

\begin{tabular}{|c|c|c|c|}
\hline & & $\begin{array}{l}\text { Number of } \\
\text { respondents }\end{array}$ & $\begin{array}{c}\% \text { of } \\
\text { respondents }\end{array}$ \\
\hline \multirow[t]{2}{*}{ Region } & Former West Germany & 1,541 & 75.5 \\
\hline & Former East Germany & 501 & 24.5 \\
\hline \multirow[t]{2}{*}{ Gender } & Male & 465 & 22.8 \\
\hline & Female & 1,577 & 77.2 \\
\hline \multirow[t]{6}{*}{ Education } & No degree & 42 & 2.1 \\
\hline & Basic level of schooling (9 years) & 587 & 28.7 \\
\hline & Secondary School & 926 & 45.3 \\
\hline & Advanced technical college & 119 & 5.8 \\
\hline & High School $^{\mathrm{a}}$ & 163 & 8.0 \\
\hline & Completed technical school or university & 205 & 10.0 \\
\hline \multirow[t]{6}{*}{ Occupational Status } & Self-employed & 43 & 2.1 \\
\hline & Civil servant & 57 & 2.8 \\
\hline & White-collar & 583 & 28.6 \\
\hline & Blue-collar & 180 & 8.8 \\
\hline & In school or higher education/training & 23 & 1.1 \\
\hline & Working, other $^{b}$ & 52 & 2.5 \\
\hline \multirow[t]{5}{*}{ Status of non-working } & Pensioner & 327 & 16.0 \\
\hline & Unemployed & 152 & 7.4 \\
\hline & Housewife/man & 452 & 22.1 \\
\hline & Obligatory military / public service & 101 & 4.9 \\
\hline & Non-working, other ${ }^{c}$ & 72 & 3.5 \\
\hline \multirow{10}{*}{$\begin{array}{l}\text { Family after-tax income } \\
\text { class }\end{array}$} & Less than 500 EUR & 36 & 1.8 \\
\hline & Between 500 and 1000 euros & 239 & 11.7 \\
\hline & Between 1,000 and 1,500 euros & 385 & 18.9 \\
\hline & Between 1,500 and 2,000 euros & 437 & 21.4 \\
\hline & Between 2,000 and 2500 euros & 382 & 18.7 \\
\hline & Between 2,500 and 3,000 euros & 242 & 11.9 \\
\hline & Between 3,000 and 3,500 euros & 159 & 7.8 \\
\hline & Between 3,500 and 4,000 euros & 68 & 3.3 \\
\hline & Between 4,000 and 4,500 euros & 44 & 2.2 \\
\hline & 4,500 euros or more & 50 & 2.4 \\
\hline \multirow[t]{3}{*}{ Age group } & Between 18 and 40 years & 863 & 42.3 \\
\hline & Between 40 and 60 years & 831 & 40.7 \\
\hline & 60 years or older & 348 & 17.0 \\
\hline \multirow[t]{2}{*}{ Partner in the household } & Yes & 1,396 & 68.4 \\
\hline & No & 646 & 31.6 \\
\hline \multirow{4}{*}{$\begin{array}{l}\text { Number of children in the } \\
\text { household }\end{array}$} & 0 & 860 & 42.1 \\
\hline & 1 & 521 & 25.5 \\
\hline & 2 & 491 & 24.0 \\
\hline & 3 or more & 170 & 8.3 \\
\hline
\end{tabular}


Table A3. Distribution of household types of respondents in the survey sample (first two rows). The last row refers to the overall German population, using data from the most recent German Income and Expenditure Survey in 2003. Numbers appearing in the third row are percentages of the sum of households belonging to the eight household types presented in this table.

\begin{tabular}{|r|c|c|c|c|c|c|c|c|}
\hline & \multicolumn{9}{|c|}{ Household type } \\
\cline { 2 - 11 } & $\begin{array}{c}1 \text { adult, } \\
0 \text { children }\end{array}$ & $\begin{array}{c}1 \text { adult, } \\
1 \text { child }\end{array}$ & $\begin{array}{c}1 \text { adult, } \\
2 \text { children }\end{array}$ & $\begin{array}{c}1 \text { adult, } \\
3 \text { children }\end{array}$ & $\begin{array}{c}2 \text { adults, } \\
\text { 0 children }\end{array}$ & $\begin{array}{c}2 \text { adults, } \\
1 \text { child }\end{array}$ & $\begin{array}{c}2 \text { adults, } \\
2 \text { children }\end{array}$ & $\begin{array}{c}2 \text { adults, } \\
3 \text { children }\end{array}$ \\
\hline Number of respondents & 445 & 125 & 57 & 19 & 415 & 396 & 434 & 151 \\
\hline \% of respondents & 21.79 & 6.12 & 2.79 & 0.93 & 20.32 & 19.39 & 21.25 & 7.39 \\
\hline \% of population in 2003 & 42.80 & 2.84 & 1.09 & 0.14 & 34.19 & 7.45 & 9.04 & 2.47 \\
\hline
\end{tabular}

Table A4. Distribution of respondents having an adjusted disposable household income that is similar to the reference income they were asked to evaluate in Part A of the questionnaire. The adjusted disposable household income is the disposable household income divided by the estimated equivalence scale for the respondent's household type. The estimated equivalence scale is the average equivalence scale from responses to Part $A$.

\begin{tabular}{|c|c|c|c|}
\hline $\begin{array}{c}\text { Respondent's } \\
\text { household type }\end{array}$ & $\begin{array}{c}\text { Number of } \\
\text { respondents }\end{array}$ & $\begin{array}{c}\text { Percentage of overall } \\
\text { sample }\end{array}$ & $\begin{array}{c}\text { Percentage of all } \\
\text { respondents who belong to } \\
\text { the same household type }\end{array}$ \\
\hline 1 adult, 0 children & 88 & 4.31 & 19.78 \\
\hline 1 adult, 1 child & 26 & 1.27 & 20.80 \\
\hline 1 adult, 2 children & 15 & 0.73 & 26.32 \\
\hline 1 adult, 3 children & 5 & 0.24 & 26.32 \\
\hline 2 adults, no children & 77 & 3.78 & 18.55 \\
\hline 2 adults, 1 child & 77 & 3.78 & 19.44 \\
\hline 2 adults, 2 children & 93 & 4.55 & 21.43 \\
\hline 2 adults, 3 children & 34 & 1.67 & 22.52 \\
\hline
\end{tabular}


Table B1a. Breakdown of the samples in Germany, Cyprus, and France

\begin{tabular}{|c|c|c|c|c|c|c|c|}
\hline & & \multicolumn{2}{|c|}{$\begin{array}{l}\text { Germany } \\
\begin{array}{c}\text { Sample: } 167 \\
\text { obs. }\end{array}\end{array}$} & \multicolumn{2}{|c|}{$\begin{array}{c}\text { Cyprus } \\
\text { Sample: } 130 \\
\text { obs. }\end{array}$} & \multicolumn{2}{|c|}{$\begin{array}{c}\text { France } \\
\begin{array}{c}\text { Sample: } 223 \\
\text { obs. }\end{array}\end{array}$} \\
\hline & & $\mathrm{N}$ & $\%$ & $\mathrm{~N}$ & $\%$ & $\mathrm{~N}$ & $\%$ \\
\hline \multirow[t]{2}{*}{ Gender } & Male & 96 & 57.49 & 73 & 56.15 & 117 & 52.47 \\
\hline & Female & 71 & 42.51 & 57 & 43.85 & 106 & 47.53 \\
\hline Partner in the & Yes & 97 & 58.08 & 75 & 57.69 & 154 & 69.06 \\
\hline household & No & 70 & 41.92 & 55 & 42.31 & 69 & 30.94 \\
\hline Living with & Yes & --- & --- & $37^{\mathrm{a}}$ & 28.46 & --- & --- \\
\hline parents & No & --- & --- & 93 & 71.54 & --- & --- \\
\hline Number of & 0 & 123 & 73.65 & 82 & 63.08 & 102 & 45.74 \\
\hline children in the & 1 & 18 & 10.78 & 18 & 13.85 & 45 & 20.18 \\
\hline \multirow[t]{2}{*}{ household } & 2 & 15 & 8.98 & 23 & 17.69 & 46 & 20.63 \\
\hline & 3 or more & 11 & 6.59 & 7 & 5.38 & 30 & 13.45 \\
\hline \multirow{5}{*}{$\begin{array}{l}\text { Family after- } \\
\text { tax income } \\
\text { class }\end{array}$} & 1 & 32 & 19.16 & 9 & 6.92 & 18 & 8.07 \\
\hline & 2 & 44 & 26.35 & 25 & 19.23 & 30 & 13.45 \\
\hline & 3 & 37 & 22.16 & 24 & 18.46 & 41 & 18.39 \\
\hline & 4 & 37 & 22.16 & 31 & 23.85 & 49 & 21.97 \\
\hline & 5 & 17 & 10.18 & 41 & 31.54 & 85 & 38.12 \\
\hline \multirow{9}{*}{$\begin{array}{l}\text { Occupational } \\
\text { group }\end{array}$} & Welfare recipient or & & & & & & \\
\hline & unemployed & 7 & 4.19 & 2 & 1.54 & 7 & 3.14 \\
\hline & Blue-collar worker & 10 & 5.99 & 2 & 1.54 & 6 & 2.69 \\
\hline & White-collar worker & 83 & 49.70 & 40 & 30.77 & 48 & 21.52 \\
\hline & $\begin{array}{r}\text { Civil servant } \\
\text { In school or higher }\end{array}$ & 13 & 7.78 & 40 & 30.77 & 29 & 13.00 \\
\hline & education/training & 34 & 20.36 & 30 & 23.08 & 102 & 45.74 \\
\hline & Self-employed & 7 & 4.19 & 13 & 10.00 & 13 & 5.83 \\
\hline & Pensioner & 10 & 5.99 & 0 & 0.00 & 6 & 2.69 \\
\hline & $\begin{array}{r}\text { Homemaker } \\
\text { Below } 9 \text { years of }\end{array}$ & 3 & 1.80 & 3 & 2.31 & 12 & 5.38 \\
\hline \multirow{5}{*}{ Education } & $\begin{array}{r}\text { education } \\
\text { Completed extended }\end{array}$ & 1 & 0.60 & 4 & 3.08 & 0 & 0.00 \\
\hline & $\begin{array}{l}\text { Elementary school } \\
\text { Completed special }\end{array}$ & 21 & 12.57 & 8 & 6.15 & 13 & 5.83 \\
\hline & $\begin{array}{l}\text { Secondary school } \\
\text { Completed secondary }\end{array}$ & 39 & 23.35 & --- & --- & 43 & 19.28 \\
\hline & $\begin{array}{r}\text { school } \\
\text { Technical }\end{array}$ & 65 & 38.92 & 65 & 50.00 & 37 & 16.59 \\
\hline & school/university degree & 41 & 24.55 & $53^{b}$ & 40.77 & 130 & 58.30 \\
\hline \multirow{4}{*}{$\begin{array}{l}\text { Number of } \\
\text { siblings during } \\
\text { childhood }\end{array}$} & 0 & 31 & 18.56 & 9 & 6.92 & 37 & 16.59 \\
\hline & 1 & 55 & 32.93 & 34 & 26.15 & 72 & 32.29 \\
\hline & 2 & 47 & 28.14 & 40 & 30.77 & 59 & 26.46 \\
\hline & 3 or more & 34 & 20.36 & 47 & 36.15 & 55 & 24.66 \\
\hline
\end{tabular}

Note. The threshold of the first "family-after tax income class" is the country-specific poverty line for a single childless adult. Then, we add increments such that the mean of the third income class is approximately the mean household income in the respective country. The breakdown has already appeared in Koulovatianos et al. (2005).

${ }^{a}$ One of the respondents who were living with their parents also had a partner and two children.

b 14 out of the 53 highly educated respondents in Cyprus had finished a technical school (3 years of higher education). 
Table B1b. Breakdown of the samples in China, India, and Botswana

\begin{tabular}{|c|c|c|c|c|c|c|c|}
\hline & & \multicolumn{2}{|c|}{$\begin{array}{l}\text { Botswana } \\
\text { Sample: } 159 \\
\text { obs. }\end{array}$} & \multicolumn{2}{|c|}{$\begin{array}{c}\text { China } \\
\text { Sample: } 196 \\
\text { obs. }\end{array}$} & \multicolumn{2}{|c|}{$\begin{array}{c}\text { India } \\
\begin{array}{l}\text { Sample: } 214 \\
\text { obs. }\end{array} \\
\end{array}$} \\
\hline & & $\mathrm{N}$ & $\%$ & $\mathrm{~N}$ & $\%$ & $\mathrm{~N}$ & $\%$ \\
\hline \multirow[t]{2}{*}{ Gender } & Male & 70 & 44.03 & 130 & 66.33 & 136 & 63.55 \\
\hline & Female & 89 & 55.97 & 66 & 33.67 & 78 & 36.45 \\
\hline Partner in the & Yes & 89 & 55.97 & 146 & 74.49 & --- & --- \\
\hline household & No & 70 & 44.03 & 50 & 25.51 & --- & --- \\
\hline \multirow{7}{*}{$\begin{array}{l}\text { Number of } \\
\text { adults in the } \\
\text { household }\end{array}$} & 1 & --- & --- & --- & --- & 12 & 5.61 \\
\hline & 2 & --- & --- & --- & --- & 73 & 34.11 \\
\hline & 3 & --- & --- & --- & --- & 35 & 16.36 \\
\hline & 4 & --- & --- & --- & --- & 56 & 26.17 \\
\hline & 5 & --- & --- & --- & --- & 22 & 10.28 \\
\hline & 6 & --- & --- & --- & --- & 10 & 4.67 \\
\hline & 7 or more & --- & --- & --- & --- & 6 & 2.80 \\
\hline \multirow{4}{*}{$\begin{array}{l}\text { Number of } \\
\text { children in } \\
\text { the } \\
\text { household }\end{array}$} & 0 & 48 & 30.19 & 159 & 81.12 & 74 & 34.58 \\
\hline & 1 & 26 & 16.35 & 27 & 13.78 & 48 & 22.43 \\
\hline & 2 & 40 & 25.16 & 7 & 3.57 & 62 & 28.97 \\
\hline & 3 or more & 45 & 28.30 & 3 & 1.53 & $30^{a}$ & 14.02 \\
\hline \multirow{6}{*}{$\begin{array}{l}\text { Family after- } \\
\text { tax income } \\
\text { class }\end{array}$} & 1 & 10 & 6.29 & 42 & 21.43 & 4 & 1.87 \\
\hline & 2 & 18 & 11.32 & 47 & 23.98 & 22 & 10.28 \\
\hline & 3 & 48 & 30.19 & 56 & 28.57 & 24 & 11.21 \\
\hline & 4 & 42 & 26.42 & 32 & 16.33 & 39 & 18.22 \\
\hline & 5 & 41 & 25.79 & 19 & 9.69 & 37 & 17.29 \\
\hline & 6 & --- & --- & --- & --- & 88 & 41.12 \\
\hline Occupational & Welfare recipient or & & & & & & \\
\hline \multirow[t]{9}{*}{ group } & unemployed & 30 & 18.87 & 4 & 2.04 & 8 & 3.74 \\
\hline & Blue-collar worker & 19 & 11.95 & 11 & 5.61 & 26 & 12.15 \\
\hline & White-collar worker & 24 & 15.09 & 5 & 2.55 & 41 & 19.16 \\
\hline & $\begin{array}{r}\text { Civil servant } \\
\text { In school or higher }\end{array}$ & 53 & 33.33 & 5 & 2.55 & 23 & 10.75 \\
\hline & education/training & 15 & 9.43 & 140 & 71.43 & 54 & 25.23 \\
\hline & Self-employed & 13 & 8.18 & 28 & 14.29 & 42 & 19.63 \\
\hline & Pensioner & 2 & 1.26 & 0 & 0.00 & 9 & 4.21 \\
\hline & Homemaker & 3 & 1.89 & 3 & 1.53 & 8 & 3.74 \\
\hline & Agricultural worker & --- & --- & --- & --- & 3 & 1.40 \\
\hline \multirow[t]{6}{*}{ Education } & No schooling & --- & --- & 4 & 2.04 & 1 & 0.47 \\
\hline & Basic schooling & 5 & 3.14 & 16 & 8.16 & 3 & 1.40 \\
\hline & $\begin{array}{r}\text { Completed primary school } \\
\text { Completed junior high }\end{array}$ & 7 & 4.40 & 9 & 4.59 & 15 & 7.01 \\
\hline & school & 21 & 13.21 & 13 & 6.63 & 44 & 20.56 \\
\hline & $\begin{array}{r}\text { Completed high school } \\
\text { Technical }\end{array}$ & 39 & 24.53 & 147 & 75.00 & 93 & 43.46 \\
\hline & school/university degree & 87 & 54.72 & 7 & 3.57 & 58 & 27.10 \\
\hline Number of & 0 & 31 & 19.50 & 71 & 36.22 & 33 & 15.42 \\
\hline siblings & 1 & 20 & 12.58 & 58 & 29.59 & 52 & 24.30 \\
\hline during & 2 & 27 & 16.98 & 35 & 17.86 & 47 & 21.96 \\
\hline childhood & 3 or more & 81 & 50.94 & 32 & 16.33 & 82 & 38.32 \\
\hline \multirow[t]{3}{*}{ Age group } & Less than 20 & --- & --- & --- & --- & 49 & 22.90 \\
\hline & Between 20 and 40 & --- & --- & --- & --- & 127 & 59.35 \\
\hline & 40 or more & --- & --- & --- & --- & 38 & 17.76 \\
\hline \multirow[t]{2}{*}{ Living area } & Urban & 107 & 67.30 & 104 & 53.06 & 190 & 88.79 \\
\hline & Rural & 52 & 32.70 & 92 & 46.94 & 24 & 11.21 \\
\hline
\end{tabular}

Note. The threshold of the first "family-after tax income class" is the country-specific poverty line for a single childless adult. Then, we add increments such that the mean of the third income class is approximately the mean household income in the respective country.

${ }^{a}$ In India. 8 households have 4 children. 2 households have 5 children, 3 households have 6 or more children. 
Table C1. Descriptive statistics of stated Likert-scale values. Number of respondents for each reference income: 428 (500 euros); 422 (1,250 euros); 385 (2,000 Euros); 402 (2,750 euros); 405 $(3,500$ euros).

\begin{tabular}{|c|c|c|c|c|c|c|c|c|c|}
\hline \multirow{2}{*}{$\begin{array}{l}\text { Reference } \\
\text { income }\end{array}$} & & \multicolumn{8}{|c|}{ Household type } \\
\hline & & $\begin{array}{c}1 \text { adult, } \\
0 \text { children }\end{array}$ & $\begin{array}{l}1 \text { adult, } \\
1 \text { child }\end{array}$ & $\begin{array}{c}1 \text { adult, } \\
2 \text { children }\end{array}$ & $\begin{array}{c}1 \text { adult, } \\
3 \text { children }\end{array}$ & $\begin{array}{l}2 \text { adults, } \\
0 \text { children }\end{array}$ & $\begin{array}{c}2 \text { adults, } \\
1 \text { child }\end{array}$ & $\begin{array}{l}2 \text { adults, } \\
2 \text { children }\end{array}$ & $\begin{array}{l}2 \text { adults, } \\
3 \text { children }\end{array}$ \\
\hline \multirow{8}{*}{$\begin{array}{c}500 \\
\text { euros }\end{array}$} & Mean & 17.60 & 20.03 & 22.58 & 23.43 & 24.37 & 24.43 & 24.96 & 27.38 \\
\hline & Median & 10 & 10 & 15 & 15 & 20 & 20 & 20 & 20 \\
\hline & Std & 19.77 & 19.76 & 19.87 & 20.37 & 21.14 & 20.98 & 21.54 & 23.18 \\
\hline & StdError & 0.96 & 0.95 & 0.96 & 0.98 & 1.02 & 1.01 & 1.04 & 1.12 \\
\hline & Min & 1 & 1 & 1 & 1 & 1 & 1 & 1 & 1 \\
\hline & Max & 100 & 100 & 100 & 100 & 100 & 100 & 100 & 100 \\
\hline & First Quartile & 5 & 10 & 10 & 10 & 10 & 10 & 10 & 10 \\
\hline & Third Quartile & 20 & 30 & 30 & 30 & 36 & 30 & 35 & 40 \\
\hline \multirow{8}{*}{$\begin{array}{l}1,250 \\
\text { euros }\end{array}$} & Mean & 51.24 & 48.81 & 49.62 & 49.81 & 56.92 & 56.89 & 57.31 & 55.85 \\
\hline & Median & 50 & 50 & 50 & 50 & 52.5 & 55 & 60 & 55 \\
\hline & Std & 25.19 & 23.74 & 22.83 & 23.24 & 22.72 & 21.85 & 22.58 & 24.17 \\
\hline & StdError & 1.23 & 1.16 & 1.11 & 1.13 & 1.11 & 1.06 & 1.10 & 1.18 \\
\hline & Min & 1 & 1 & 1 & 1 & 1 & 1 & 1 & 1 \\
\hline & Max & 100 & 100 & 100 & 100 & 100 & 100 & 100 & 100 \\
\hline & First Quartile & 30 & 30 & 30 & 30 & 40 & 40 & 40 & 40 \\
\hline & Third Quartile & 70 & 68.75 & 68.75 & 70 & 70 & 70 & 70 & 70 \\
\hline \multirow{8}{*}{$\begin{array}{l}2,000 \\
\text { euros }\end{array}$} & Mean & 73.76 & 68.42 & 66.99 & 63.37 & 77.18 & 75.73 & 74.70 & 72.70 \\
\hline & Median & 80 & 70 & 70 & 65 & 80 & 80 & 80 & 75 \\
\hline & Std & 23.74 & 22.77 & 22.47 & 23.14 & 19.84 & 19.35 & 19.98 & 22.31 \\
\hline & StdError & 1.21 & 1.16 & 1.15 & 1.18 & 1.01 & 0.99 & 1.02 & 1.14 \\
\hline & Min & 1 & 1 & 1 & 1 & 1 & 1 & 1 & 1 \\
\hline & Max & 100 & 100 & 100 & 100 & 100 & 100 & 100 & 100 \\
\hline & First Quartile & 60 & 50 & 50 & 50 & 69 & 65 & 60 & 60 \\
\hline & Third Quartile & 90 & 90 & 85 & 80 & 90 & 90 & 90 & 90 \\
\hline \multirow{8}{*}{$\begin{array}{l}2,750 \\
\text { euros }\end{array}$} & Mean & 87.60 & 85.28 & 81.72 & 78.66 & 89.03 & 87.67 & 86.13 & 83.59 \\
\hline & Median & 95 & 90 & 85 & 80 & 92.5 & 90 & 90 & 90 \\
\hline & Std & 17.75 & 16.95 & 18.00 & 19.95 & 14.58 & 14.64 & 15.92 & 18.81 \\
\hline & StdError & 0.89 & 0.85 & 0.90 & 0.99 & 0.73 & 0.73 & 0.79 & 0.94 \\
\hline & Min & 10 & 15 & 20 & 10 & 20 & 40 & 30 & 15 \\
\hline & $\operatorname{Max}$ & 100 & 100 & 100 & 100 & 100 & 100 & 100 & 100 \\
\hline & First Quartile & 80 & 80 & 70 & 70 & 80 & 80 & 80 & 70 \\
\hline & Third Quartile & 100 & 100 & 100 & 100 & 100 & 100 & 100 & 100 \\
\hline \multirow{8}{*}{$\begin{array}{l}3,500 \\
\text { euros }\end{array}$} & Mean & 91.63 & 88.59 & 87.28 & 84.42 & 93.59 & 92.28 & 89.99 & 87.28 \\
\hline & Median & 100 & 100 & 90 & 90 & 100 & 100 & 100 & 100 \\
\hline & Std & 16.27 & 17.23 & 17.00 & 18.53 & 12.26 & 14.07 & 15.84 & 19.14 \\
\hline & StdError & 0.81 & 0.86 & 0.84 & 0.92 & 0.61 & 0.70 & 0.79 & 0.95 \\
\hline & Min & 1 & 1 & 1 & 1 & 1 & 1 & 1 & 1 \\
\hline & Max & 100 & 100 & 100 & 100 & 100 & 100 & 100 & 100 \\
\hline & First Quartile & 90 & 80 & 80 & 75 & 90 & 90 & 87 & 80 \\
\hline & Third Quartile & 100 & 100 & 100 & 100 & 100 & 100 & 100 & 100 \\
\hline
\end{tabular}


Table C2. Descriptive statistics of Normalized Likert-scale Evaluations.

\begin{tabular}{|c|c|c|c|c|c|c|c|c|}
\hline \multirow[b]{2}{*}{$\begin{array}{l}\text { Reference } \\
\text { income }\end{array}$} & & \multicolumn{7}{|c|}{ Household type } \\
\hline & & $\begin{array}{l}1 \text { adult, } \\
1 \text { child }\end{array}$ & $\begin{array}{c}1 \text { adult, } \\
2 \text { children }\end{array}$ & $\begin{array}{c}1 \text { adult, } \\
3 \text { children }\end{array}$ & $\begin{array}{c}2 \text { adults, } \\
0 \text { children }\end{array}$ & $\begin{array}{c}2 \text { adults, } \\
1 \text { child }\end{array}$ & $\begin{array}{l}2 \text { adults, } \\
2 \text { children }\end{array}$ & $\begin{array}{l}2 \text { adults, } \\
3 \text { children }\end{array}$ \\
\hline \multirow{8}{*}{$\begin{array}{c}500 \\
\text { euros }\end{array}$} & Mean & 0.23 & 0.41 & 0.46 & 0.51 & 0.51 & 0.52 & 0.61 \\
\hline & Median & 0.00 & 0.00 & 0.00 & 0.14 & 0.20 & 0.12 & 0.29 \\
\hline & Std & 0.62 & 0.83 & 0.92 & 0.87 & 0.90 & 1.03 & 1.06 \\
\hline & StdError & 0.03 & 0.04 & 0.04 & 0.04 & 0.04 & 0.05 & 0.05 \\
\hline & Min & -1.79 & -1.79 & -2.08 & -1.20 & -1.79 & -3.91 & -2.30 \\
\hline & Max & 3.00 & 3.91 & 4.09 & 3.91 & 3.91 & 4.09 & 4.25 \\
\hline & First Quartile & 0.00 & 0.00 & 0.00 & 0.00 & 0.00 & 0.00 & 0.00 \\
\hline & Third Quartile & 0.41 & 0.69 & 0.84 & 0.69 & 0.69 & 1.10 & 1.10 \\
\hline \multirow{8}{*}{$\begin{array}{l}1,250 \\
\text { euros }\end{array}$} & Mean & -0.03 & 0.00 & 0.00 & 0.17 & 0.18 & 0.18 & 0.12 \\
\hline & Median & 0.00 & 0.00 & 0.00 & 0.00 & 0.00 & 0.00 & 0.00 \\
\hline & Std & 0.38 & 0.48 & 0.58 & 0.48 & 0.53 & 0.59 & 0.72 \\
\hline & StdError & 0.02 & 0.02 & 0.03 & 0.02 & 0.03 & 0.03 & 0.03 \\
\hline & Min & -1.61 & -2.20 & -2.64 & -1.61 & -2.20 & -2.20 & -4.50 \\
\hline & Max & 2.30 & 3.00 & 3.40 & 3.69 & 3.40 & 3.91 & 4.09 \\
\hline & First Quartile & -0.22 & -0.22 & -0.22 & 0.00 & -0.11 & -0.15 & -0.18 \\
\hline & Third Quartile & 0.00 & 0.18 & 0.18 & 0.29 & 0.34 & 0.34 & 0.34 \\
\hline \multirow{8}{*}{$\begin{array}{l}2,000 \\
\text { euros }\end{array}$} & Mean & -0.06 & -0.09 & -0.17 & 0.08 & 0.07 & 0.05 & -0.01 \\
\hline & Median & 0.00 & -0.05 & -0.13 & 0.00 & 0.00 & 0.00 & 0.00 \\
\hline & Std & 0.26 & 0.34 & 0.47 & 0.33 & 0.38 & 0.43 & 0.58 \\
\hline & StdError & 0.01 & 0.02 & 0.02 & 0.02 & 0.02 & 0.02 & 0.03 \\
\hline & Min & -1.95 & -1.95 & -4.25 & -2.20 & -2.20 & -2.20 & -4.38 \\
\hline & Max & 1.39 & 1.61 & 1.95 & 2.08 & 2.14 & 2.20 & 2.30 \\
\hline & First Quartile & -0.15 & -0.22 & -0.34 & -0.05 & -0.11 & -0.13 & -0.21 \\
\hline & Third Quartile & 0.00 & 0.00 & 0.00 & 0.14 & 0.13 & 0.13 & 0.13 \\
\hline \multirow{8}{*}{$\begin{array}{l}2,750 \\
\text { euros }\end{array}$} & Mean & -0.02 & -0.07 & -0.12 & 0.03 & 0.02 & 0.00 & -0.05 \\
\hline & Median & 0.00 & 0.00 & -0.05 & 0.00 & 0.00 & 0.00 & 0.00 \\
\hline & Std & 0.14 & 0.21 & 0.31 & 0.26 & 0.28 & 0.32 & 0.38 \\
\hline & StdError & 0.01 & 0.01 & 0.02 & 0.01 & 0.01 & 0.02 & 0.02 \\
\hline & Min & -0.59 & -0.85 & -2.20 & -0.92 & -0.81 & -1.10 & -1.25 \\
\hline & Max & 1.10 & 1.39 & 1.39 & 1.95 & 2.08 & 2.20 & 2.30 \\
\hline & First Quartile & -0.06 & -0.15 & -0.22 & 0.00 & -0.05 & -0.11 & -0.17 \\
\hline & Third Quartile & 0.00 & 0.00 & 0.00 & 0.00 & 0.00 & 0.00 & 0.00 \\
\hline \multirow{8}{*}{$\begin{array}{l}3,500 \\
\text { euros }\end{array}$} & Mean & -0.04 & -0.05 & -0.09 & 0.04 & 0.02 & -0.02 & -0.07 \\
\hline & Median & 0.00 & 0.00 & 0.00 & 0.00 & 0.00 & 0.00 & 0.00 \\
\hline & Std & 0.17 & 0.18 & 0.24 & 0.27 & 0.19 & 0.23 & 0.36 \\
\hline & StdError & 0.01 & 0.01 & 0.01 & 0.01 & 0.01 & 0.01 & 0.02 \\
\hline & Min & -2.30 & -0.92 & -1.50 & -0.69 & -0.92 & -1.32 & -4.32 \\
\hline & Max & 1.39 & 1.39 & 1.61 & 4.09 & 1.39 & 1.39 & 1.39 \\
\hline & First Quartile & -0.05 & -0.11 & -0.16 & 0.00 & 0.00 & -0.05 & -0.11 \\
\hline & Third Quartile & 0.00 & 0.00 & 0.00 & 0.00 & 0.00 & 0.00 & 0.00 \\
\hline
\end{tabular}


Table D1. Average equivalence scales. Equivalence scale estimates taken from the regression in Table 1 in the text depend on the level of material comfort. These equivalence scale estimates are used to construct a distribution of one-member households' equivalent incomes from the (most recent) German Income and Expenditure Survey in year 2003. The averages of the equivalence scales imputed in the German Income and Expenditure Survey income distribution (for each household type) are reported in the first column of this table.

\begin{tabular}{|c|c|c|}
\hline $\begin{array}{c}\text { Household } \\
\text { type }\end{array}$ & $\begin{array}{c}\text { Average } \\
\text { equivalence scales } \\
\text { from the estimates } \\
\text { of the present } \\
\text { study }\end{array}$ & $\begin{array}{c}\text { OECD-modified } \\
\text { equivalence scale }\end{array}$ \\
\hline 1 adult, 1 child & 1.32 & 1.30 \\
\hline 1 adult, 2 children & 1.55 & 1.60 \\
\hline 1 adult, 3 children & 1.83 & 1.90 \\
\hline 2 adults, 0 children & 1.64 & 1.50 \\
\hline 2 adults, 1child & 1.83 & 1.80 \\
\hline 2 adults, 2 children & 2.04 & 2.10 \\
\hline 2 adults, 3 children & 2.29 & 2.40 \\
\hline
\end{tabular}




\section{Figures for Appendices C and D}

Figure C1. Box plots of stated Likert-scale values for the reference household.

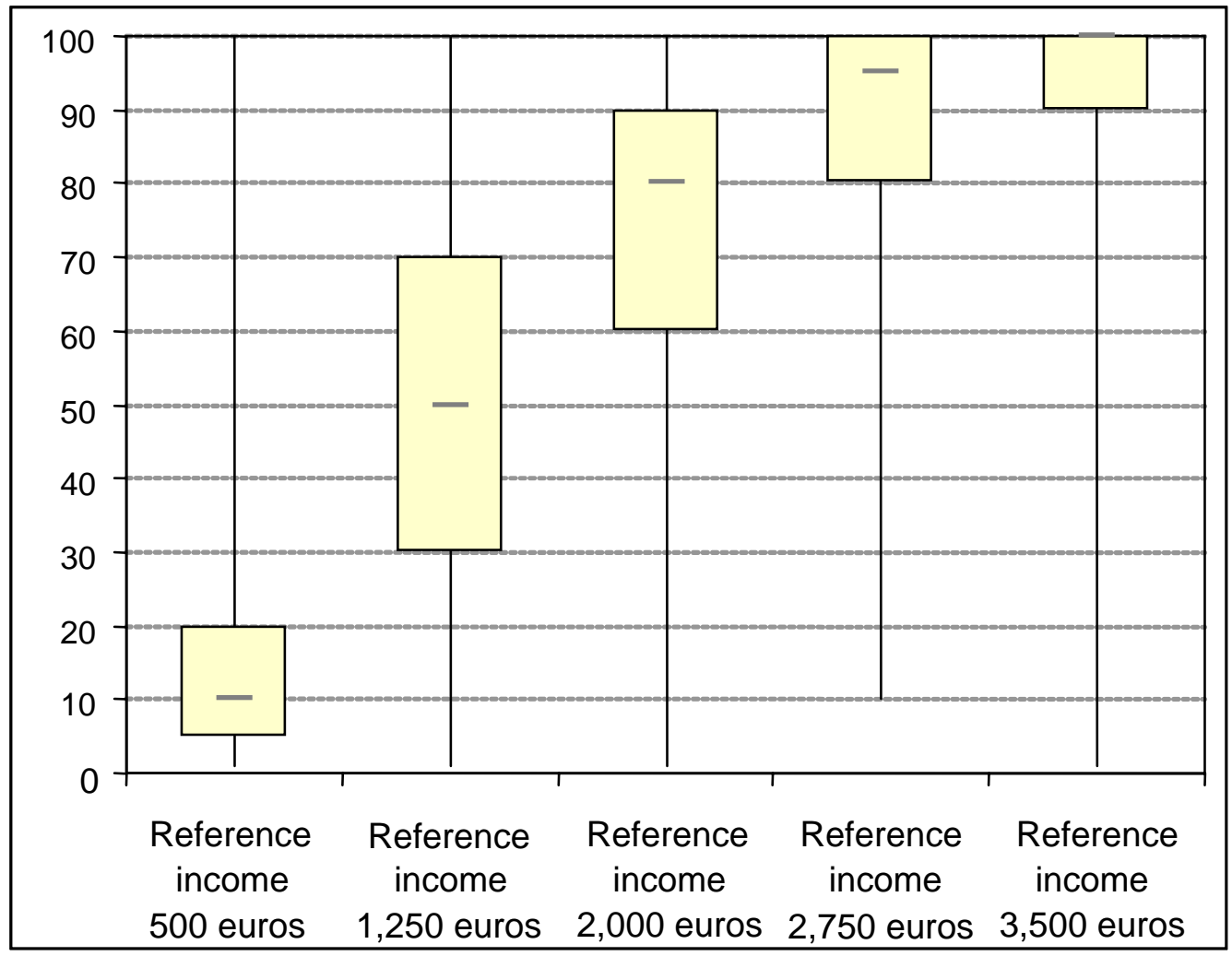

Figure C2. Box plots of Normalized Likert-scale Evaluations for different household types at a reference income of 500 euros.

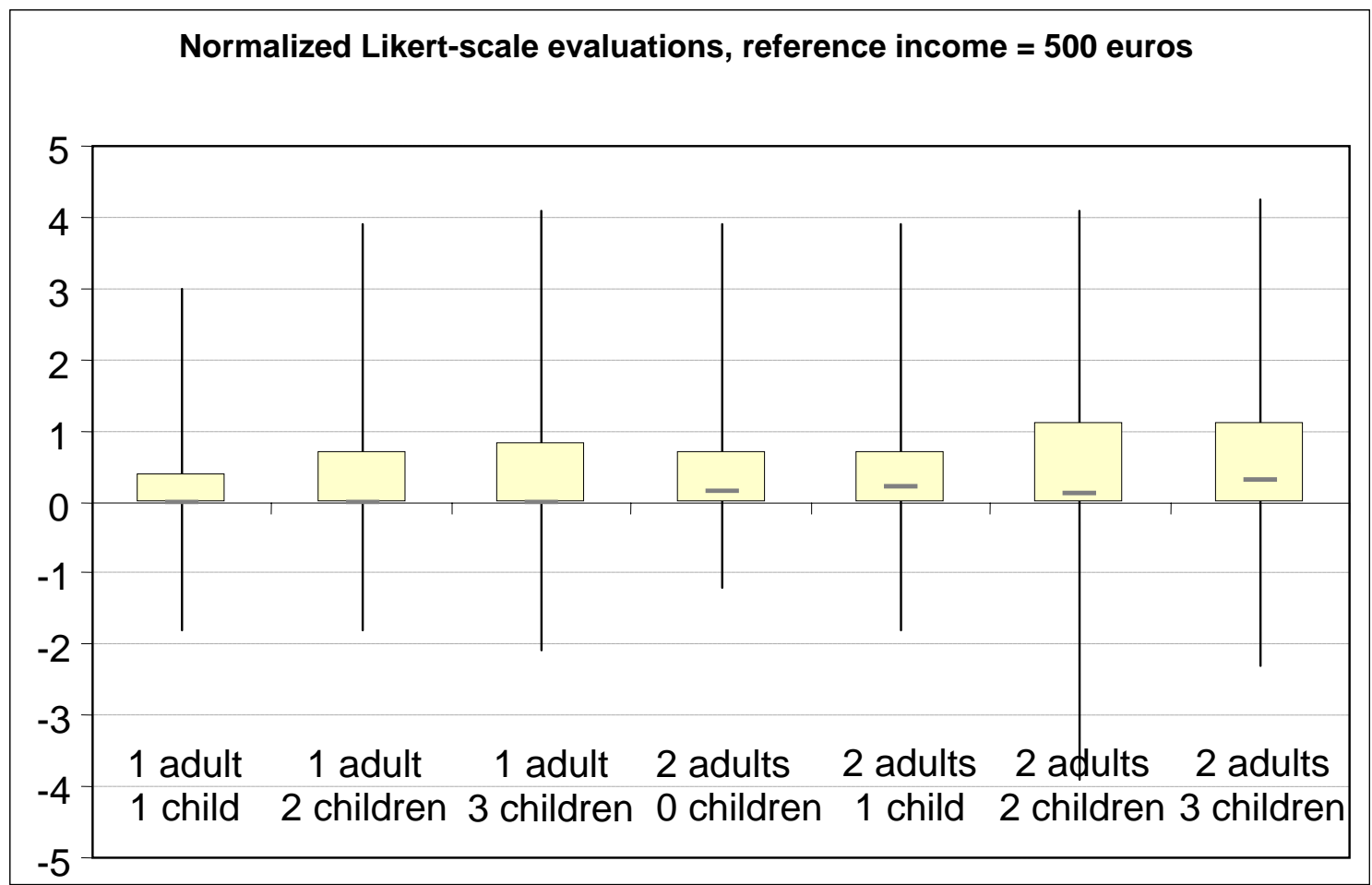


Figure C3. Box plots of Normalized Likert-scale Evaluations for different household types at a reference income of 1,250 euros.

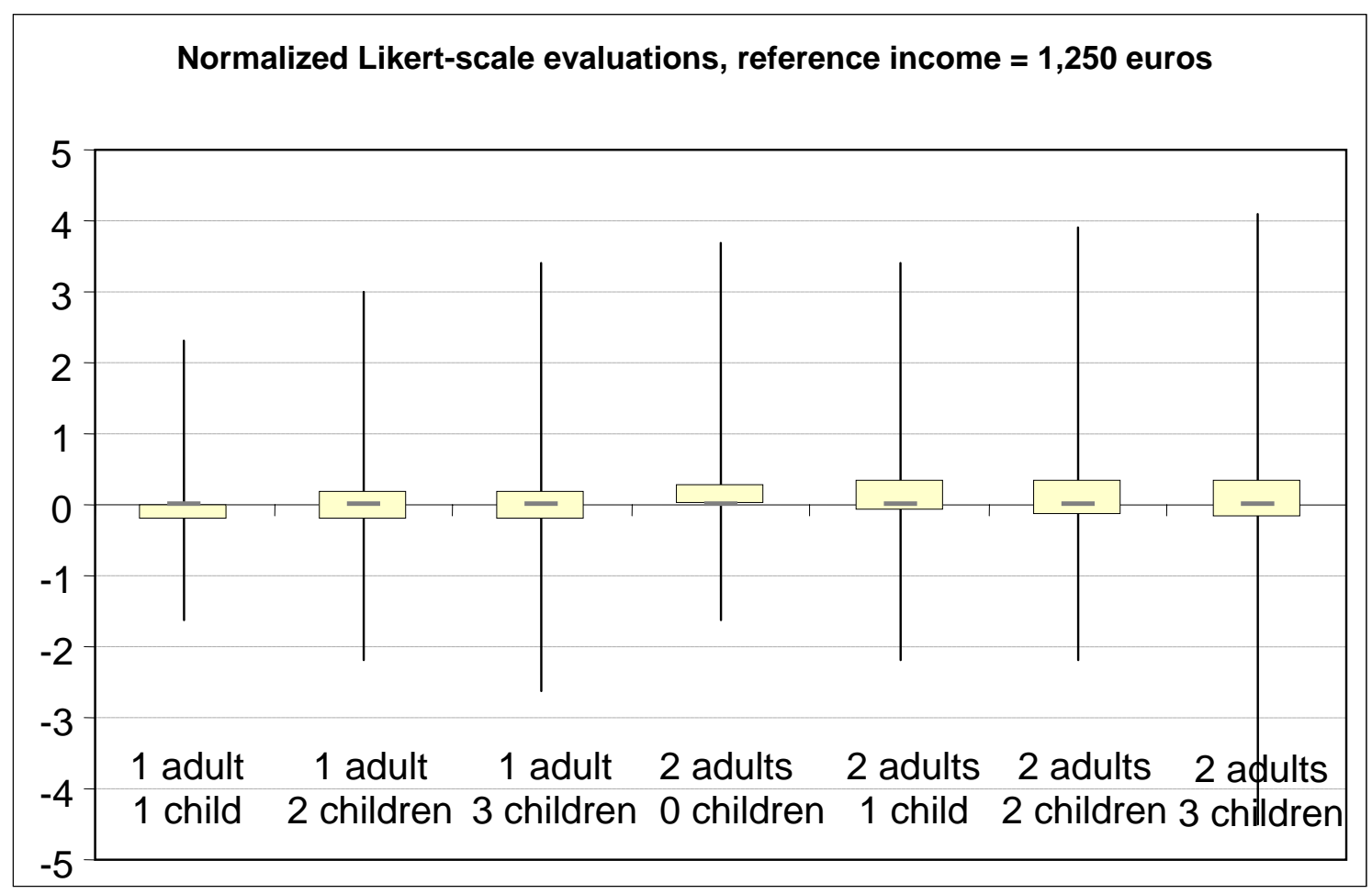

Figure C4. Box plots of Normalized Likert-scale Evaluations for different household types at a reference income of 2,000 euros.

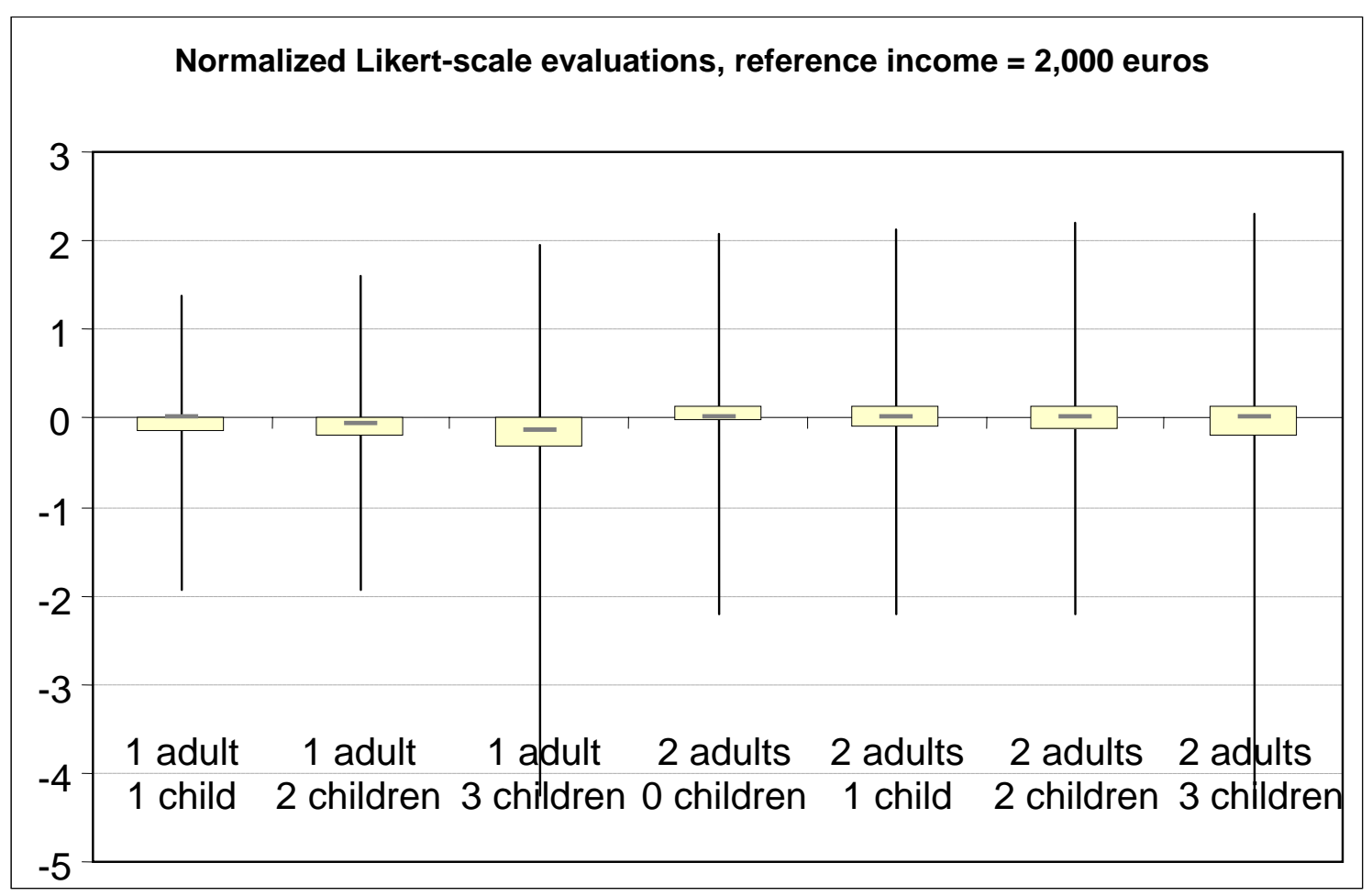


Figure C5. Box plots of Normalized Likert-scale Evaluations for different household types at a reference income of 2,750 euros.

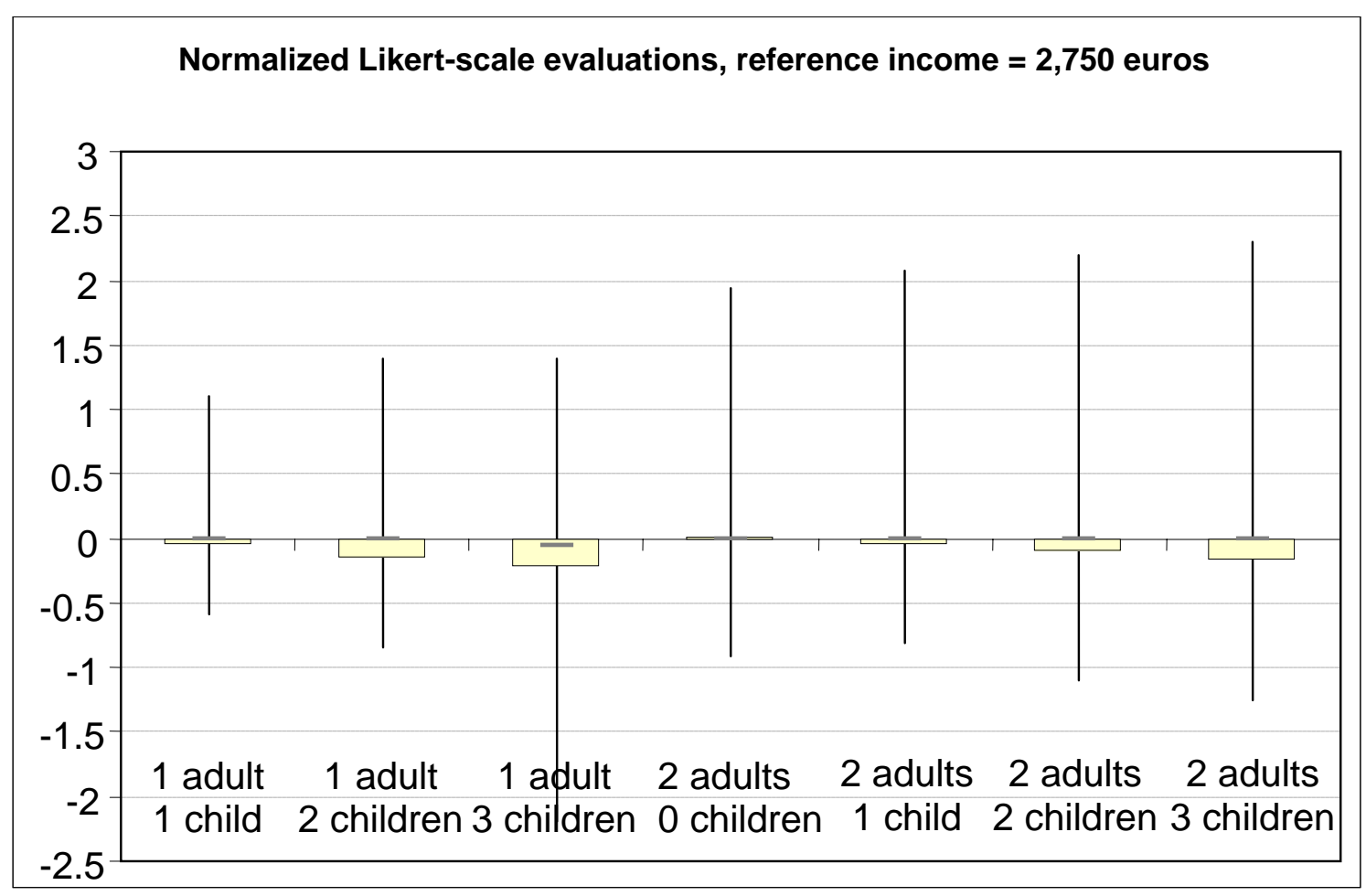

Figure C6. Box plots of Normalized Likert-scale Evaluations for different household types at a reference income of 3,500 euros.

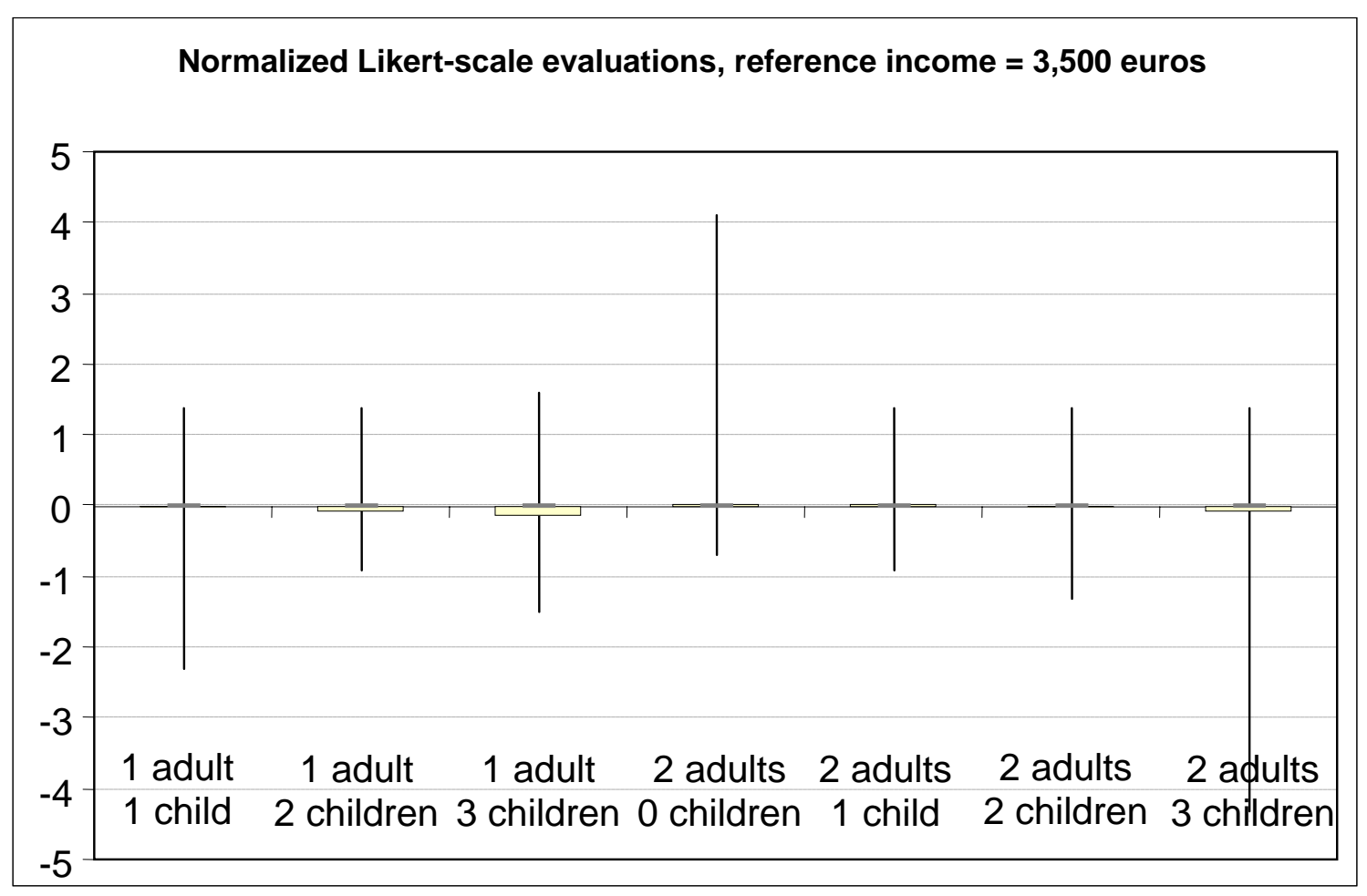


Figure D1. Distribution of one-member-household equivalent incomes calculated using the OECDmodified equivalence scales and equivalence-scale estimates taken from the regressions in Table 1 from the present survey. Household-income data are taken from the 2003 German Income and Expenditure Survey.

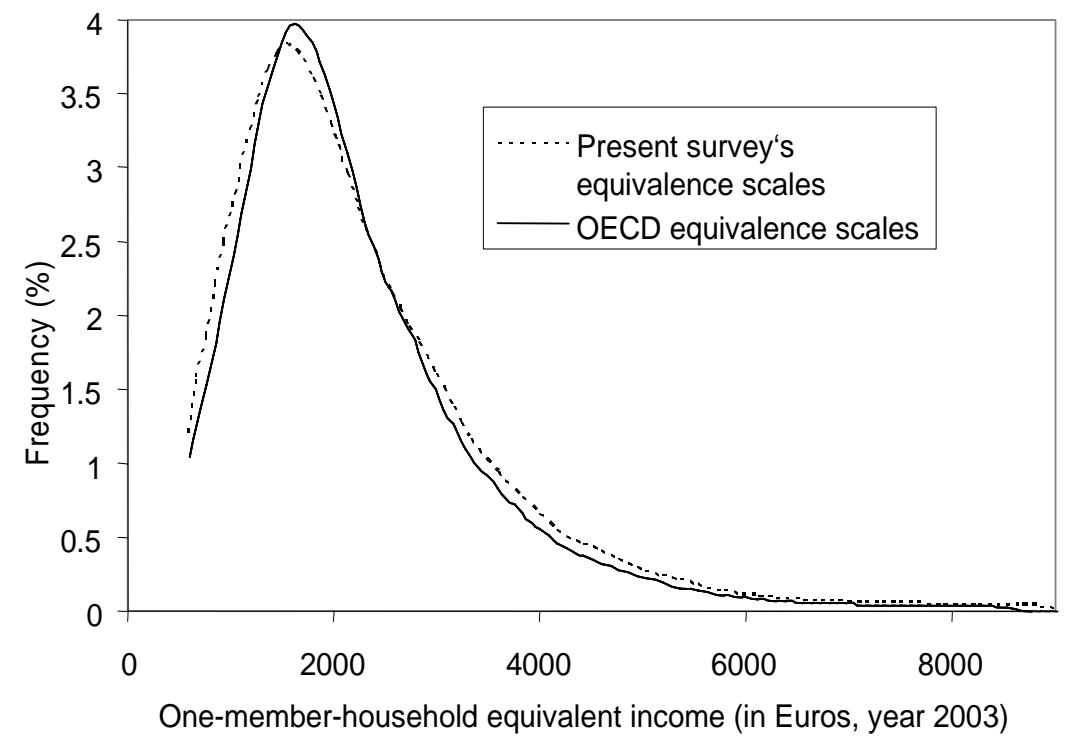




\section{Appendix E}

Survey Instrument Documentation 
Information on the connection between a household's demographic composition and the level of material comfort that its income can buy for its members is important for researchers in diverse disciplines. This survey instrument is designed to obtain direct estimates of this connection from respondents.

The survey was implemented in automated and electronic form by a professional research institute, the FORSA Research Institute for Social Research and Statistical Analysis ("Gesellschaft für Sozialforschung und statistische Analysen mbH"). Each participating household was equipped with a "set-top box" that provided Internet access and that was linked to the household's television set.

An introduction addressed to respondents provides a short explanation of the survey topic and a clarification of the concepts that follow. The actual questionnaire consists of two Parts, Part A and Part B. Part A contains the main evaluation task: to provide incomes that equalize the level of material comfort across different hypothetical household types. Part B poses the same assessment problem as in Part A, but using a different means of communication. Respondents are asked to assess the material comfort of different hypothetical household types with specific income levels on Likert scales.

Key advantages of the survey instrument:

- Direct assessments of incomes that equalize the level of material comfort of different household types, enabling the quantification of household-size economies.

- Posing the same evaluation problem using different means of communication in Parts $A$ and $B$ allows for a test of the effectiveness of the survey instrument, suggested in Part A.

- Relevance of the main evaluation task with observable characteristics of the respondent enables a test of effectiveness of the survey instrument. The socioeconomic and demographic composition of the respondent's household may limit her/his available information and ability to evaluate hypothetical household types and levels of material comfort, thus contaminating the results due to a limited information bias. Comparing answers from respondents whose socio-economic and demographic characteristics are close to those of the hypothetical households they examine with answers from all other respondents enables a test for limited-information bias.

- Low respondent burden: respondents can complete the questionnaire (Introduction, Parts A and B) in about 10-25 minutes.

- High flexibility: Parts A and B can be adjusted easily so as to encompass other hypothetical household types and levels of material comfort. 


\section{Introduction for the respondents}




\section{Purpose of the survey}

In general, different household types may need different incomes in order to attain the same level of material comfort. Since assessing such incomes in an objective way is difficult, we would like to ask you for your personal evaluation of these incomes for a number of different household types. Please note that in this questionnaire there are no "right" or "wrong" answers. Your answers should only reflect your personal judgements.

[Technical note to the researcher. Respondents click a button to switch to the next screen.]

\section{Instruction}

You will frequently read the expression "monthly net household income." Such a "monthly net household income" is the income amount a household has at its disposal after paying taxes and social security contributions (health insurance contributions, compulsory long term care insurance contributions, unemployment insurance contributions, and contributions to the pension system).

"Monthly net household income" encompasses:

Salary and earnings,

Income from self-employment,

Pensions,

Unemployment benefits and social benefits,

Accommodation allowance,

Child allowances,

Incomes from rent and lease, and

Other incomes such as returns on investment, interest, etc.

[Technical note to the researcher. Respondents click a button to go to the next screen.] 


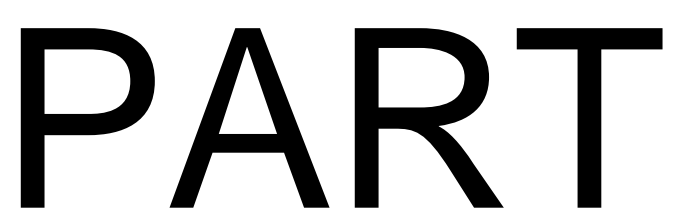

A 
Now, please think about a situation where a single, childless adult has a monthly net household income of 500 euros.

In this survey, there are seven other household types:

with 1 adult and 1 child

with 1 adult and 2 children

with 1 adult and 3 children

with 2 adults and no children

with 2 adults and 1 child

with 2 adults and 2 children

with 2 adults and 3 children

Assume that adults are ages 35 to 55 and children are ages 7 to 11 .

[Technical note to the researcher. Respondents click a button to go to the next screen.]

What monthly net household income would each of these seven household types need in order to attain the same level of material comfort as the single-childlessadult household with a monthly net household income of 500 euros?

You should state this monthly net household income for each household type in the table that will follow on the next screen. Please note that your answers should reflect only your personal judgements.

[Technical note to the researcher. Respondents click a button to go to the next screen.] 
What monthly net household income would each household type need in order to attain the same level of material comfort as the single-childless-adult household with the monthly net household income of 500 euros?

Please state income amounts in euros.

\begin{tabular}{|l|l|}
\hline 1 adult without children & 500 euros \\
\hline 1 adult, 1 child & \\
\hline 1 adult, 2 children & \\
\hline 1 adult, 3 children & \\
\hline 2 adults, no children & \\
\hline 2 adults, 1 child & \\
\hline 2 adults, 2 children & \\
\hline 2 adults, 3 children & \\
\hline
\end{tabular}

[Technical note to the researcher. The reference income level provided in the table is randomly assigned to the respondents. If a respondent does not report an income amount for a household type, there is a reminder: "Please fill in income amounts in all empty cells of the table." If a respondent's entries are not numbers, there is a reminder: "Please state numbers only." If a respondent states income amounts that are decreasing inversely with household size, a box opens: "Usually, larger household types also need higher incomes in order to attain a specific living standard. Please, make sure that you are not stating how much income should be added compared to a smaller household type, but how much the total net household income should be. Please, make sure that the entries you made are indeed total net household incomes." This box opens only once, and its intention is to reduce misunderstandings by respondents. However, if a respondent did not adjust the entries she/he made in the table, she/he was free to do so. Respondents click a button to go to the next screen.] 


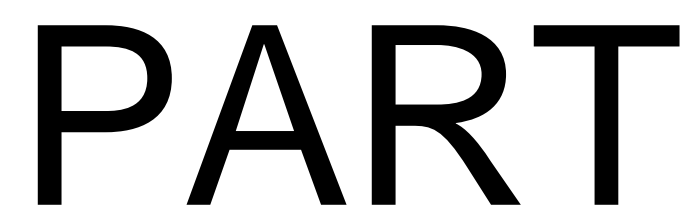

B 
We will show you several household types with a given monthly net household income. Please evaluate the material comfort that these monthly net household incomes bring to the different household types on a scale ranging from 1 to 100 points. The values in this scale stand for the following:

\section{Level of material comfort}

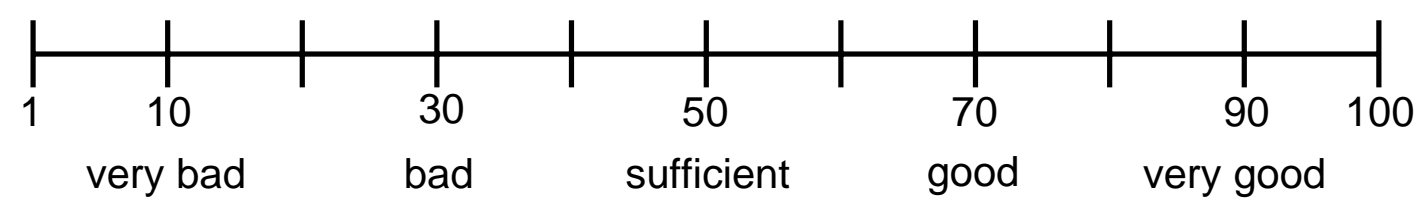

Please complete the following table by evaluating the monthly net income of each household type on the scale of 1-100.

All values between 1 and 100 are permissible.

\begin{tabular}{|l|l|}
\hline & $\begin{array}{l}\text { Level of } \\
\text { material } \\
\text { comfort } \\
\text { (in points) }\end{array}$ \\
\hline 1 adult, no children with 3,500 euros & \\
\hline 1 adult, 1 child with 3,900 euros & \\
\hline 1 adult, 2 children with 4,200 euros & \\
\hline 1 adult, 3 children with 4,550 euros & \\
\hline 2 adults, no children with 4,850 euros & \\
\hline 2 adults, 1 child with 5,250 euros & \\
\hline 2 adults, 2 children with 5,550 euros & \\
\hline 2 adults, 3 children with 5,850 euros & \\
\hline
\end{tabular}

[Technical note to the researcher. The numbers provided in this table are estimates of average equivalent incomes for five reference income levels from an independent study. The five reference incomes are the same as the reference income levels in Part A. So, altogether, five profiles of equivalent incomes (including a reference income for the single-childless-adult household) were evaluated by the survey sample, one profile per respondent. One out of these five equivalent-income profiles was randomly assigned to a respondent. If a respondent reports less than eight Likert scale values, there is a reminder: "Please fill in all empty cells of the table." If a respondent's answers do not fall in the given range of the Likert scale (1-100), there is a reminder to "please state numbers between 1 and 100 only."] 